\title{
Transreactions
}

in Condensation

Polýmers

Stoyko Fakirov (Ed.)

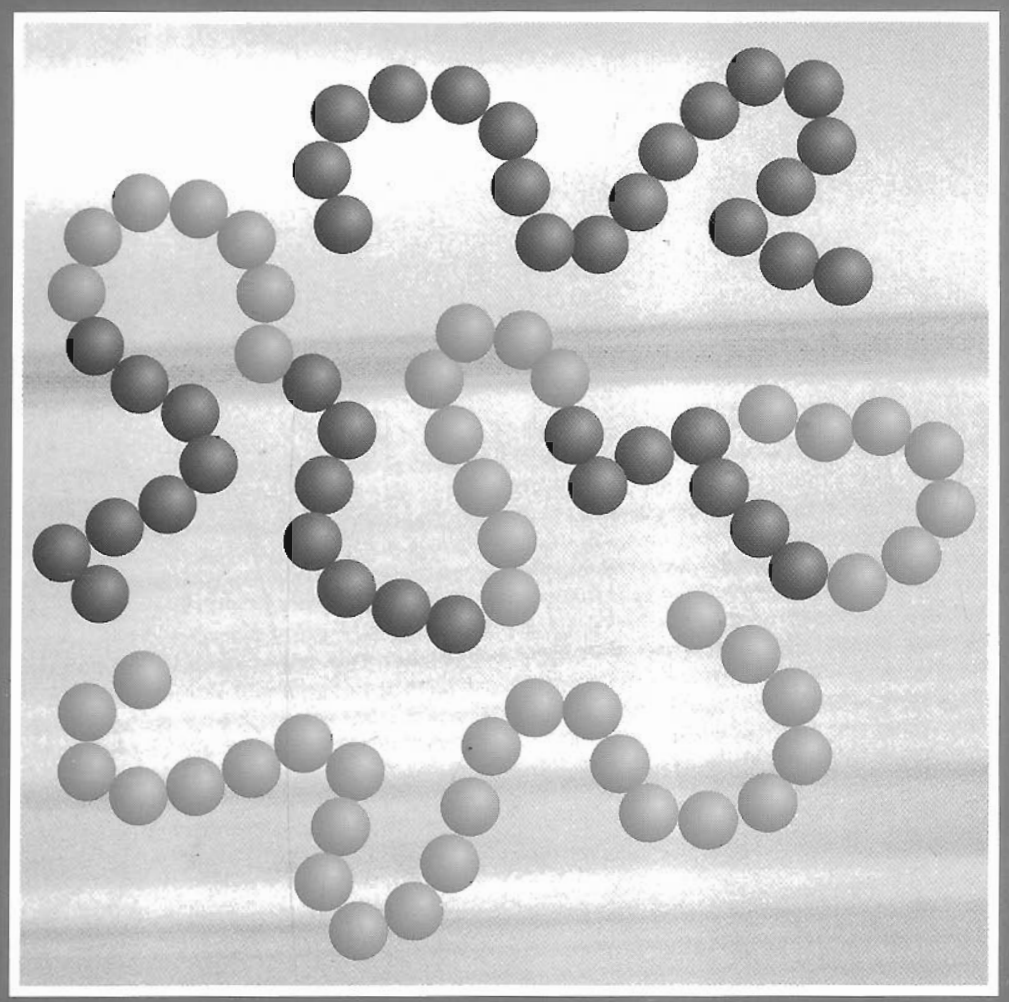




\title{
Chapter 1
}

\section{Interchange Reactions in Condensation Polymers and Their Analysis by NMR Spectroscopy}

\author{
H. R. Kricheldorf, Z. Denchev
}

\section{Introduction}

Interchange reactions* are a phenomenon that concerns numerous classes of polymers. Recently, these interactions have been subject to extensive research due to the fact that they open the route to some new methods of polymer modification and even the preparation of novel polymer materials.

Interchange reactions take place at elevated temperatures (most frequently in the melt) between functional groups belonging to molecules with different degrees of polymerisation or different chenical compositions. As a rule, they are reversible equilibrium interactions, typical of polycondensates, and have been recognised since these polymers were first made. Most prominent examples are polyesters and polyamides, where interchange reactions are best studied and understood. However, during recent decades, a number of publications have dealt with interchange reactions that involve urethane and urea groups, $\mathrm{Si}-\mathrm{O}$ bonds, etc.; these also deserve special attention.

* There is a great variety of different terms used in the literalure when addressing the interchange reactions, e.g., transreactions, transesterification, ester - ester interchange. etc. In this chapter, the general term "interchange reactions" is used consistently. It is classical English, widely accepted and highly versatile. 


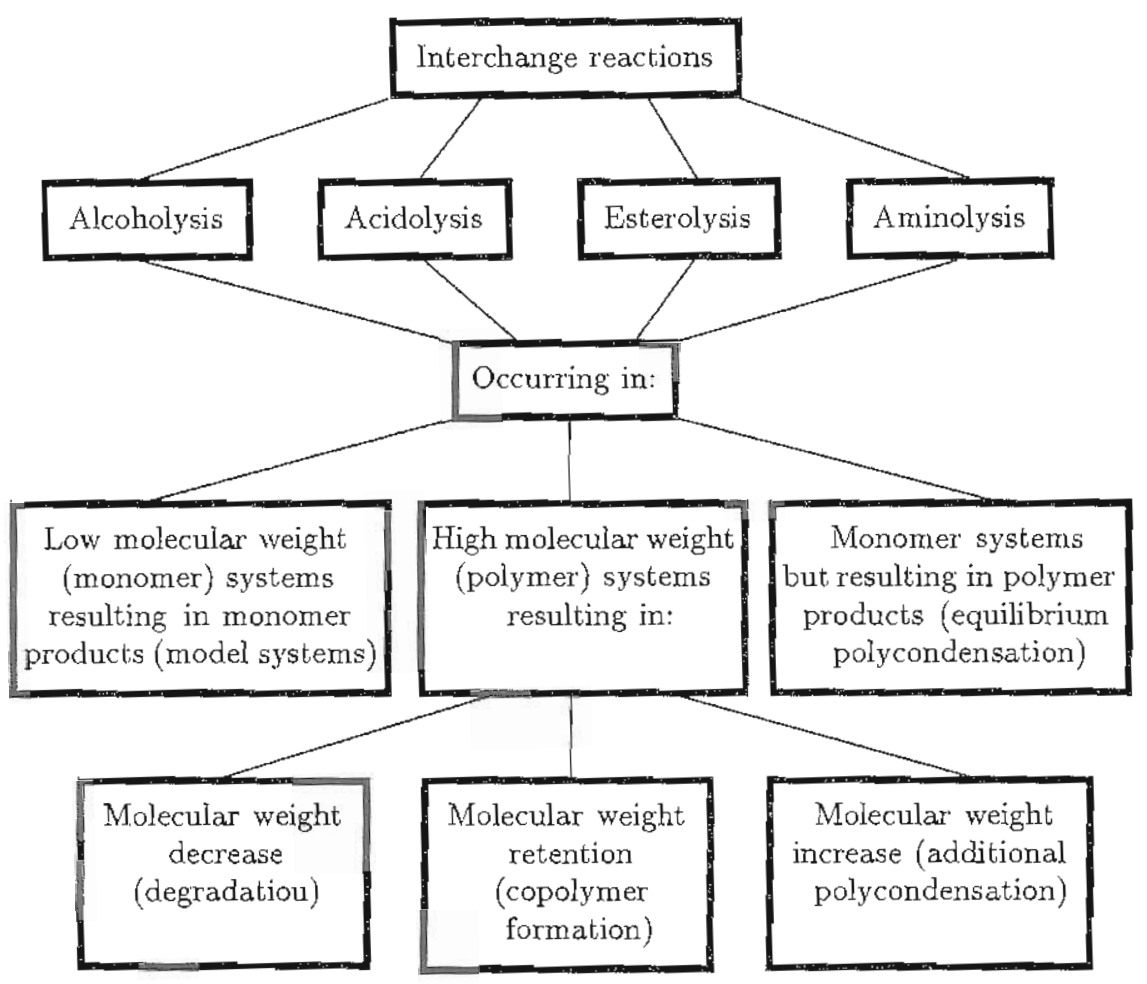

Figure 1. Relationships between interchange reactions

This chapter covers the chardeteristics of some significant types of interchange reactions, such as acidolysis, alcoholysis, aminolysis, esterolysis, taking place in low or high molecular weight systems and resulting in different products - low molecular weight compounds, homo- or copolymers. The scheme in Figure 1 depicts the mutual connections and relations between all the types of interchange reaction. However, this classification is quite superficial: for instance, when discussing the interchange reactions in polymer systems, attention is focused on copolymer formation, although it is clear that, depending on the conditions of treatment and chemical conposition of the blend constituents, the process should be accompanied by either degradation or additional polycondensation. These three processes are closely connected and should be considered as inevitable parts of the condensation equilibrinm.

It is worth noting that there had been some indications that interchange reactions might be possible in some carbochain polymers (i.e., with allcarbon backbones). Thesc also result in polymer modification, but occur to a much lesser degree. For this reason they are treated as secondary 
reactions, taking place during the polyaddition $[1,2]$, and are beyond the scope of this chapter.

Very often it is of prime importance to discover the effect of the interchange reactions on the microstrncture of the respective system instance, to find out whether or not a copolymer is formed as a result of interchange reactions in monomer or polymer systems, or to determine the sequence length distribution, etc. High resolution nuclear magnetic resonance (NMR) has proved to be the most useful method for the direct experimental determination of the polymer microstructure. Of the two nuclei ${ }^{1} \mathrm{H}$ and ${ }^{13} \mathrm{C}$, which possess spin and are common in synthetic polymers, ${ }^{1} \mathrm{H}$ initially served as the spin probe in NMR polymer studies. However, though ${ }^{1} \mathrm{H}$ is nore abundant than ${ }^{13} \mathrm{C}$, proton NMR spectra of synthetic polymers suffer from a narrow dispersion of chemical shifts and extensive ${ }^{1} \mathrm{H}-{ }^{1} \mathrm{H}$ spin coupling. ${ }^{13} \mathrm{C}$ NMR, as currently practiced, does not suffer from these difficulties, of which the latter has recently been turned to advantage for ${ }^{1} \mathrm{H}$ NMR by $2 \mathrm{D}$ techniques. The advent of proton-decoupled spectra recorded in Fonrier-transform mode has quickly made ${ }^{13} \mathrm{C}$ NMR spectroscopy the method of choice for determiuing polymer microstructures. Other methods, such as ${ }^{15} \mathrm{~N}$ and ${ }^{29} \mathrm{Si} \mathrm{NMR}$, are rapidly gaining importance as irreplaceahle tools for the characterisation of siloxanes and $\mathrm{N}$-containing polycondensates. For all these reasons, the basic principles and importaucc of modern NMR techniques in view of their application for interchange reaction characterisation are discussed iu this chapter.

\section{Nuclear magnetic resonance as an analytical tool $\left({ }^{1} \mathbf{H},{ }^{13} \mathrm{C},{ }^{15} \mathrm{~N}\right.$ and $\left.{ }^{29} \mathrm{Si} \mathrm{NMR}\right)$}

\subsection{Basics of the method}

NMR spectroscopy belongs among the radiospectroscopic nethods, where the basic trausitions are those between spin (or magnetic) energy levels of the nuclei. In contrast to the optical transitions $(\epsilon, g$, , vibrational, rotational, electronic), the nucleus can absorb radiofrequencies only if the molecules are placed in a strong, external magnetic field. This is because in the absence of magnetic field, the different spin states of the nuclei have the same energy, i.e., they are degenerate.

\subsubsection{Magnetic properties of the nucleus}

While the muclei of all atoms possess charge and mass, not every nucleus has angular momentum and a magnetic moment. Nuclei with odd mass numbers have spin angular momentum quantum numbers $I$, with values that are odd-integral multiples of $1 / 2$. Nuclei with even nass numbers are spinless if their muclear charge is even, and have integral spin $I$ if their nuclear charge is odd. 
The angular nomentum of a nucleus with spin $I$ is simply $I(h / 2 \pi)$, where $h$ is Planck's constant. If $I \neq 0$, the nucleus will possess a nagnetic moment, $\mu$, which is taken parallel to the angular-momeutum vector. A set of magnetic quantum numbers $m$, given by the series

$$
m=I, I-1, I-2, \ldots,-I
$$

describes the values of the magnetic moment vector which are permitted along any chosen axis. For nuclei of interest hore $\left({ }^{1} \mathrm{H},{ }^{13} \mathrm{C},{ }^{15} \mathrm{~N},{ }^{19} \mathrm{~F},{ }^{29} \mathrm{Si}\right.$, $\left.{ }^{31} \mathrm{P}\right), I=1 / 2$, and thus $m=+1 / 2$ and $-1 / 2$. In general, there are $2 I+1$ possible orientations of $\mu$, or magnetic states of the mecleus. The ratio of the magnetic moment and the angular momentum is called the magnetogyric ratio, $\gamma$ :

$$
\gamma=2 \pi \mu / h I
$$

and is characteristic of a given nucleus.

The nuclei commonly observed in NMR studies of polymers usually have spin $I=1 / 2$, and are characterised by $2 I+1=2$ magnetic states, $m=+1 / 2$ and $-1 / 2$. Both nuclear magnetic statcs have the same energy in the absence of a maguetic field, but they correspond to states of different potential energy upon application of a uniform magnetic field $H_{0}$. The magnetic moment $\mu$ is either aligned along $(m=+1 / 2)$ or against ( $m=$ $-1 / 2$ ) the field $H_{0}$, with the latter state corresponding to a higher encrgy. Detection of the transitions of the magnetic nuclei betwcen these spin states $[m=+1 / 2$ (parallel), $m=-1 / 2$ (antiparallel) $]$ are made possible by the NMR phenomenon.

\begin{tabular}{|c|c|c|c|c|c|c|c|}
\hline Nucieus & $\begin{array}{l}\text { Natural } \\
\text { abundance } \\
(\%)\end{array}$ & $\begin{array}{c}\text { Alomic } \\
\text { number } \\
I\end{array}$ & $\begin{array}{l}\text { Magneto- } \\
\text { gyric } \\
\text { ratio } \gamma \\
\text { (rad.s.Oe) }\end{array}$ & $\begin{array}{l}\text { Magnetic } \\
\text { moment } \mu \\
\text { (magne- } \\
\text { tons) }\end{array}$ & $\begin{array}{l}\text { Quadropole } \\
\text { moment } Q \\
\left(10^{-24} \mathrm{~cm}^{2}\right)\end{array}$ & $\begin{array}{l}\text { Relative } \\
\text { amplibude } \\
\text { of the } \\
\text { signal }\end{array}$ & $\begin{array}{c}\text { Resonance } \\
\text { irequency } \\
(\mathrm{MH} / \mathrm{z})\end{array}$ \\
\hline$\overline{{ }^{1} \mathrm{H}^{1}}$ & 99.98 & $1 / 2$ & 26753 & 2.79270 & - & 1.000 & 100 \\
\hline${ }^{2} \mathrm{HI}^{1}(\mathrm{D})$ & 0.016 & 1 & 4107 & 0.85738 & 0.00274 & 0.010 & 15.4 \\
\hline $11 B^{5}$ & 81.17 & $3 / 2$ & 8583 & 2.6880 & 0.0355 & 0.165 & 32.2 \\
\hline${ }^{12} \mathrm{C}^{6}$ & 98.89 & 0 & - & - & -- & - & - \\
\hline${ }^{13} \mathrm{C}^{6}$ & 1.11 & $1 / 2$ & 6728 & 0.70210 & - & 0.016 & 25.1 \\
\hline${ }^{14} \mathrm{~N}^{7}$ & 99.64 & 1 & 1934 & 0.40357 & 0.02 & 0.001 & 7.2 \\
\hline${ }^{15} N^{7}$ & 0.36 & $1 / 2$ & -2712 & -0.28304 & - & 0.001 & 10.1 \\
\hline${ }^{16} 0^{8}$ & 99.76 & 0 & - & - & - & $\ldots$ & -- \\
\hline${ }^{17} \mathrm{O}^{8}$ & 0.037 & $5 / 2$ & -3628 & -1.8930 & -0.004 & 0.029 & 13.5 \\
\hline${ }^{19} \mathrm{~F}^{9}$ & 100 & $1 / 2$ & 25179 & 2.6278 & - & 0.834 & 94.0 \\
\hline${ }^{28} \mathrm{Si}^{14}$ & 92.28 & 0 & - & - & - & - & - \\
\hline${ }^{29} \mathrm{Si}^{14}$ & 4.67 & $1 / 2$ & -5319 & -0.55477 & - & 0.078 & 19.9 \\
\hline $31 \mathrm{P}^{15}$ & 100 & $1 / 2$ & 10840 & 1.1305 & 一 & 0.066 & 40.5 \\
\hline $32 \mathrm{~S}^{15}$ & 95.06 & 0 & - & - & - & $\ldots$ & - \\
\hline${ }^{33} \mathrm{~S}^{16}$ & 0.74 & $3 / 2$ & 2054 & 0.04271 & $=0,064$ & 0.002 & 7.67 \\
\hline
\end{tabular}

Table 1. Magnetic characteristics of some atomic nuclei [3] 
The magnetic characteristics of some atomic nuclei which are of interest in organic chemistry and more or less appropriate for experimental NMR studies, are given in Table 1 . It is seen that the hydrogen nucleus (the proton) combines all the properties that are favourable for NMR analysis: a spin number of $1 / 2$ (i.e., lack of quadrupole momentum), high natural abundance of the isotope and the largest magnetic moment. All these properties, together with the presence of hydrogen in the majority of organic compounds, explain the exceptional role and significance of this nucleus in NMR spectroscopy. After the protons, the nuclci of fluorine and phosphorus should be mentioned as convenient objects for NMR studies.

It is seen in Table 1 that the most widespread isotopes of elements that are significant in organic chemistry, such as ${ }^{12} \mathrm{C},{ }^{16} \mathrm{O},{ }^{28} \mathrm{Si}$ and ${ }^{32} \mathrm{~S}$, cannot be studied by the NMR technique $(I=0)$. The ${ }^{14} \mathrm{~N}$ investigations are strongly hampered by the presence of a quadrupole momentum. For these reasons ${ }^{13} \mathrm{C},{ }^{15} \mathrm{~N}$ and ${ }^{29} \mathrm{Si}$ are most appropriate for $\mathrm{NMR}$ studies despite the fact that their natural abundance is low.

\subsubsection{Resonance}

Let us discuss the interactions of maguetic fields applied to the magnetic moments of nuclei with spin $I=1 / 2$. Figure 2 is a schematic of the nuclear magnetic noment $\boldsymbol{\mu}$ in the presence of an applied magnetic field $\boldsymbol{H}_{0}$, acting along the $z$-axis of the coordinate system. The angle $\theta$ between the magnetic. moment and the applied field does not change, because the torque

$$
L=\mu \times H_{0}
$$

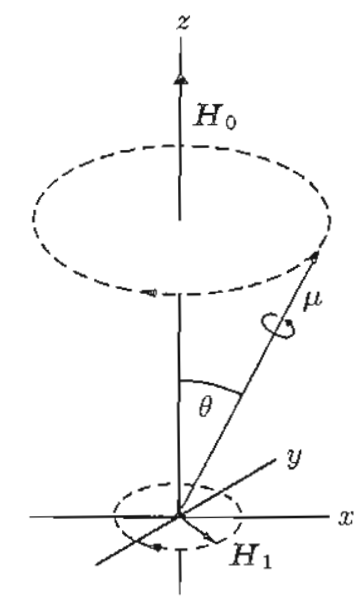

Figure 2. Nuclear magnetic moment in a magnetic field [4] 
tending to tip $\mu$ toward $\boldsymbol{H}_{0}$ is exactly balanced by the spinning of the magnetic moment, resulting in nuclear precession about the $z$-axis. Increasing $H_{0}$, in an attempt to force the alignment of $\boldsymbol{\mu}$ along the $z$-axis, results in faster precession only. A good analogy is provided by the precession of $a$ spinning top in the Earth's gravitational field.

The precessional or Larmor frequency, $\nu_{0}$, of the spinning nucleus is given by

$$
\nu_{0}=\frac{\gamma}{2 \pi} H_{0}
$$

and is independent of $\theta$. However, the energy of the spin system does depend on the angle between $\mu$ and $H_{0}$ :

$$
E=-\mu \cdot H_{0}=-\mu H_{0} \cos \theta
$$

We may change the orientation $\theta$ between $\mu$ and $H_{0}$ by application of a weak rotating magnetic field $H_{1}$ orthogonal to $H_{0}$ (Figure 2). Now $\mu$ will experience the combined effects of $H_{1}$ and $H_{0}$ if the angular frequency of $H_{1}$ coincides with $\nu_{0}$, the precessional frequency of the spin. The nucleus absorbs energy from $H_{1}$ in this situation and $\theta$ changes; otherwise $H_{1}$ and $\mu$ would not remain in phase and no energy would be transferred between them.

If the rotational rate of $H_{1}$ is varied through the Larmor frequency of the nucleus, a resonance condition is achieved, accompanied by a transfer of energy from $\boldsymbol{H}_{1}$ to the spinning nucleus and an oscillation of the angle $\theta$ between $H_{0}$ and $\mu$. At $H_{0}=2.34 \mathrm{~T}$ ( $1 \mathrm{~T}=1$ tesla $=10$ kilogauss , the resonant frequencies of the ${ }^{1} \mathrm{H},{ }^{19} \mathrm{~F},{ }^{31} \mathrm{P},{ }^{13} \mathrm{C},{ }^{29} \mathrm{Si}$, and ${ }^{15} \mathrm{~N}$ nuclei are $\nu_{0}=100,94,40.5,25.1,19.9$, and $10.1 \mathrm{MHz}$, respectively [4].

\subsubsection{Interactions and relaxations of nuclear spins}

Figure 3 illustrates the magnetic energy levels lor a spin $-1 / 2$ nucleus in a magnetic field $H_{0}$. The energy distribution between nuclear spin states is

$$
\Delta E=2 \mu H_{0}
$$

and the relative populations of the upper $(+)$ and lower $(-)$ states is given by the Boltzmann expression

$$
\frac{N_{+}}{N_{-}}=\exp \left(-\frac{\Delta E}{k T}\right)=\exp \left(-\frac{2 \mu H_{0}}{k T}\right)
$$

The excess population of the lower energy state is

$$
\frac{N_{--}-N_{+}}{N_{-}}=\frac{2 \mu H_{0}}{k T}
$$


where the approximation $e^{-x}=1-x$, for small $x$, has been adopted.

Figure 3 shows the creation of two energy levels when a nucleus is placed in a strong external magnetic field. This effect is called Zeeman's splitting of energy levels. If one considers the well-known expression

$$
\Delta E=h \nu
$$

where $\nu$ is the frequency of the energy quantum absorbed or emitted by the nucleus; one obtains

$$
\begin{gathered}
\Delta E=h \nu=\frac{H}{2 \pi} \gamma H_{0} \\
2 \pi \nu=\gamma F I_{0}
\end{gathered}
$$

The last expression is a basic relationship in NMR, showing that for a nucleus of a given type, characterised by a magnetogyric ratio $\gamma$, the rosonant frequency $v$ is proportional to the applied external magnetic field $H_{0}$.

At a field strength $H_{0}=2.34 \mathrm{~T}$, the difference between magnelic energy levels for proton nuclei is $\sim 10^{-2}$ cal, which results in an excess population of $\sim 2 \times 10^{-5}$ spins of lower energy. For an assemblage of nuclei, this small spin population difference leads to a correspondingly small macroscopic moment directed along $H_{0}$. Removal of $H_{0}$ results in a loss of the macroscopic moment, because the magnetic energy levels are degenerate in the absence of the field \{4\}.

At resonance, the nuclei pass to upper energy levels by energy absorption or unce versa, to lower energy levels by energy emission. Since the absorptive transitions are prevailing, a tendency exists toward equalisation of the populations of the levels with time. When such a state (called saturation) is achieved, the energy absorbed by the sample becomes equal to that emitted and the NMR signal disappears. However, under appropriate experimental conditions, the NMP observations could be infinitely long. This is due to the fact that emissionless processes (called relaxation) are

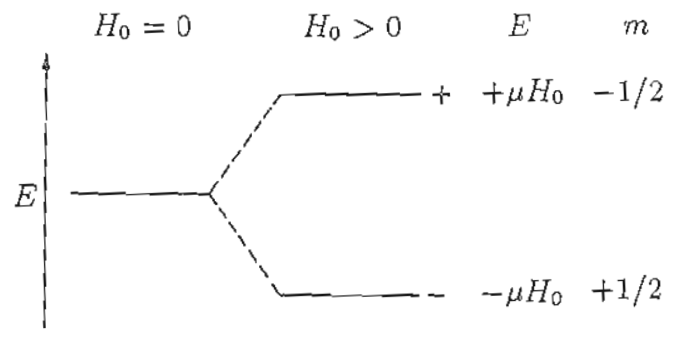

Figure 3. Energy Ievels for a spin -1/2 nucleus in a magnetic field $H_{0}[5]$ 
taking place in the sample; as a result the energy absorbed by the nuclei decreases and the system is kept at a state of Boltzmann equilibrium.

The question arises, what mechanisms are responsible for relaxing upper-level spins to the lower level after application of $\boldsymbol{H}_{0}$, thereby maintaining parity between the spin and sample temperatures? Such a relaxation is possible because each spin is not completely isolated from the rest of the rnolecules in the sample, called the lattice. The spins and the lattice may be considered to be separate coexisting systems which are weakly coupled through an inefficient yet very important link, by which thermal energy may be exchanged. The molecular motions of the neighbonring nuclei, which constitute the lattice, provide the mechanism for transferring thermal energy between the spins and their surroundings.

The relative motions of neighbouring nuclei generate fluctuating magnetic fields which are experienced by the observed nucleus as it precesses about the direction of the applied field $H_{0}$. A broad range of frequencies will be associated with the fluctuating fields produced by the lattice motions, because these motions are almost random in respect to the observed nucleus. Components of the fluctuating magnetic fields, generated by the lattice motions, which lie along $H_{0}$ (Figure 2) and have frequency $\nu_{0}$ will, like $H_{1}$, induce transitions between the magnetic encrgy levels of the observed nuclei. The rates of this spin-lattice relaxation must therefore be directly connected to the rates of molecular motions in the lattice.

The spin-lattice relaxation time, $T_{1}$, is the time required for the difference between the excess and equilibrium spin populations to be relaxed by a factor of $e$. For liquids, $T_{1}$ is usually in the range of $10^{-2}-10^{2} \mathrm{~s}$, while in solid samples $T_{1}$ nIray be as long as hours. Spin-lattice relaxation re-

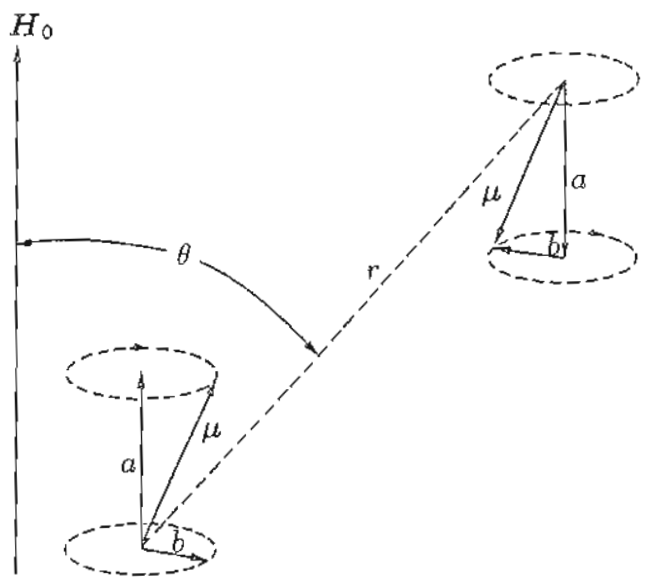

Figure 4. A pair of processing nuclear moments witl stalic (a) and rotating (b) component [4] 
sults in a change in energy via a redistribution of magnetic moments with components along the applied field $H_{0}$. As a result, $T_{\perp}$ is often termed the longitudinal relaxation time: it is associated with a decay of the macroscopic muclear moment along the direction of the applied field $H_{0}$ (the z-direction; see Figure 2).

There is a second mode by which nuclear magnetic moments may interact. This interaction is illustrated in Figure 4. Here a pair of nnclear moments are precessing about the $H_{0^{-}}$axis, and each is decomposed into a static component along $H_{0}(a)$ and a rotating component in the $x y$ plane (b). If the rotating component precesses at the Larmor frequency $\nu_{0}$, a neighbouring nucleus may be induced to nndergo a spin transition, resulting in a spin exchange. No net change in the total energy is produced by the exchange of neighbouring nuclear spins, but the lifetimes of the interacting spins are clearly affected. This exchange of neighbouring nuclear spins is called spin-spin relaxation and is characterised by $T_{2}$, the spin-spin relaxation time. $T_{2}$ is also called the transverse relaxation time, because it is related to the rate of change of magnetization in the $x y$ plane, which is transverse to the $H_{0}$ field direction.

\subsubsection{Chemical shift}

We have seen that by application of a rotating magnetic field $H_{\perp}$ transverse to the static field $H_{0}$, about which a spinning unclear magnet is precessing, we can flip the nuclear spin by rotating $H_{1}$ at the precession or Larmor frequency $\nu_{0}$. If all nuclei of the same type, e.g., all protons were to resonate at the same field strength $H_{0}, \mathrm{NMR}$ would not be a spectroscopic tool useful for the study of molecular structures. Fortunately, soon after the application of NMR to condensed phases it was observed that the characteristic resolnant frequency of a nnclens depends on its chemical or structural environment.

The cloud of electrons about each nuclens produces orbital currents when placed in a magnetic field $H_{0}$. These currents produce small local magnetic fields which are proportional to $H_{0}$ but are opposite in direction, thereby effectively shjelding the nuclens from $H_{0}$. Consequently, a slightly higher value of $H_{0}$ is needed to achieve resonance. The actual local field, $H_{\text {loc }}$, experienced by a nucleus, can be expressed as

$$
H_{\text {loc }}=H_{0}(1-\sigma)
$$

where $\sigma$ is the screening constant. It is highly sensitive to chemical structure but independent of $H_{0}$. The resonant Larmor frequency becomes

$$
\nu_{0}=\frac{\mu H_{\mathrm{loc}}}{h I}=\frac{\mu H_{0}(1-\sigma)}{h I}
$$

and the difference between magnetic energy levels is now (see Eq. (6))

$$
\Delta E=2 \mu H_{\mathrm{loc}}=2 \mu H_{0}(1-\sigma)
$$


Nuclear screening decreases the spacing of nuclear magnetic energy levels. An increase in the nnagnetic shielding requires an increase in $H_{0}$ at constant $\nu_{0}$ and a decrease in $\nu_{0}$ at constant $H_{0}$ to achieve resonance.

Nuclear shielding is influenced by the number and types of atoms and groups attached to or near the observed nucleus. The dependence of $\sigma$ on the molecular structure is of major significance to NMR as a tool in the study of molecular strnctures.

There is no natural fundamental scale unit in NMR spectroscopy. Both the energies of transition between spin quantum levels and the nuclear shielding produced by the screening constant $\sigma$ are proportional to the applied field $H_{0}$. In addition, there is no natural zero of reference in NMR. These difficulties are overcome by (i) expressing the resonant frequencies of nuciei in parts per million (ppm) relative changes in $H_{0}$ and (ii) referring the observed changes or displacements in resonance, called chemical shilts, to the ppm relative change in the resonant frequency of an arbitrary reference substance added to the sample. In ${ }^{1} \mathrm{H}$ and ${ }^{13} \mathrm{C}$ NMR spectroscopy, it is customary to use tetramethylsilane (TMS) as the reference compound, where the chemical shifts $\delta$ of both the ${ }^{1} \mathrm{H}$ and ${ }^{13} \mathrm{C}$ nuclei are taken as $\delta=0$ ppm.

It is beyond the scope of this chapter to discuss the factors affecting the chemical shift. For this reason, we could encourage the reacler to consult the general NMR texts [5-8]. However, it is worth mentioning here the most important factors, namely: electronegativity of the substituents, magnetic anisotropy, electric field effect, hydrogen bond formation, repulsive electron effects.

The chemical shifts of carbon-bonded protons are almost insensitive to temperature and sample concentrations. However, protons bonded to heteroatoms (e.g, $\mathrm{O}-\mathrm{H}, \mathrm{N}-\mathrm{H}$ and $\mathrm{S}-\mathrm{H}$ ) display strong dependence on the above factors. These effects are caused mostly by the tendency of $\mathrm{OH}, \mathrm{SH}$ and $\mathrm{NH}$ protons to form hydrogen bonds. In general, this leads to screening effects, i.e., to downfield shifts, although the reasons are not always well understood.

It is always strongly recommended to check the possibility of hydrogen bond formation between the sample and the solvent. For instance, ditnethyl sulfoxide (DMSO) forms strong hydrogen bonds with $\mathrm{OH}$ and $\mathrm{NH}$ groups, resulting in significant changes in the chemical shifts.

\subsubsection{Spin-spin coupling}

It is well established that in numerous cases the NMR signals are split into scveral components. This is illustrated in Figure 5, where the proton spectrum of $1,1,1,2,3,3$-hexachloropropane is depicted. It is seen that the signals of the two protons are split into doublets. This observed fact is due to the so-called spin-spin interaction.

It is established that the magnetic inoments of the nuclei interact both 


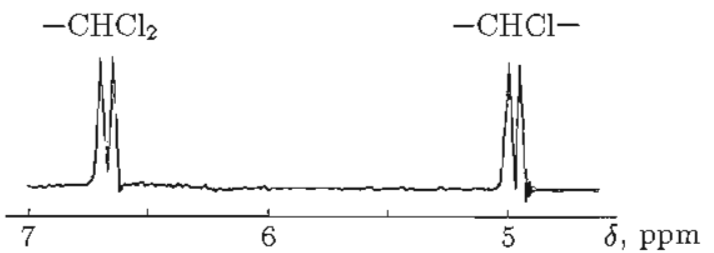

Figure 5. NMR spectrum of $\mathrm{CCl}_{3} \mathrm{CHClCHCl}_{2}$ in solution [3]

directly (through the space) and indirectly - by the valence clcctrons. The former effect is called direct spin-spin (or dipole) coupling and does not influence the NMR spectra taken in liquid or gaseous media since it is nullified due to the fast molecular motion. In the case of solids, the direct spin-spin interaction leads to a quite significant broadening of the resonance signals.

From now on, we will discuss only the indirect (or scalar) coupling. It is observed in the NMR spectra of liquids and gases, and is of prime importance in their interpretation. Two neighbonring nuclear spins will feel, in addition to $H_{0}$, the local magnetic field $H_{\text {loc }}$ they are producing. $H_{\text {loc }}$ is given by

$$
H_{\mathrm{loc}}= \pm \mu r^{-3}\left(3 \cos ^{2} \theta-1\right)
$$

where $\gamma$ is the distance between nuclei, and $\theta$ is the angle between $H_{0}$ and the line joining the nuclei (see Fignre 4 ). The fact that $H_{\text {loc }}$ may add to or subtract from $H_{0}$, depending on whether the neighbouring magnetic dipole is aligned with or against $H_{0}$, is reflected by the \pm sign. This type of spin-spin coupling is called dipolar coupling and serves to broaden the resonance line of a nuclens.

There are two important situations where dipolar coupling does not contribute to line broadening. The first is when all neighbouring nuclei are rigidly oriented at the magic angle of $\theta=54.7^{\circ}$, where $\cos ^{2} \theta=1 / 3$ and $H_{\text {loc }}=0$ (see $\mathrm{Eq}$. (15)). If the relative orientations of neighbouring spins vary rapidly with respect to the time a nucleus spends in a given spin state, i.e., with respect to the spin-spin relaxation time $T_{2}$, than $H_{\text {loc }}$ is given by its space average,

$$
H_{\mathrm{loc}}=\mu r^{-3} \int_{0}^{\pi}\left(3 \cos ^{2} \theta-1\right) \sin \theta d \theta
$$

which also vanishes. Both these circumstances are important for observing high-resolution NMR spectra of polymers.

Nuclear spins may also be coupled by orbital motions of their valence electrons or polarisation of their spins occurring indirectly through the intervening chenical bonds. Unlike dipolar coupling of nuclear spins, this 
(a)

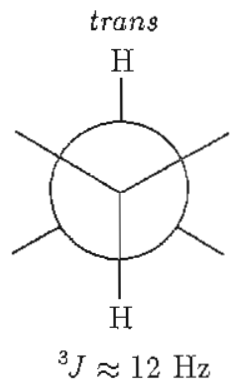

(b)

gauche

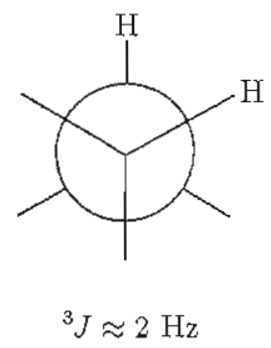

Figure 6. Vicinal ${ }^{3} J^{1} \mathrm{H} \sim^{1} \mathrm{H}$ scalar coupling in a saturated hydrocarbon [4]

indirect or scalar coupling is not affected by molecular tumbling and is also independent of $H_{0}$. Two spin $-1 / 2$ nuclei so coupled will each split. the other's resonance into a doublet, because in a large collection of such nuclear pairs the probabilities of each finding the other's spin along $(+1 / 2)$ or against $(-1 / 2) H_{0}$ are almost equal. If one nucleus of the pair is further coupled to a second group of two identical nuclei with,$+++-(-+)$, and - - spin orientalions, then the resonance of the first nucleus will appear as a 1:2:1 triplet. The resonance of the identical pair will be a doublet. $A$ single nucleus coupled to three equivalent neighbouring spins with +++ ; ,,$++-+-+-++(+--,-+-,--+)$; and -- - orientations would exhibit a 1:3:3:1 qnartet resonance. A spin $-1 / 2$ nucleus with $n$ equivalently coupled neighbours also of spin $1 / 2$ will have its resonance split into $n+1$ peaks.

In the NMR spectra of polymers, only ${ }^{1} \mathrm{H}-{ }^{1} \mathrm{H},{ }^{13} \mathrm{C}-{ }^{1} \mathrm{H},{ }^{13} \mathrm{C}-{ }^{19} \mathrm{~F},{ }^{15} \mathrm{~N}-$ ${ }^{1} \mathrm{H},{ }^{19} \mathrm{~F}-{ }^{19} \mathrm{~F},{ }^{19} \mathrm{~F}-{ }^{1} \mathrm{H},{ }^{29} \mathrm{Si}-{ }^{1} \mathrm{H}$, and ${ }^{31} \mathrm{P}-{ }^{1} \mathrm{H}$ scalar couplings are important. The magnitude and sign of the scalar coupling of two magnetic nuclei depend on substituents and geometry. The strength of the coupling in Hertz is designated ${ }^{x} J$, where the superscript $x$ denotes the numher of intervening: chemical bonds between the coupled nuclei. A particularly useful relation is based on the observed geometry-dependent vicinal ${ }^{1} \mathrm{H}-{ }^{1} \mathrm{H}$ coupling ${ }^{3} J$ illustrated in Figure6. Here it is observed that when the vicinal protons are trans (a) the scalar coupling is large (about $12 \mathrm{~Hz}$ ), but it is markedly rednced to about $2 \mathrm{~Hz}$ in their gauche arrangement (b).

\subsubsection{Experimertal observation of NMR}

In an NMR experiment, one investigates an assemblage of nuclei of a given type (e.g., protons) rather than the separate nucleus. In general, nuclei always take the level (or the state) of lower energy. In the case of nuclei with $J=1 / 2$, this is the state with $m= \pm 1 / 2$ (see Figure 3 ). However, the molecular thermal motion opposes this trend since its energy is several 


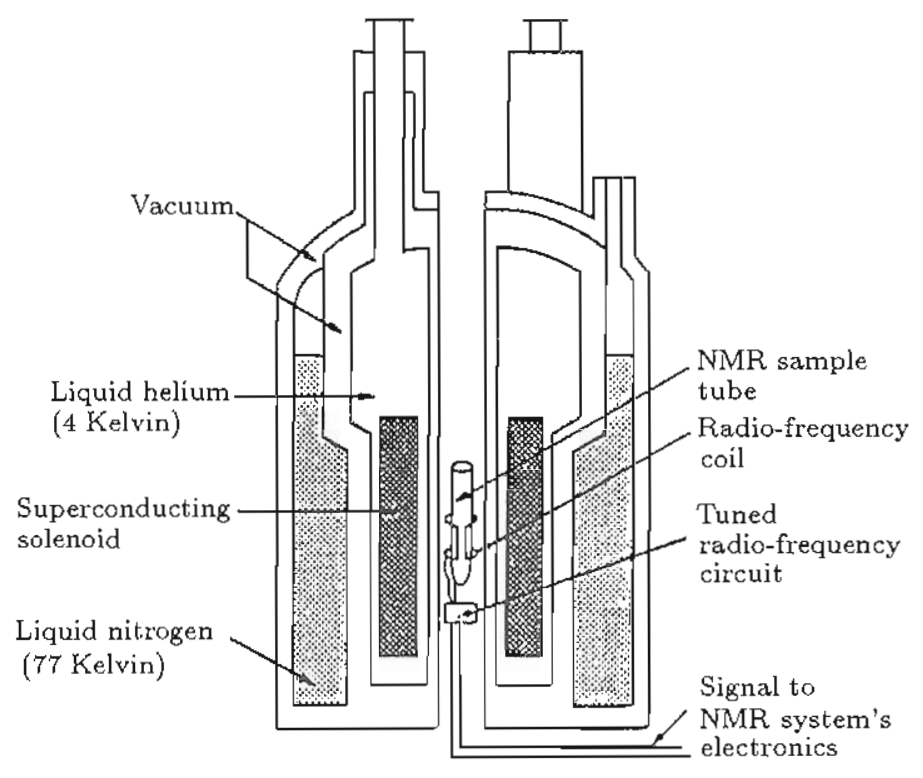

Figure 7. Cross-section of a superconducting NMR magnet [6]

times higher. As a result, an equilibrinm state is reached, characterised by the Boltzmann expression (Eq. (7)). The excess population of the lower energy state (Eq. (8)) is rather small. For magnetic fields between 2.0 and $2.5 \mathrm{~T}$ at room temperature, calculations according to Eq. (8) show that the population of spins at the lower energy level is higher by only $0.001 \%$ than that at the higher level. Nevertheless, it is precisely this minor difference that makes absorption transitions more probable than the emission ones. As a result, the sample absorbs external energy at its Larmor frequency. The NMR experiment is to register this absorption with suitable instrnmentation.

Figure 7 is a drawing of a snperconducting magnet used in a modern high-field NMR spectrometer. The magnet is placed in a liquid helium bath to maintain its superconductivity. The radio-freqnency (rf) coil provides the energy appropriate to excite the nnclei in the sample to resonance.

The degeneracy of the nuclear magnetic spin energy levels is removed by the static magnetic field $\boldsymbol{H}_{0}$. Application of the rotating magnetic or electromagnetic field $H_{1}$ excites transitions between these energy levels. When the frequency of the $\boldsymbol{H}_{1}$ field ( $\mathrm{xf}$, in $\mathrm{MHz}$ ) is eqnal to the Larmor frequency of the observed nucleus, the resonance condition occurs, i.e.,

$$
H_{1}=\nu_{0}=\gamma \frac{H_{0}}{2 \theta}
$$

Most samples will have multiple Larmor frequencies, because most 
molecules have more than a single magnetically equivalent group (e.g., $\mathrm{CH}$; $\mathrm{CH}_{2}, \mathrm{CH}_{3}$ ), leading to several resonance frequencies or chernical shifts. The method used to excite the nuclei and achieve resonance must clearly be capable of covering all of the Larmor frequencies in the sample.

Two principal methods have been developed to achieve the resonance condition in NMR spectroscopy - continuous wave (CW) and Fourier transform (FT). In the CW method each magnetically equivalent nucleus is successively made to resonate by sweeping either of the magnetic fields, the rf $H_{1}$ or the static $H_{0}$ field. As each nucleus is brought into resonance by the field-sweeping process, a voltage is induced iu the ri pick-up coil (see Figure 7). After amplification, this signal is detected directly in the frequency domain and recorded in a plot of voltage (intensity) vs. frequency.

In contrast, the FT method employs signal detection in the time domain, followed by a Fourier transformation into the frequency domain. Simultaneous excitation of all the Larmor frequencies is provided by applying a. pulse (short burst) of $\mathrm{rf}$ signal at or near $\nu_{0}$, resulting in an ecqualisation of the populations of the nuclear spin energy levels. Equilibrium spin populations are reestablished in a free induction decay (FID) process following the rf pulse. The vector diagram in Figure 8 can be used to visualise the

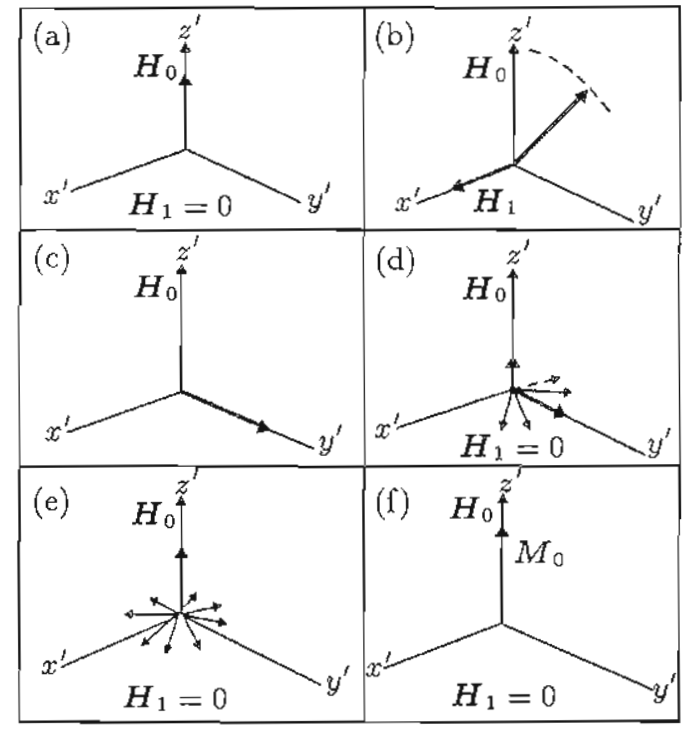

Figure 8. Pulsed NMR experiment in the rotating frame. (a) Net magnetisation $\boldsymbol{M}_{0}$ along $H_{0}$; (b,c) rf field $H_{1}$ applied perpendicular to $H_{0}$ for a duration sufficient to tip $M_{0}$ by $90^{\circ}$ into the $x^{\prime} y^{\prime}$ plane; (d,e) spins begin to relax in the $x^{\prime} y^{\prime}$ plane by spin-spin $\left(T_{2}\right)$ processes, and in the $z^{\prime}$-direction by spin-lattice $\left(T_{1}\right)$ processes; (f) equilibrinm $M_{0}$ is reestablished along $H_{0}[4]$ 
effect of the rf pulse $\left(\boldsymbol{H}_{1}\right)$ on the nuclear spins and their subsequent FID to equilibrium.

At equilibrium in the presence of $\boldsymbol{H}_{0}$, more spins will be aligned along $\boldsymbol{H}_{0}$ than against it, and this is indicated by the net magnetic moment $\boldsymbol{M}_{0}$, drawn along the field direction $z^{\prime}$ in Figure 8 a (note that the prines indicate that the reference frame $x^{\prime} y^{\prime} z^{\prime}$ is rotating at the Larmor frequency). The net magnetisation has been tipped $90^{\circ}$ into the $x^{\prime} y^{\prime}$ plane (Figure 8b,c) by application of an $\mathrm{rf}$ pulse $\boldsymbol{H}_{1}$ with duration that is just sufficient to equalise the magnetic energy levels, i.e., $M_{0}=0$ along $z^{\prime}$.

Following the of pulse (Figure 8d,e), the spins begin to reestablish their initial state through $T_{1}$ and $T_{2}$ relaxation processes. Spin-spin interactions in the transverse $\left(x^{\prime} y^{\prime}\right)$ plane cause dephasing of the spins in this plane ( $T_{2}$ process), while spin-lattice interactions cause the spins to relax along the $z^{\prime}$-direction ( $T_{1}$ process). Usually many signals must be accumulated before a spectrum with adequate signal-to-noise ratio can be obtained, particularly for nuclei with low natural abundance, snch as ${ }^{13} \mathrm{C},{ }^{15} \mathrm{~N}$ and ${ }^{29} \mathrm{Si}$. The pulse repetition rate is governed by the relaxation time $T_{1}$.

Figure 9 gives a pulse sequence representation of the vector diagram in Figure 8. The detected signal, or FID, is obtained as a voltage in the
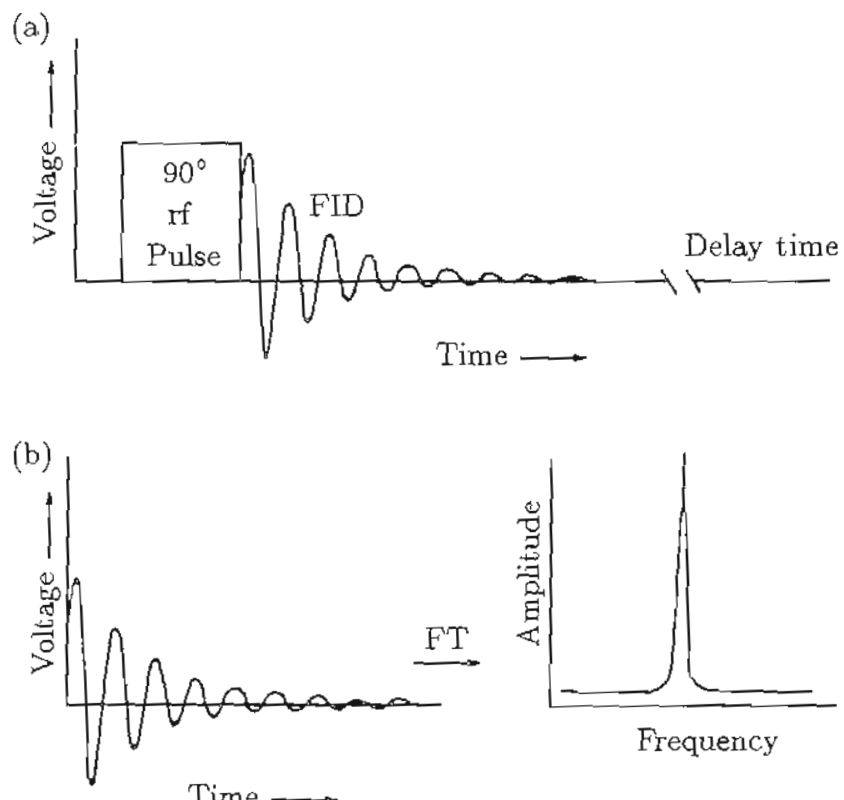

Time $\rightarrow$

Figure 9. Repetitive pulse sequence (a) and Fourier transformation of the timedomain FID into the frequency-domain NMR signal (b) [4] 


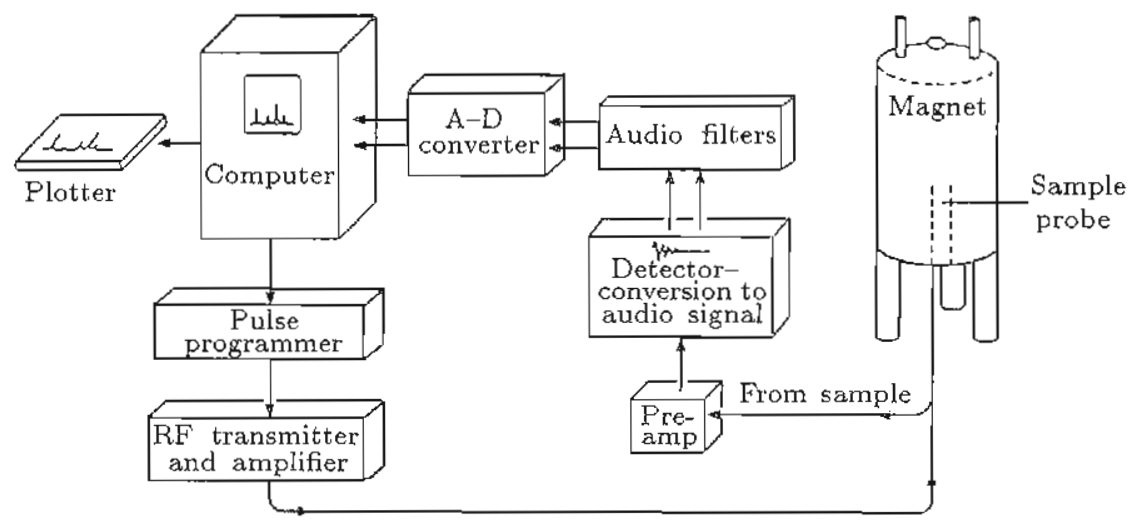

Figure 10. Block diagram of a pulsed FT NMR spectrometer [6]

time domain. The pulse is sent out repeatedly to improve the signal-tonoise ratio, and the delay time between pulses nust be long enough for $T_{1}$ relaxation processes to complete. Fourier transformation of the timedomain signal resnlts in the usual frequency-domain spectrum. The FT method saves time by collecting data all at once, rather than from the slow CW sweep of the field, and is well suited to signal averaging by collecting many FIDs from weak signals before Fourier-transforming them.

Finally, Figure 10 shows the block diagram of a modern pulsed NMR spectrometer. The sample is first positioned in the most homogeneous part of the magnetic field (see Figure 7). Then the computer activates the pulse programmer and precisely timed digital pulses are sent out. The rf pulses are generated by superimposing rf signals on these pulsed digital signals. The rf pulses are amplified and sent to the sample, whore they produce FIDs. Upon amplification and detection by audio conversion, these signals are filtered and converted into a digital representation using an analogueto-digital (A - D ) converter. These digital signals are finally stored in the computer for further processing or plotting.

\subsection{High resolution NMR of polymers}

Though NMR spectroscopy is over 40 years old, it still remains in a state of rapid development. Magnetic field strengths of current superconducting NMR spectrometers are almost 40 -fold stronger than those employed in the first permanent-magnet prototype spectrometers. Pulse programmable FT spectrometers allow the selective observation of nuclei based on their unique structural (chemical) and motional characteristics. Almost daily, new concepts (2D NMR, cross-polarisation, etc.) and new techniques (INEPT, DEPT, magic-angle sample spinning, etc.) are reported and applied to a variety of molecular systems, including both synthetic and biopolymers. 
Though the first report of polymer NMR spectra (a wide-line ${ }^{1} \mathrm{H}$ NMR study of natural rubber [9]) appeared the year after the discovery of the NMR phenomenon in bulk matter $[10,11]$, it was only in the late 1950 s that high-resolution NMR spectra were recorded for polymers. Even frorn polymer solutions, which are often very viscous, reasonably well resolved NMR. spectra can be obtained, such as those reported for polystyrene $[12,13]$.

The rapid local motions of polymer chain segments (nanosecond to picosecond range) produce high-resolution NMR spectra of dissolved polymers. The volumes pervaded by dissolved macromolecules are much larger than their molecnlar volumes and produce highly viscous solutions through. polymer-polymer entanglements and entrapment of surrounding solvent molecules. However, as already mentioned, both the frequency at which a magnetic nucleus resonates and the width of the resulting resonance peak depend on the local structure and its motional dynamics in the immediate vicinity of the observed rucleus. Thus, NMR serves as a local rnicroscopic probe of nolecular structure and its motions, and can even provide highly resolved spectra of dissolved polymers, regardless of the fact that their overall motion may be sluggish since their local segmental motions are rapid.

\subsection{1. ${ }^{1} H$ NMR in the study of interchange reactions}

Historically, the proton $\left({ }^{l} \mathrm{H}\right)$ was the first rucleus abserved in the magnetic resonance of polymers. The average sequence length in vinyl copolymers and the stereosequence in stereoregular polymers have been initially studied by high resolution NMR spectroscopy [14]. At that time, there had been very few reports on the determination of sequence length in condensation polymers [15]. The first noteworthy work on this subject was performed by Yamadera et al. [16]. In their paper, the ${ }^{1} \mathrm{H}$ spectra of the following homo- and copolyesters were measured: poly(ethylene terephthalate) (PET), poly(ethylene isophthalate) (PEI), poly(ethylene orthophthalate) (PEO), poly(ethylene sebacate) (PES), poly(ethylene trans-hexahydroterephthalate) (PEK), poly(resorcinol terephthalate) (PRT), poly(ethylene terephthalate/isophthalate) (PET-I, 50:50), poly(ethylene terephthalate/orthophthalate) (PETO, 50:50), poly(ethylene terephthalate/sebacate) (PET-S, 50:50), poly (ethylene terephthalate/hexahydroterephthalate) (PET-H, 50:50), poly(ethylene/resorcinol terephthalate) (PE-RT, 50:50). These samples were prepared from glycols and dimethyl esters of the acids by polycondensation in the melt under reduced pressure.

The transesterification reaction was carried out between PET and PES, mixed in various proportions at intervals of $10 \%$ and stirred under a nitrogen atmosphere at $276^{\circ} \mathrm{C}$ for $10,30,60,120$, and $180 \mathrm{~min}$. The NMR spectra were measured in a trifluaroacetic acid solntion $(0.05 \mathrm{~g} / \mathrm{ml})$ at $70^{\circ} \mathrm{C}$ with a Varian A-60 spectrometer.

In the NMR spectra of copolyesters, such as PET-O, PET-S and PET- 


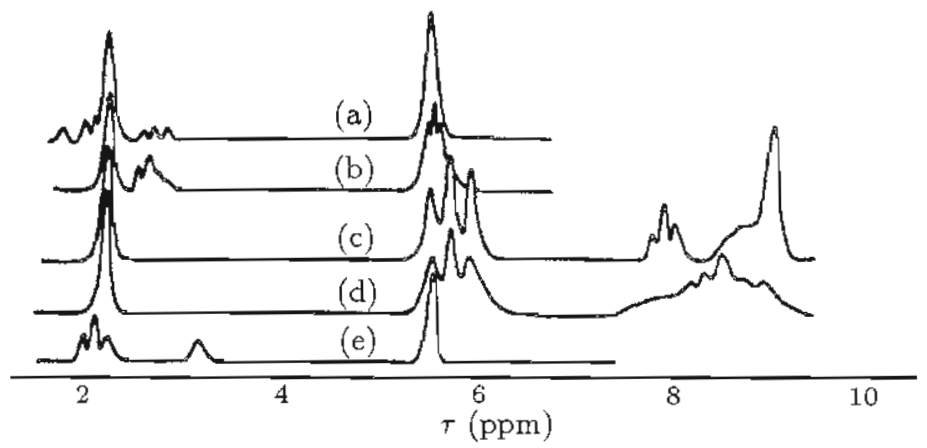

Fignie 11. NMR spectra of copolyesters (50:50): (a) PET-I; (b) PET-O; (c) PETS; (d) PET-H, and (e) PE-RT [16]

$\mathrm{H}$, three peaks are observed in the region of 5.5-6.0 ppm (Figure 11). Two peaks (one at each side) are assigned to the ethylene groups placed between the same acid groups, because they coincide with the ethylene proton signals of the homopolyesters. A central peak, which is not observed in the spectra of the respective homopolycsters, is due to the ethylene glycol residue bonded to the different acid groups at both sides. The intensity of this peal represents the amount of the "heterolinkage".

For instance, the ethylene glycol residue (-G-) in PET-S can be adjacent to terephthalate at both sides ( $\mathrm{T}-\mathrm{G}-\mathrm{T}$ ), to sebacate at both sides ( $\mathrm{S}-\mathrm{G}-\mathrm{S}$ ) or to terephthalate and sebacate $(\mathrm{T}-\mathrm{G}-\mathrm{S})$. The respective proton signals appear at 5.53,5.93 and $5.73 \mathrm{ppm}$. No fine splitting is observed in the proton signal of the ethylene glycol residue in the heterolinkage because of the small difference in the chemical shifts between the two methylene protons.

PET-S is taken as an example. Molar fractions of terephthalate $\left(P_{\mathrm{T}}\right)$ ard sebacate $\left(P_{\mathrm{S}}\right)$ are obtained from the intensities of the three kinds of signals in the NMR spectrum:

$$
\begin{aligned}
& P_{\mathrm{T}}=P_{\mathrm{T}-\mathrm{G}-\mathrm{S}} / 2+P_{\mathrm{T}-\mathrm{G}-\mathrm{T}} \\
& P_{\mathrm{S}}=P_{\mathrm{T}-\mathrm{G}-\mathrm{S}} / 2+P_{\mathrm{S}-\mathrm{G}-\mathrm{S}}
\end{aligned}
$$

where $P_{\Gamma-\mathrm{G}-\mathrm{T}}, P_{\mathrm{S}-\mathrm{G}-\mathrm{S}}$ and $P_{\mathrm{T}-\mathrm{G}-\mathrm{S}}$ represent the ratios of the integrated intensities of $\mathrm{T}-\mathrm{G}-\mathrm{T}, \mathrm{S}-\mathrm{G}-\mathrm{S}$, and $\mathrm{T}-\mathrm{G}-\mathrm{S}$ signals, respectively, to the total intensity of the ethylene glycol residues.

If one could irspect the units along the PET-S copolymer chair from one end to the other, the probability of finding a $\mathrm{T}$ unit next to an $\mathrm{S}$ unit would be

$$
P_{\mathrm{ST}}=P_{\mathrm{T}-\mathrm{G}-\mathrm{S}} / 2 P_{\mathrm{S}}
$$


Similarly, an $S$ unit exists next to a $T$ unit with a probability of

$$
P_{\mathrm{TS}}=P_{\mathrm{T}-\mathrm{G}-\mathrm{S}} / 2 P_{\mathrm{T}}
$$

The degree of randomness is defined by

$$
B=P_{\mathrm{ST}}+P_{\mathrm{TS}}
$$

When $B=1$, the $\mathrm{T}$ and $\mathrm{S}$ units take a randorn distribution and the probability of finding a copolymer unit obeys Bernonlli statistics. If $B<1$, these units tend to cluster in blocks of each unit, and finally $B=0 \mathrm{in}$ a homopolymer mixture, whereas if $B>1$, the sequence length becomes shorter, and $B=2$ in an alternating polymer.

The number-average sequence length of a $\mathrm{T}$ unit $\left(\bar{L}_{n T}\right)$ and an $\mathrm{S}$ unit $\left(\bar{L}_{n S}\right)$ are given by

$$
\begin{aligned}
& \bar{L}_{n T}=2 P \mathrm{PT} / P_{\mathrm{T}-\mathrm{G}-\mathrm{S}}=1 / P_{\mathrm{TS}} \\
& \bar{L}_{n S}=2 \mathrm{PS} / P_{\mathrm{T}-\mathrm{G}-\mathrm{S}}=1 / P_{\mathrm{ST}}
\end{aligned}
$$

Table 2 shows the result of transesterification between PET and PES. For all feed ratios examined, the value of $B$ becomes almost 1 and the number-average sequence lengths $\bar{L}_{n S}$ and $\bar{L}_{n T}$ approach the theoretical values of a random copolymer after transesterification for $3 \mathrm{~h}$.

The above results illustrate the implementation of the ${ }^{1} \mathrm{H}$ NMR technique for sequential analysis of copolymers obtained in a molten binary homopolymer blend, where interchange reactions are possible. Obviously, as these progress, the polymer blend transforms into a block copolymer with the length of both PET and PES nnits decreasing to reach the values of a random copolymer, obeying the Bernoulli statistics.

In the studies of Devaux et al. [17-19], the more complex system comprising poly (butylene terephthalate) (PBT) and bisphenol A polycarbonate (PC) was analysed. Employing again the ${ }^{1} \mathrm{H}$ NMR technique and bearing in mind the mathematical approach of Yamadera and Murano [16], the authors determine the sequence length of PBT and PC units in a copolymer obtained from the starting physical blend by means of exchange interaction

Table 2. Changes in sequence distribution during transesterification between PET and $\mathrm{PES}$ at various feed ratios [16]

\begin{tabular}{ccrrr}
\hline PET/PES & Time $(\min )$ & $\bar{L}_{n S}$ & $\bar{L}_{n T}$ & $B$ \\
\hline $50 / 50$ & 10 & 10.905 & 10.638 & 0.186 \\
& 30 & 3.289 & 3.236 & 0.613 \\
60 & 2.404 & 2.353 & 0.841 \\
120 & 2.222 & 2.165 & 0.912 \\
& 180 & 2.141 & 2.092 & 0.945 \\
\hline
\end{tabular}


(i.e., transesterification). This method is discussed in detail in Chapter 3 aud for this reason it will not be given here. It is worth mentioning the same trend toward copolymer randomisation after application of appropriate annealing conditions $-T_{\mathrm{a}}>250^{\circ} \mathrm{C}$ and $t_{\mathrm{a}}>200 \mathrm{miu}$.

Recently, a new ${ }^{1} \mathrm{H}$ NMR technique luas been developed, allowing the assignment of resonances of very complex molecules -- the so-called chenical shift correlated (or COSY) spectrum. The basic principle of this technique may be seen in Figure 12.

If, instead of transforming (FT) the free induction decay (FID) immediately after the $90^{\circ}$ rf pulse in the usual way (see Section 2.1.6), one allows a time interval for the nuclear spins to precess in the transverse plane and for the evolution of interactions between them, it is possible to obtain important information concerning the nuclear spin system. One may divide such an experiment into three time domains, as indicated in Figure 12. The nuclear spins are allowed to equilibrate with their surroundings via spin-lattice relaxation during the preparation period. Following the $90_{x}^{\circ}$ if

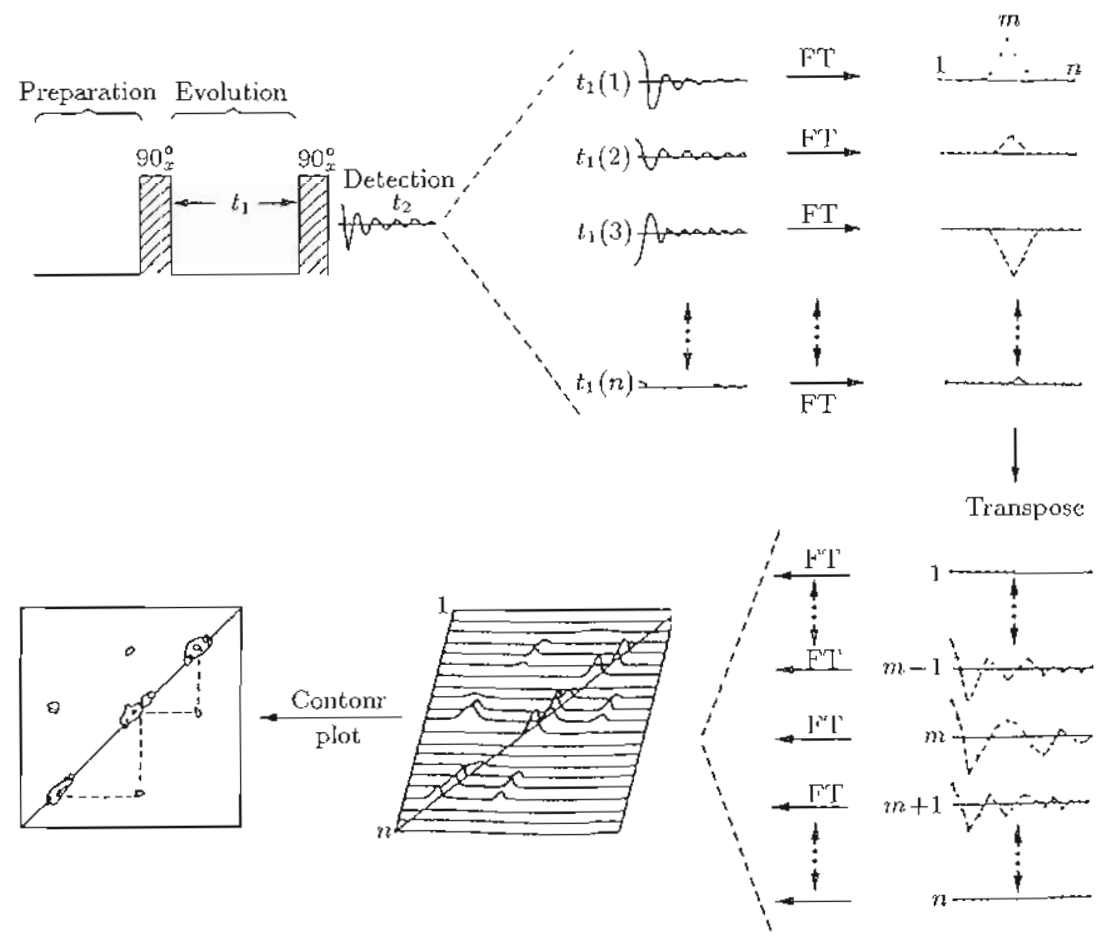

Figure 12. Schematic representation of a two-dimensional (2D) correlated (COSY) experiment and spectrum. The correlated infuence of the J-coupling between nuclei of different chemical shifts is shown [4] 
pulse, the $x, y$, and $z$ components of the nuclear spins evolve nnder all the forces acting on them, including their direct through-space dipole-dipole and through-bonds scalar $(J)$ couplings. This time, $t_{1}$, is termed the evolution period and provides, along with the acquisition or detection time, $t_{2}$, common to all pulse experiments, the two-dimensional (2D) character of this experiment. Systematic incrementation of the evolution time $t_{1}$ (see Figure 12) provides the second time dependence. After each $\iota_{1}$ period, a second $90_{x}^{\circ}$ rf pulse is applied and the exchange of nuclear spin magnetisation may occur. The FID is acquired during $t_{2}$ and transformed.

The pulse sequence shown in Figure 12 is appropriate for the observation of a COSY spectrum, where the correlating influence between nuclear spins is their scalar $J$-coupling. The FID following each $t_{1}$ is different becuuse the interacting spins modulate each other's response. Each FID detected in $t_{2}$ is transformed, producing a series of 1024 matrix rows, one for each $t_{1}$-value. Each row ruay consist of 1024 points (square data matrix), representing the frequency-domain spectrum for a particular value of $t_{1}$, while the columns provide iuformation about how the FIDs were modulated as a function of $t_{1}$.

By looking down the columns of the data matrix, in an operation called

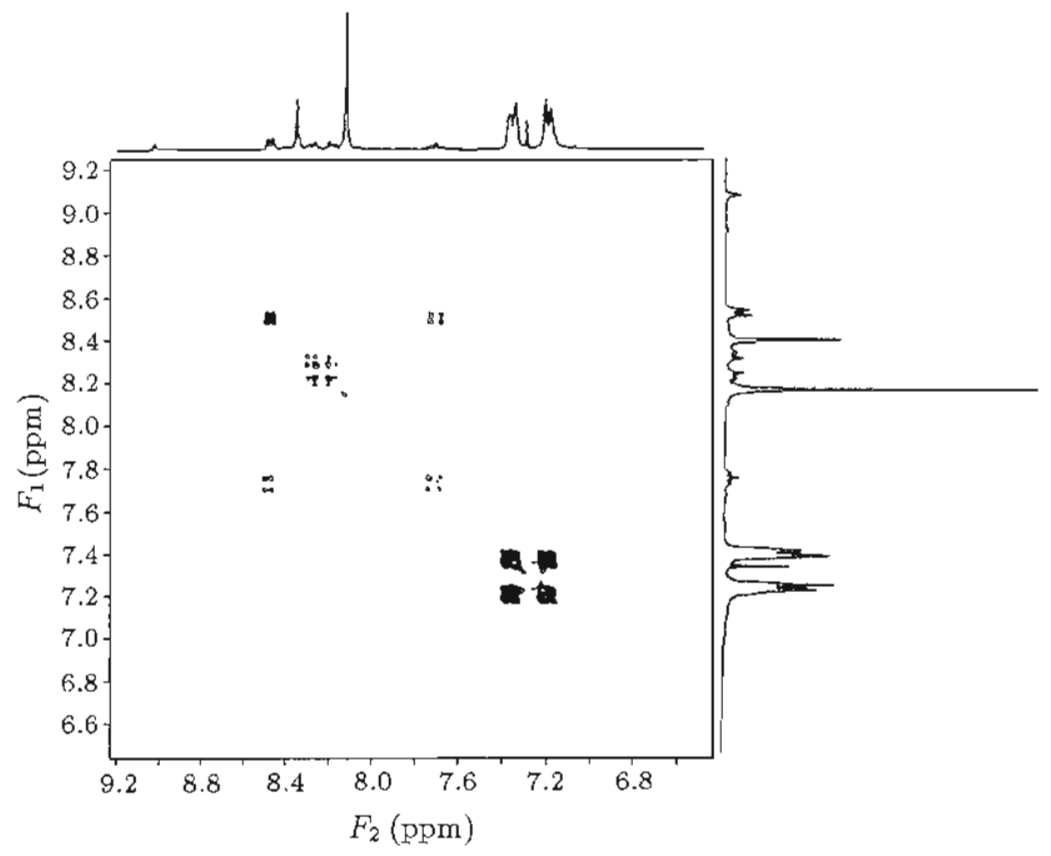

Fignre 13. COSY spectra of the solnble fraction of a PBT/PAr blend after transesterification [20] 
the "transpose" in Figure 12, 1024 new FIDs are constructed. (Note that at this stage the spectrum is represented, for the sake of simplicity, as a single resonance.) A second Fourier transformation is performed on the newly transposed FIDs, leading to a $2 \mathrm{D}$ data matrix which is actually a surface in three-dimensional space. The surface may be represented as either a stacked plot or a contour plot. The latter is usually preferred, since the stacked plot does not clearly show complex relationships and is very timeconsuming to record.

Nuclei which do not exchange magnetisation have the same frequencies, $F_{1}$ and $F_{2}$, respectively, during $t_{1}$ and $t_{2}$ (i.e., $F_{1}=F_{2}$ ) and yield the normal spectrum along the diagonals of the contour plot. Scalar-coupled nuclei exchange their magnetisation and have a final frequency differing from the initial one, i.e, $F_{\perp} \neq F_{2}$. These coupled nuclei give rise to the off-diagonal contours or cross peaks shown in Figure 12.

If one considers the particular case of an equimolar $\mathrm{PBT} /$ polyarylate (PAr) system after intensive transesterification $\left(240 \mathrm{~min}\right.$ at $250^{\circ} \mathrm{C}$ ), the COSY spectra of Figure 13 are obtained [20]. This figure makes evident the scalar coupling of the protons absorbing at $7.71 \mathrm{ppm}$ and $8.56 \mathrm{ppm}$ (a triplet and a doublet, respectively). As indicated by the authors [20], these peaks should be ascribed to the aromatic protons of an asymmetrically substituted isophthalyl unit

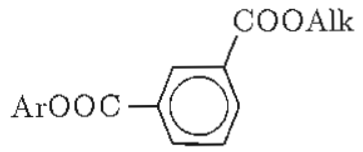

Becanse of the extreme complexity of the PBT/PAr system, at this point there is no method developed for sequence analysis of these copolymer's,

\subsection{2. ${ }^{13} \mathrm{C} N M R$ in the study of interchange reactions}

The ${ }^{13} \mathrm{C}$ nncleus occurs at a natural abundance of only $1.1 \%$ and has a small magnetic moment - about one quarter that of the proton. Both factors tend to mitigate against the observation of high-resolution ${ }^{13} \mathrm{C} \mathrm{NMR}$ spectra. However, the decrease in observational sensitivity of the ${ }^{13} \mathrm{C}$ nuclens can be compensated by employing the pulsed FT technique, combined with spectrum accumulation, as described in Section 2.1.6. The time saved by the pulsed FT recording of spectra makes possible the accumulation of a sufficient number of spectra to produce a suitable signal-to-noisc ratio. Further increase in ${ }^{13} \mathrm{C}$ signal intensity is obtained by removing the nuclear spin coupling between ${ }^{13} \mathrm{C}$ nuclei and their directly bonded protons, and from the accompanying nuclear Overhanser enhancement (NOE). Removal of the strong $\left(125-250 \mathrm{~Hz}\right.$ ) ${ }^{13} \mathrm{C}-{ }^{1} \mathrm{H}$ nuclear coupling, by providing a second If field at the proton resonance frequency, tesults in the collapse of ${ }^{13} \mathrm{C}$ multiplets and an improved signal-to-noise ratio. Saturation of nearby protons 
produces a non-equilibrium polarisation of the ${ }^{13} \mathrm{C}$ nuclei, which exceeds the thermal value aud yields an increase in the observed signal strength. It has been demonstrated [21] that the dipole-dipole coupling mechanism dominates for the ${ }^{13} \mathrm{C}$ isotope and a maximum NOE factor of 3 is produced by a directly bonded proton.

Having discussed several of the means utilised to overcome the inherent insensitivity of the ${ }^{13} \mathrm{C}$ nucleus, let us now mention the principal advantage of ${ }^{13} \mathrm{C}$ NMR spectroscopy of organic molecules, including polymers. It is the increased sensitivity of ${ }^{13} \mathrm{C}$ shieldings to molecular structure, conformation and solvation (in the 200 pprn range for neutral organics, compared to 10-12 ppm for ${ }^{1} \mathrm{H}$ shieldings), which has resulted in the replacement of ${ }^{1} \mathrm{H}$ NMR by ${ }^{13} \mathrm{C}$ NMR as the method of choice in molecular structure investigations.

It is important to mention here that in ${ }^{13} \mathrm{C}$ spectra, the intensities of the signals do not always correlate well with the number of corresponding $\mathrm{C}$ atoms. This effect is explained by the different relaxation rates of the $\mathrm{C}$ atoms, which depend very strongly on their surroundings. For instance, the $\mathrm{C}$ atoms which are not bonded to $\mathrm{H}$-atoms usually give weaker signals than those of $\mathrm{CH}_{3}, \mathrm{CH}_{2}$, and $\mathrm{CH}$ groups. However, by employing proper pulse sequences and times, this problem can be eliminated, so that reliable quantification of the ${ }^{13} \mathrm{C}$ NMR signals is possible.

Nevertheless, the ${ }^{13} \mathrm{C}$ NMR spectra are much simpler than the proton ones. Generally, their interpretation is based on the chemical shifts of the signals. Peak intensity or multiplicity is rarely used. As in the protor spectra, the chemical shifts are usually referenced to an internal TMS standard.

Let us now consider a particular example of how ${ }^{13} \mathrm{C}$ NMR can be used for the characterisation of the microstructure of condensation homo- and copolymers [22]. In Figure 14, the CO signals of different Nylon 6-Nylon 6,6 copolyamides are compared. The copolyamides are prepared in two basic ways: (A) from the corresponding neat polyamides tia transamidation (i.e., by interchange reaction) or (B-D) from monomers. Obviously, the appearance of four types of $\mathrm{CO}$ groups is an indication of copolymer formation, this process being strongly dependent on the starting system (homopolymer or monomer mixture) and in the second case on the AH salt/ $\varepsilon$-caprolactam monomer ratio.

In the case of an equimolar ratio of the monomer units, four amide groups should be expected, namely: (a) characteristic of neat Nylon 6; (d) characteristic of neat Nylon 6,6; (b) and (c) structures obtained by the interchange reactions. The first two amide groups should be attributed to the correspouding homopolyamides, while the last two belong to transitional Nylon 6-Nylon 6,6 structures that do not exist in the starting neat polymers or monomers.

Let us define the signal intensities of the homolinkages $A-A$ and $B-$ $B$, and of the corresponding transitional structures $A-B$ and $B-A$ in the following way: $I_{\mathrm{A}}=$ signal intensity of the $\mathrm{A}-\mathrm{A}$ bond; $I_{\mathrm{A}^{\prime}}=$ signal intensity 


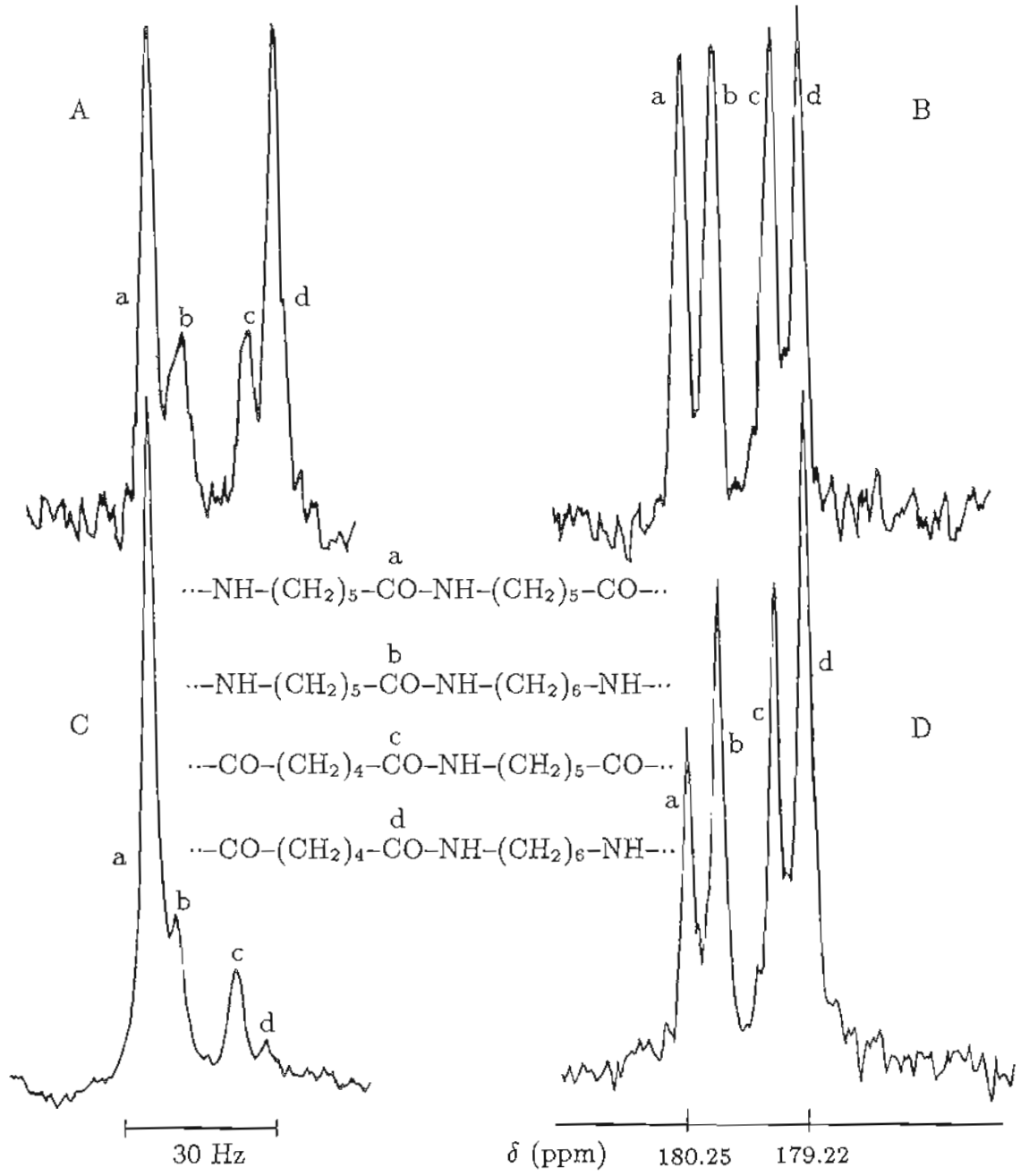

Figure 14. CO signals in the ${ }^{13} \mathrm{C}$ NMR spectra of various Nylon 6-Nylon 6,6 copolyamides measured in sulfuric acid (98\%): A - prepared by transamidation. from a Nylon $6 /$ Nylon 6,6 blend for 2 h at $280-290^{\circ} \mathrm{C} ; \mathrm{B}-$ by copolymerisation of $\mathrm{AH}$ salt and $\varepsilon$-caprolactam (1:1) for $8 \mathrm{~h}$ at $260^{\circ} \mathrm{C} ; \mathrm{C}-$ by copolymerisation of $\mathrm{AH}$ salt and $\varepsilon$-caprolactam $(1: 6) ; \mathrm{D}-$ hy copolymerisation of $\mathrm{AH}$ salt and $\varepsilon-$ caprolactan $(3: 2)[22]$ 
of the $\mathrm{A}-\mathrm{B}$ bond; $I_{\mathrm{B}}=$ signal intensity of the $\mathrm{B}-\mathrm{B}$ bond; $I_{\mathrm{B}^{\prime}}=$ signal intensity of the $B-A$ bond, and $k$-monomer ratio $A / B$ in the copolymer. The average length of both Nylon 6 and Nylon 6,6 blucks in the resulting copolymers is given by

$$
\tilde{L}_{\mathrm{A}}=I_{\mathrm{A}} / I_{\mathrm{A}^{\prime}}+1 ; \quad \bar{L}_{\mathrm{B}}=I_{\mathrm{B}} / I_{\mathrm{B}^{\prime}}+1
$$

Since in a binary system the number of $A-B$ and $B-A$ units should be the same,

$$
I_{\mathrm{A}^{\prime}}=I_{\mathrm{B}^{\prime}}
$$

it follows that

$$
I_{\mathrm{A}}+I_{\mathrm{A}^{\prime}}=k\left(I_{\mathrm{B}}+I_{\mathrm{B}^{\prime}}\right)
$$

On reaching the thernodynamic equilibrium, one may use Eqs. (28)-(30) instead of $\mathrm{Eq} \cdot(27)$ :

$$
\begin{gathered}
I_{\mathrm{A}}=k I_{\mathrm{A}^{\prime}} ; \quad I_{\mathrm{A}^{\prime}}=I_{\mathrm{A}} / k ; \quad I_{\mathrm{A}} / I_{\mathrm{A}^{\prime}}=k \\
I_{\mathrm{B}}=I_{\mathrm{B}^{\prime}} / k ; \quad I_{\mathrm{B}^{\prime}}=k I_{\mathrm{B}} ; \quad I_{\mathrm{B}^{\prime}} / I_{\mathrm{B}}=k \\
\frac{I_{\mathrm{A}}}{I_{\mathrm{B}}}=\frac{k I_{\mathrm{A}^{\prime}}}{I_{\mathrm{B}^{\prime}} / k}=k^{2} \frac{I_{\mathrm{A}^{\prime}}}{I_{\mathrm{B}^{\prime}}}=k^{2}
\end{gathered}
$$

The validity of the above equations is clearly demonstrated by the peak intensity ratios in Figure $14 B-D$, where $k$ is known for all polymer samples. For instance, when $k=1: 6(\mathrm{C})$, this gives for $I_{\mathrm{A}} / I_{\mathrm{B}}$ a value of $1: 36$, which is close to the experimentally established one.

Also very interesting are the results for $\bar{L}_{A}$ and $\vec{L}_{B}$ in Figure 14 A: the Nylon 6-Nylon 6,6 copolymer prepared via interchange reactions from neat polyamides by annealing for 2 h at $280-290^{\circ} \mathrm{C}$ produces four $\mathrm{CO}$ peaks. Although they are not completely resolved, a rough estimate of the block lengths according to Eq. (25) gives an average length of about four Nylon 6 and four Nylon 6,6 units. In the copolymer produced from an equimolar monomer blend snbjected to polycondensation for $8 \mathrm{~h}$ at $260^{\circ} \mathrm{C}$ (Figure $14 \mathrm{~B}$ ), the average length of each block type is of about 2.0. Similar results are obtained in a polyester blend comprising poly(hexamethylene terephthalate) and poly (ethylene adipate). Again, $\bar{L}_{A}=\bar{L}_{B} \sim 4$ for copolymers obtained wia interchange reactions in a binary blend of the neat polyesters, and $\bar{L}_{A}=\bar{L}_{B} \sim 2$ for the copolymer produced from the correspondirg diacids and diols. More recently, Backson et al. [23] got the same results for the PET/PBT system. A possible explanation for not reacliing a completely random copolymer in a binary homopolymer system by interchange reactions is given in Chapter 8 .

Let us now consider an example of ${ }^{13} \mathrm{C}$ NMR sequence analysis in ternary aliphatic copolyamides [24]. Copolymerisation of three suitable 
monomers should lead to ternary copolyamides containing nine different amide groups, if each monomer has reacted with itself and with both other monomers. A product resulting from co-condensation of $\mathrm{AH}$ salt and two lactams is considered.

A mixture of $50 \mathrm{mmol}$ portious of E-caprolactan, of AH salt and of 12 dodecanelactam was first heated for 30 min at $200^{\circ} \mathrm{C}$ under a slow stream of nitrogen and then for $8 \mathrm{~h}$ at $260^{\circ} \mathrm{C}$. A similar experiment was carried out with $100 \mathrm{mmol}$-caprolactam, $50 \mathrm{mmol} \mathrm{AH}$ salt and $50 \mathrm{~mm}$ 12-dodecanelactam. It was found that the copolyamide contains nine different amide groups which can be identified by their $\mathrm{CO}$ signals in the $90.5 \mathrm{MHz}{ }^{13} \mathrm{C}$ NMR spectra. From the intensities of the $\mathrm{CO}$ signals, the ratio of monomer units in the copolymers, and hence the rcactivity of the monomers, can be estimated. Furthermore, the average length of the homogeneous blocks can be calculated.

As already mentioned, a maximum of nine $\mathrm{CO}$ signals is expected in the product of the above co-condensation (Nylon 6-6,6-12), and this is precisely the case visualised by the spectra shown in Figure 15.

If the signals of all the different amide groups of a copolyamide arc resolved, as in the case studied, two kinds of information can be obtained from a quantitative evaluation of the ${ }^{13} \mathrm{C} \mathrm{NMR}$ spectra: (i) the ratio of monomer units in the isolated copolymer allows one to estimate the relative reactivities of the monomers under the polymerisation conditions chosen and (ii) the signal intensities of the homogeneons amide bonds $(A-A, B-B, C-C)$ compared to the heterogeneous ones allow the calculation of the average length of the homogencous blocks. Thus, one can deteruine whether a block copolymer, an alternating sequence, or a random copolyner is formed. The following definitions are used in the discussion: $A, B, C$ denote the three different monomer units; $I_{\mathrm{AA}}, I_{\mathrm{AB}}, I_{\Lambda \mathrm{C}}=$ intensitios of the $\mathrm{A}-\mathrm{A}, \mathrm{A}-\mathrm{B}$ and $\mathrm{A}-\mathrm{C}$ bonds, respectively (signals $x, x^{\prime}, x^{\prime \prime}$ in Figure 15); $I_{\mathrm{BB}}, I_{\mathrm{BA}}, I_{\mathrm{BC}}=$ intensities of the $\mathrm{B}-\mathrm{B}, \mathrm{B}-\mathrm{A}$ and $\mathrm{B}-\mathrm{C}$ bonds, respectively (signals $y, y^{\prime}, y^{\prime \prime}$ ); $I_{\mathrm{CC}}, I_{\mathrm{CA}}, I_{\mathrm{CB}}=$ intensities of the $\mathrm{C}-\mathrm{C}, \mathrm{C}-\mathrm{A}$ and $\mathrm{C}-\mathrm{B}$ bonds, respectively (signals $z, z^{\prime}, z^{\prime \prime}$ iu the same fignre). The ratios of monomer units in the copolymer are described as $k$-values accolding to the following equations:

$$
\begin{aligned}
& k_{\mathrm{AB}}=\mathrm{A} / \mathrm{B}=1 / k_{\mathrm{BA}} \\
& k_{\mathrm{AC}}=\mathrm{A} / \mathrm{C}=1 / k_{\mathrm{CA}} \\
& k_{\mathrm{BC}}=\mathrm{B} / \mathrm{C}=1 / k_{\mathrm{CB}}
\end{aligned}
$$

The ratio of ruonomer units in a copolymer is given by the coucentration of monomers in the reaction mixture if polymerisation is quantitative. If not, the ratio also depends on the reactivity of the monomers and must be calculated from signal iuteusities or by means of other methods.

For such a calculation, one may use all the signals that fulfill two conditions. The sigual must stem from structurally idcntical groups in the various monomer units, as is the case $\mathrm{CO}-\alpha-\mathrm{CH}_{2}$ and $\omega-\mathrm{CH}_{2}$ groups in 
$-\mathrm{NH}-\left(\mathrm{CH}_{2}\right)_{5}-\stackrel{x}{\mathrm{CO}}-\mathrm{NH}-\left(\mathrm{CH}_{2}\right)_{5}-\mathrm{CO}-$ $-\mathrm{NH}-\left(\mathrm{CH}_{2}\right)_{5}-\mathrm{CO}-\mathrm{NH}-\left(\mathrm{CH}_{2}\right)_{6}-\mathrm{NH}-$ $-\mathrm{NH}-\left(\mathrm{CH}_{2}\right)_{5}-\stackrel{x}{\prime \prime}^{\prime \prime}-\mathrm{NH}-\left(\mathrm{CH}_{2}\right)_{11}-\mathrm{CO}-$

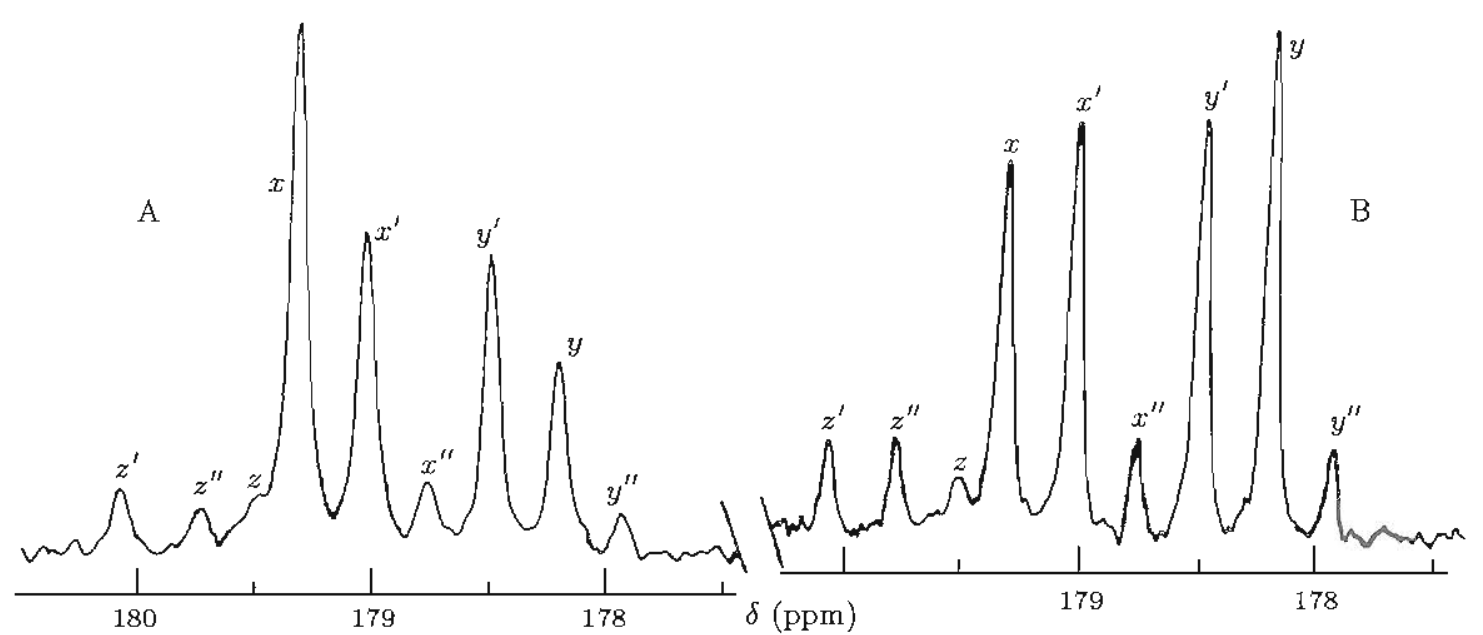

Figure 15. CO signals in the ${ }^{13} \mathrm{C}$ NMR spectra $\left(90.5 \mathrm{MHz}, \mathrm{FSO}_{3} \mathrm{H}\right)$ of a Nylon 6-6,6-12 copolymer prepared from a mixture of $\varepsilon$-caprolactam, AH salt and 12-dodecanelactam, and (B) a 1:1:1 mixture of the same monomers [24] 


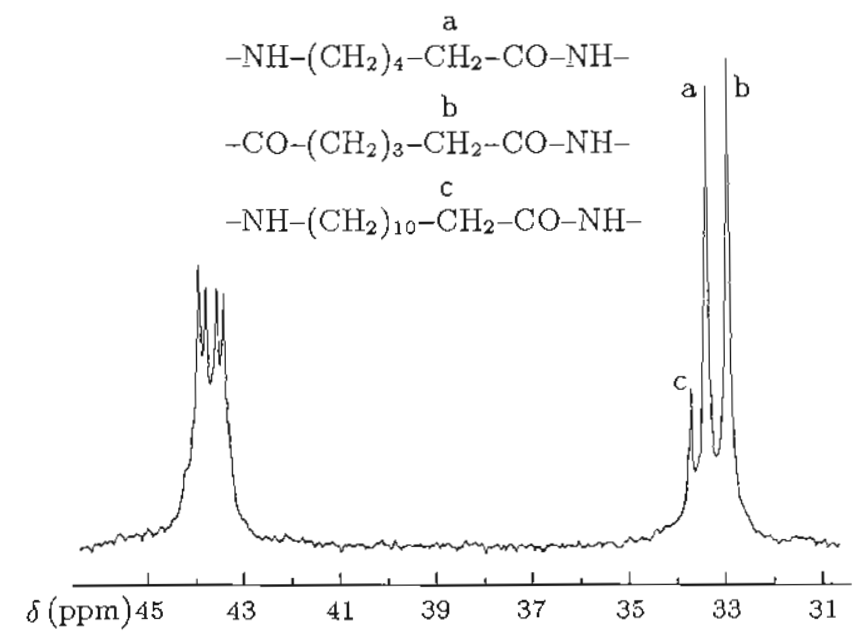

Figure 16. $\alpha-\mathrm{CH}_{2}$ and $\omega-\mathrm{CH}_{2}$ signals in the ${ }^{13} \mathrm{C}$ NMR spectrum (90.5 $\mathrm{MHz}$, $\mathrm{FSO}_{3} \mathrm{H}$ ) of a Nylon 6-6,6-12 copolymer prepared from a 1:1:1 mixture of $\mathrm{E}_{-}$ caprolactam, AH salt and 12-dodecanelactam (see Figure 15B) [24]

most aliphatic polyamides. Thus the signal intensities are not infuenced by different nuclear Overhauser effects or different segmental motions. The second condition is that the signals of different monomer units must be resolved to such an extent that unambiguous assignment and quantitative evaluation is possible. In the case of Nylon 6-6,6-12, considered here, both $\mathrm{CO}$ and $\alpha-\mathrm{CH}_{2}$ siguals obey these requirements. If clearly separated, as shown in Figure 16, the $\alpha-\mathrm{CH}_{2}$ signals are advantageous for a quantitative evaluation for two reasons: the absence of splitting provides a better signal-to-noise ratio, and in the case of the CO signals, the intensities of more peaks are to be measured according to Eqs. (34)-(36):

$$
\begin{aligned}
& k_{\mathrm{AB}}=\left(I_{\mathrm{AA}}+I_{\mathrm{AB}}+I_{\mathrm{AC}}\right) /\left(I_{\mathrm{BB}}+I_{\mathrm{BA}}+I_{\mathrm{BC}}\right) \\
& k_{\mathrm{AC}}=\left(I_{\mathrm{AA}}+I_{\mathrm{AB}}+I_{\mathrm{AC}}\right) /\left(I_{\mathrm{CC}}+I_{\mathrm{CA}}+I_{\mathrm{CB}}\right) \\
& k_{\mathrm{BC}}=\left(I_{\mathrm{BB}}+I_{\mathrm{BA}}+I_{\mathrm{BO}}\right) /\left(I_{\mathrm{CC}}+I_{\mathrm{CA}}+I_{\mathrm{CB}}\right)
\end{aligned}
$$

Since all the interesting signals are not always well resolved, it is important to keep in mind that in all kinds of copolymers, corresponding heterogeneous bonds should be present in equal concentrations. Hence for ternary copolyamides, the following equations must be fulfilied:

$$
\begin{aligned}
& I_{\mathrm{AB}}=I_{\mathrm{BA}} \\
& I_{\mathrm{AC}}=I_{\mathrm{CA}} \\
& I_{\mathrm{BC}}=I_{\mathrm{CB}}
\end{aligned}
$$

From Figures $15 \mathrm{~B}$ and 16 , the following values were estimated: $k_{\mathrm{AB}}=0.9$; 
$k_{\mathrm{AC}}=4.5 ; k_{\mathrm{BC}}=5.0 ; \mathrm{A}: \mathrm{B}: \mathrm{C}=10: 9: 2$, indicating that the reactivity of the monomers decreases in the order:

AH salt $>\varepsilon$-caprolactam $\gg 12$-dodccanelactam

For the calculation of the average length of the homogeneous blocks in random copolyamides, only the CO signals are useful. The average block length of each monomer nnit is given as follows:

$$
\begin{aligned}
& \bar{L}_{A}=\left[I_{\mathrm{AA}} /\left(I_{\mathrm{AB}}+I_{\mathrm{AC}}\right)\right]+1 \\
& \bar{L}_{B}=\left[I_{\mathrm{BB}} /\left(I_{\mathrm{BA}}+I_{\mathrm{BC}}\right)\right]+1 \\
& \bar{L}_{C}=\left[I_{\mathrm{CC}} /\left(I_{\mathrm{CA}}+I_{\mathrm{CB}}\right)\right]+1
\end{aligned}
$$

Thus the block length of Nylon 6 in Nylon 6-6,6-12, prepared from a 1:1:1 monomer mixture (Figure 15B) is 1.75 , while it is 2.75 in the analogous copolyamide prepared from a 2:1:1 monomer mixtnre (Figure 15A). On the other hand, the average block length of Nylon 12 is in the range of 1.1-1.2 in these copolyamides. Since the block length of Nylon 6,6 is also below 3 , the conclusion can be drawn that these ternary copolymers possess a structure that is more random than blocky in character.

Another point of interest is to determine whether the sequence of a copolyamide is the result of a thermodynamically controlled equilibrium cansed by transamidation reactions or it originates from a kinetically controlled polymerisation. In the former case, the intensity ratios of the CO signals obey Eqs. (43)-(45), since the concentrations of all the kinds of amide groups depend exclusively on the ratios of the respective monomer units under these conditions:

$$
\begin{aligned}
& I_{\mathrm{AA}}=I_{\mathrm{AB}} k_{\mathrm{AB}}=I_{\mathrm{AC}} k_{\mathrm{AC}}=I_{\mathrm{B}} k_{\mathrm{AB}}^{2}=I_{\mathrm{C}} k_{\mathrm{AC}}^{2} \\
& I_{\mathrm{BB}}=I_{\mathrm{BA}} k_{\mathrm{BA}}=I_{\mathrm{BC}} k_{\mathrm{BC}}=I_{\mathrm{A}} k_{\mathrm{BA}}^{2}=I_{\mathrm{C}} k_{\mathrm{BC}}^{2} \\
& I_{\mathrm{CO}}=I_{\mathrm{CA}} k_{\mathrm{CA}}=I_{\mathrm{CB}} k_{\mathrm{CB}}=I_{\mathrm{A}} k_{\mathrm{CA}}^{2}=I_{\mathrm{B}} k_{\mathrm{CB}}^{2}
\end{aligned}
$$

In order to test whether or not the sequence is thermodynamically controlled, the signal intensities of the homogeneous and heterogeneons bonds must be compared. If the CO signals of the homogeneous bonds are less intense than given by Eqs. (43)-(45), the formation of an alterrating sequence is favoured. If the signals of the homogencous bonds are more intense, a tendency to block formation exists. This investigation reveals that the copolyamides of Fignre 15 possess a thermodynamically controlled primary structure, as expected for condensation at $250^{\circ} \mathrm{C}$.

A problem, which cannot be solved immediately by NMR spectroscopy, is the block length distribution within one chain and between different chains of one sample. However, if the copolyamide sequence is themodynamically controlled, it is expected that the hlock length distribution 
is likewise thermodynamically controlled, by analogy with the molecular weight distribution. Ir other words, the average block length is also the most probable block length in every part of the chain and in all chains of one sample.

Finally, it should be pointed out that the quantitative evaluation of ${ }^{13} \mathrm{C}$ NMR spectra has a limited accuracy for several reasons. If the copolymer chain is built up of monomer units that are very different in structure, their segnental mobilities (and hence $T_{1}$ values) may be different. fn this case, appropriate pulse width and repetition time should be selected to provide accurate intensity ratios. Furthermore, possible differences in the NOE mnst be taken into account. Limiting factors are, of course, the signalto-noise ratio and the resolution of signals. In most cases, only an FT NMR spectrometer working at a high field strength can provide ${ }^{13} \mathrm{C}$ NMR spectra of good quality.

\subsubsection{Other nuclei $-{ }^{15} \mathrm{~N}$ and ${ }^{29} \mathrm{Si}$}

Because ${ }^{15} \mathrm{~N}$ and ${ }^{29}$ Si nuclei can be found in several important classes of polymers, here their NMR characteristics are briefly ontlined in relation to the more commonly observed ${ }^{1} \mathrm{H}$ and ${ }^{13} \mathrm{C}$ nuclei. ${ }^{15} \mathrm{~N}$ and ${ }^{29} \mathrm{Si}$ are spin $-1 / 2$ nuclei, and occur in 0.37 and $4.7 \%$ natural abundance, respectively. They each exhibit a range of chemical shifts at least as broad as observed for ${ }^{13} \mathrm{C}$ nuclei.

Thongh more abundant than ${ }^{13} \mathrm{C}(4.7$ vs. $1.1 \%)$, the ${ }^{29} \mathrm{Si}$ nucleus has even smaller nuclear dipole and magnetogyric ratio than ${ }^{13} \mathrm{C}$, so ${ }^{29} \mathrm{Si}$ resonances about twice as sensitive as ${ }^{13} \mathrm{C}$ resonances should be expected. However, since the magnetic moment and spin of the ${ }^{29} \mathrm{Si}$ mucleus are antiparallel, $\gamma$ is negative. When broad-band proton decoupling is used to remove ${ }^{29} \mathrm{Si}^{1}{ }^{1} \mathrm{H}$ scalar coupling, instead of a signal cnhancement, as observed in ${ }^{13} \mathrm{C} \mathrm{NMR}$, the ${ }^{29} \mathrm{Si}$ signal may be reduced in intensity. In addition, the spin-Iatlice relaxation times for ${ }^{29} \mathrm{Si}$ nuclei in the dissolved state are typically rather long, much like those of ${ }^{13} \mathrm{C}$ nuclei. Nevertheless, pulsed FT NMR techniqnes have made the ${ }^{29} \mathrm{Si}$ nucleus a valuable probe of silicon polymer microstrncture.

There are two special features in measuring silicon NMR. The first concerns the fact that silicon-containing materials constitnte a major part of the construction materials of the probe head, resulting in a broad background signal at about $-110 \mathrm{ppm}$. There are three ways to alleviate the problem: (i) if the signals are narrow, the smallest sweep possible shonld be used; (ii) if there are couplings to protons, population transfer pulse prograns can be used; and (iii) if the lines are broad, subtract from a blank spectrum obtained under otherwise identical conditions.

The other peculiarity concerns spectra of organosilicon compounds obtained with broad band decoupling of the protons. The NOE can then lead to null signals, if the $\left({ }^{29} \mathrm{Si},{ }^{1} \mathrm{H}\right)$ dipole-dipole contribntious to the other 
longitudinal relaxation paths of the silicon is close to 2.52. Because relaxation times depend on the correlation time of the molecule, the signal intensity of a ${ }^{29} \mathrm{Si}$ spectrum with an NOE varies with temperature. Again, there are three ways to remove this problem: (i) Doping the sample with a shiftless relaxation reagent, e.g., chromium acetylacetonate $\left(\mathrm{Cr}(\mathrm{acac})_{3}\right)$ (ca. $10^{-2}$ mol. $1^{-1}$ ), which also gives shorter relaxation times as a side benefit. There are several disadvantages of this approach. The silicon compound can interact strongly with the chromium complex, the purity of the sample is impaired and population transfer experiments are not effective ary more. (ii) Inverse gated decoupling. Here proton decoupliug is only active during acquisition with long waiting times ( 3 to 5 times the relaxation time $T_{1}$ ) between scans. The advantage of not polluting the sanuple is offset by an ineffective use of spectrometer time, which can be somewhat alleviated by using shorter pulses $\left(40^{\circ}\right)$ and shorter recovery tinnes (20 s). (iii) Using population transfer pulse programs [25].

Nitrogen has two useful nuclei for NMR spectroscopy, ${ }^{14} \mathrm{~N}$ and ${ }^{15} \mathrm{~N}$, each with advantages and drawbacks; the latter restricted the use of nitrogen NMR in the early decades of NMR spectroscopy, but FT spectroscopy, higher field magnets, larger samples, clever pulse techniques, and multidimensional spectroscopy have greatly expanded the usc of nitrogen NMR $[26]$.

Both muclei have rather low magnetogyric ratios $\gamma$, so their sensitivity to NMR cletection is rather low, relaxation processes are rather slow; coupling constants $J(\mathrm{~N}, \mathrm{X})$ are small and $J(\mathrm{~N}, \mathrm{~N})$ values very small. The spin $-1 / 2$ nucleus ${ }^{15} \mathrm{~N}$ is often used in high resolution work but its naturai abundance is low, $0.36 \%$. Another disadvantage is that $\gamma\left({ }^{15} \mathrm{~N}\right)$ is negative, so $\mathrm{NOE}$ factors are negative. ${ }^{15} \mathrm{~N}$ signals become more negative with proton decoupling. The maximal proton-induced $\mathrm{NOE}$ factor for ${ }^{15} \mathrm{~N}$ is -4.93 . A disadvantageous NOE can be improved by the use of paramagnetic additives, such as $\operatorname{Cr}(\operatorname{acac})_{3}$.

In mumerous studies enrichment of ${ }^{15} \mathrm{~N}$ is required, which may not be expensive if nitric acid, ammoninm salts, or nitrites can be used as starting materials. With enrichment to $99 \%$, the NMR receptivity is six times that of ${ }^{13} \mathrm{C}$ in natural abundance. Sensitivity enlancement by polarisation transfer, by INEPT, or related methods is helpful, particularly if there are protons directly attached to the ${ }^{15} \mathrm{~N}$. The gain, compared to ${ }^{13} \mathrm{C}$, is now greater, since $\gamma\left({ }^{15} \mathrm{~N}\right)$ is smaller than $\gamma\left({ }^{13} \mathrm{C}\right)$.

The highly abnidant ${ }^{14} \mathrm{~N}$ nucleus $(99.64 \%)$ has almost six times the receptivity of ${ }^{13} \mathrm{C}$ in natural abundance (1\%). However, ${ }^{14} \mathrm{~N}$ is quadrupolar $(I=1)$, so that ${ }^{14} \mathrm{~N}$ NMR spectroscopy commonly suffors from line broadening and loss of spin-spin coupling due to relaxation being too fast. The ${ }^{1 /} \mathrm{N}$ quadrupole moment is relatively small, however, and if the local symmetry is high or the sample viscosity is low, ${ }^{14} \mathrm{~N}$ studies can be performed in high resolution. This possibility is often overlooked nowadays, although the phenomenon of the chemical shift was discovered long ago 
in ${ }^{14} \mathrm{~N}$ resonance in an aqueous solution of ammontum nitrate, giving two sharp lines. Quantitative work on ${ }^{14} \mathrm{~N}$ or ${ }^{15} \mathrm{~N}$ resonance is difficult because of the multiplicity of factors afiecting the signal intensities, and on ${ }^{14} \mathrm{~N}$ spectroscopy because of the line width.

Nitrogen NMR spectroscopy affords a variety of information, with the choice of a spin $1 / 2$ or a quadrupolar nucleus, and an unusual variety of both types, giving a range of $1350 \mathrm{ppm}$ in chemical shift. Nitrogen forms bonds with all the elements except for the completely inert ones. Nitrogen can be found in nine stable oxidation states with bond orders up to three and coordination numbers up to six, the highest being in metal clusters. Furthermore, the shifts, coupling constants, and ${ }^{14} \mathrm{~N}$ line widths can be intcrpreted in terms of bond type, because of the characteristic influences of loue pair and $\pi$ electrons associated with the observed nucleus, these electrons being of great importance to chemical structure and reactivity.

\section{Interchange reactions involving different functional groups}

As seen in the previous section, exchange reactions in both monomer and polymer systems have a significant effect on the structure of the materials obtained, and therefore on their properties. In this section, we consider the most important interchange reactions, as shown schematically in Figure 1, namely: alcoholysis, acidolysis, esterolysis, aminolysis, and some special types of exchange interactions, all taking place in low and high molecular weight systems. The pattem that will be followed for each interaction type is given below:

- Definition, peculiarities in monomer (model) systenis (where applicable);

- Possible application for polymer syntliesis;

- Occurrence in polymer systcms and accompanying effects on their microstructurc;

- Recent developments involving the corresponding exchange interaction.

\subsection{Reactions taking place in polyesters involving ester groups}

By amalogy with classical organic chemistry, most interchange reactions taking place or resulting in polyesters might be generalised as substitutions at carbonyl carbon atoms throngh an addition-elimination process as illustrated in Scheme 1 [27], where $\mathrm{X}=\mathrm{OH}, \mathrm{OR}^{\prime \prime}, \mathrm{OCOR}^{\prime \prime \prime}$ and $\mathrm{CI}, \mathrm{Y}$ can be a neutral or negatively charged nucleophilic agent $\left(\mathrm{R}^{\prime} \mathrm{OH}\right.$ and $\mathrm{R}^{\prime} \mathrm{O}$ or $\mathrm{ROO}_{2}$, respectively), and $\mathrm{R}, \mathrm{R}^{\prime}, \mathrm{R}^{\prime \prime}$, and $\mathrm{R}^{\prime \prime \prime}$ are alkyl or aryl groups. 


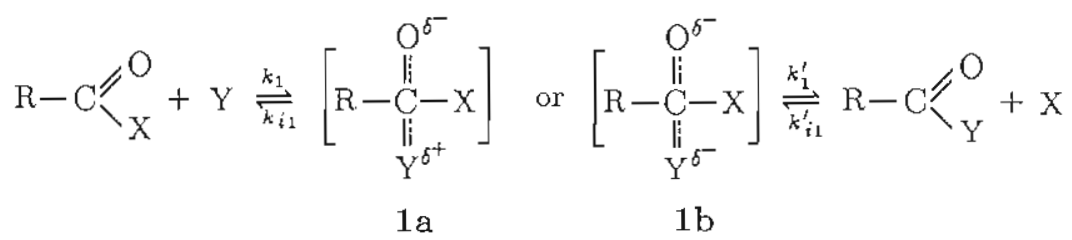

Scheme 1

The addition intermediates $1 \mathrm{a}$ and $\mathbf{1 b}$, for neutral and negatively charged nucleophilic agents, respectively, cannot be isolated or detected in any direct manner, and are therefore postulated on the basis of isotopic oxygen-exchange reactions and by extrapolating evidence of stable addition compounds observed for anlyydrides, amides, etc. Experimental evidence also suggests that formation of the addition internediate probably occurs through a perpendicular approach to the carbonyl carbon atom by the attacking nucleophile.

The overall reaction is stepwise in natnre and the relative rates of formation and partition of the addition intermediate determine the overall rate and the equilibrinm between reactants and products. In general, the formation of the addition intermediate 1 has been found to be the slow step, and a catalyst is often used to increase the rate of this stage. The chemical structures of $R, R^{\prime}, R^{\prime \prime}, R^{\prime \prime \prime}, X$, and $Y$ may infuence both the rate of formation of 1 and its partition and, conseqnently, the overall rate and equilibrium.

According to the mechanism proposed, an increase in the electronwithdrawing power of $\mathrm{R}$ will result in easier formation of 1 . However, the resonance interaction of $R$ with the carbonyl group tends to stabilise the ground state with respect to the transition state, which must be similar to the tetrahedral intermediate, and hence reduces the rate of formation of 1 . Bulky groups on $\mathrm{R}$ can hinder the nucleophilic attack and therefore rednce the rate of the first step.

Structural changes in $\mathrm{X}$ are related to both inductive and resonance effects and are more clifficult to interpret. The electron-withdrawing power of $X$ increases both the rate of formation of 1 and its partition toward products. Increased resonance of $\mathrm{X}$ with the carbonyl group increases the stability of the ground state and results in a lower rate; resonance interaction increases in the order $\mathrm{Cl}<\mathrm{O}_{2} \mathrm{CR}^{\prime}<O \mathrm{R}^{\prime}<\mathrm{NR}_{2}^{\prime \prime}$. The effectiveness of the nucleophile $Y$ is, of course, related to the reactivity of the carboxylic acid derivatives; the more reactive the latter, the wider the range of nucleophiles which can be used effectivcly. The overall rate of the reaction depends on the rate of formation of 1 and on its partition between reactants and products; when $X$ and the attacking nucleophile $Y$ are equally good leaving groups, the increase in nucleophilicity parallels the increasc in the overall rate. 
The most widely used reactions for the preparation of polyesters are direct esterifcation $\left(\mathrm{X}=\mathrm{OH}, \mathrm{Y}=\mathrm{R}^{\prime} \mathrm{OH}\right)$ and alcoholysis $\left(\mathrm{X}=\mathrm{OR}^{\prime \prime}, \mathrm{Y}=\right.$ $\left.\mathrm{R}^{\prime} \mathrm{OH}\right)$, usually performed at high temperature in the molt, and reactions of acyl chlorides $(X=C l)$ with hydroxy compounds $\left(\mathrm{R}^{\prime} \mathrm{OH}\right)$ or phenolates $\left(\mathrm{R}^{\prime} \mathrm{O}^{-}\right)$, generally carried out at low/medium temperature in solution or by interfacial synthesis. Exchange reactions, such as acidolysis $(\mathrm{X}=\mathrm{OH}$, $\left.\mathrm{Y}=\mathrm{R}^{\prime} \mathrm{CO}_{2} \mathrm{R}^{\prime \prime \prime}\right)$ and ester-ester exchange $\left(\mathrm{X}=\mathrm{OR}^{\prime \prime}, \mathrm{Y}=\mathrm{R}^{\prime} \mathrm{CO}_{2} \mathrm{R}^{\prime \prime \prime}\right)$ can also take place at high temperalure in the presence of suitable catalysts [27].

\subsubsection{Alcoholysis}

The intercbange reaction between ester and hydroxyl groups is usually called alcoholysis. This is a reaction of great commercial importance, since most of the industrial processes of polyester manufacture make use exclusively or in large part of alcoholysis, which is represented in Scheme 2 for $(-\mathrm{A}-\mathrm{B}-$ ) and (-D-) type monomers, respectively.

$$
\begin{gathered}
n \mathrm{RO}_{2} \mathrm{C}-\mathrm{B}-\mathrm{CO}_{2}-\mathrm{R}+n \mathrm{HO}-\mathrm{A}-\mathrm{OH} \leftrightharpoons(-\mathrm{OC}-\mathrm{B}-\mathrm{CO}-\mathrm{O}-\mathrm{A}-\mathrm{O}-)_{n}+2 n \mathrm{ROH} \\
n \mathrm{HO}-\mathrm{D}-\mathrm{CO}_{2} \mathrm{R} \leftrightharpoons(-\mathrm{O}-\mathrm{D}-\mathrm{CO}-)_{n} \mathrm{OR}+(n-1) \mathrm{ROH}
\end{gathered}
$$

Sclieme 2

Ester derivatives have lower melting points, higher solubility in diols and can usually be obtained at a higher purity grade than the corresponding acids. Therefore, they often lead to better-quality products with easier process control. However, higher costs, resulting from more expensive raw malerials, higher energy consumption and more exponsive plants, sometimes make direct esterification more convenient, as in the case of PET [28].

According to the geueral Scheme 1 for additiou-elimiuation reactions, alcoholysis is assumed to occur through nucleophilic attack of a hydroxy compound on a carbonyl carbon atom. The reaction rate is therefore determined by both $k_{1}$, tbe rate of uucleophilic attack, and $k_{2,1} / k_{1}^{\prime}$, the partitioning of the addition intermediatc, and the equilibrium constant is given by $K=k_{1} k_{1}^{l} / k_{i, 1} k_{i, 1}^{l}$. In this way, reaction rates and ecpulibrium constants clepend on the chemical structure of $A$ and $R$. It is found that aliphatic diols can react with both alkyl and aryl esters, while phenolic compounds, which are poorer nucleophiles and better leaving groups than aliphatic hydroxy compounds, require $\mathrm{R}=$ aryl to yield polyesters. As found for direct, esterification, compounds with tertiary hydroxyl groups are generally not. suitable for polyesterification via alcoholysis.

When $\mathrm{RO}$ is a better leaving group than $\mathrm{AO}$ and $\mathrm{HO}-\mathrm{A}-\mathrm{OH}$ is more mucleophilic than $\mathrm{ROH}$, the equlibria in Scheme 2 are shifted toward the products and it could be assumed that polyester should be obtained under mild conditions and without removal of by-products, analogously to 
the situation with polyamides [29]. Ogata et al. [30] attempted to prepare polyesters starting from "active diesters", i.e., from diest.crs where $\mathrm{R}$ is a good leaving group. They actually observed an increase in the cquilibrium constants from values lower than unity, usually observed for both $\mathrm{A}$ and $R$ aliphatic radicals [31], to values of $6-17$ for phenoxy, thiophenyl, and 3-oxypyridyl leaving groups. However, the reactions of "active" adipates, terephthalates and isophthalates with ethylene glycol and butane diol occur only in the presence of suitable catalysts and, when performed in a closed system, yield only low molecular weight polyesters. The authors concluded that application of vacuum to remove $\mathrm{ROH}$ is also required in order to achieve high molecular weights.

In contrast to direct esterification, alcoholysis proceeds very slowly in the absence of catalysts $[32,33]$, even at high temperature. Strong protic acids, such as p-toluenesnlphonic acid, sulfuric acid, etc., catalyse alcoholysis, but they are not as effective as they are in direct esterification [33]. Furthermore, since they catalyse side reactions as well, the resulting polyesters are gencrally of poorer quality and are more prone to hydrolysis, compared to those prepared iu the presence of metal derivatives, which are therefore the preferred catalysts. Due to the economic relevance of alcoholysis, an enormous number of patents have been published claiming, however, catalysts of uncertain value or novelty. Acetates of lead(II), lead(I), zinc, manganese, calcium, cobalt, and cadmium, and oxides such as $\mathrm{Sb}_{2} \mathrm{O}_{3}$ and $\mathrm{GeO}_{2}$, for the first and second stages of reaction, respectively, and titanium alkoxides for both stages, have been found to be the most effective catalysts [34]. Their overall activity is probably the result of various factors; solubility in the reaction medium $[32,35]$, exchange-reaction capability of the original ligands with reactants, and effects on conconitant reactions are probalbly the most relevant. All these factors can obviously be affected by reaction conditions, such as type and concentration of functional groups, and temperature. The effects of catalysts on the exchange interactions in polyesters are considered in detail in Chapter 2.

The role of alcoholysis is importaut in the preparation of polyesters (both neat and copolymers) by ring-opening polymerisation of cyclic esters [27]. Equilibria occurring in riug-opening polymerisation procecding via alcoholysis are shown in Scheme 3. Active hydrogen donors, such as water, alcohols, amines, and similar substances, can be conveniently used to start hydroly tic polymerisation; a proper choice of initiator may provide a useful method of controlling the nature of the end-groups. Alcohols, amines, and similar monofunctional initiators lead to macromolecules with a functional hydroxyl group at one end only; water, aliphatic diols, and other similar difunctional initiators give macromolecules with functional groups, and the chains grow at both ends. In principle, the molecular weight of the resulting polyesters may be controlled by the ratio of lactone concentration to that of initiator [36]. 


$$
\begin{gathered}
\mathrm{XH}+\mathrm{O}=\underset{\mathrm{O}}{\mathrm{C}}-\mathrm{A} \rightleftharpoons \mathrm{XCO}-\mathrm{A}-\mathrm{OH} \\
\mathrm{XCO}-\mathrm{A}-\mathrm{OH}+n \mathrm{O}=\mathrm{C}-\mathrm{C} \rightleftharpoons \mathrm{XCO}\left(\mathrm{ACO}_{2}\right)_{n} \mathrm{AOH}
\end{gathered}
$$

Scheme 3

It has been reported that non-catalysed polymerisation initiated with hydrogen donors occurs at a relatively slow rate and gives only low molecular weight polyesters. The polymerisation is probably started by nucleophilic attack of the initiator on the carbonyl group of the monomer and proceeds by subsequent nucleophilic attack of the resulting hydroxyl endgroups.

Metal ion salts or titanium and tin alkoxides are cffective catalysts for this reaction and lead to an increase in both reaction rate and molecular weight. These catalysts, however, usually lead to broader molecular weight distributions because redistribution by interchange reactions occurs simultaneously with the stepwise chain growth [27]. When water is used as initiator, direct osterification may occur during polymerisation at high temperature and contribute to molecular weight broadening and, provided that volatile products are removed, to molecular weight increase, along with nucleophilic propagation. When acids or bases are used as catalysts, an ionic mechanism unay become the predominant one [36].

In general, polymerisation of lactones and cyclic esters depends to a considerable degree on their chemical structure and, in particular; on their ring size and on the type and position of the substituents. High ring strain, originating from both angle distortion (three- and four-membered rings) and hydrogen-atom crowding within the ring (rings with more that seven or eight aloms), favours polynerisation, while substituents diminish the polymerisability of these monomers by increasing the ring stability with respect to the open chair. Consequently, most of the four-, seven- and eight-membered ring cyclic esters and carbonates are polymerisable, although some substituted ones can resist polymerisation [37]. Accordingly, $\gamma$-butyrolactone, a cyclic ester with a five-membered ring, does not polymerise under the usual reaction conditions, even though it has been reported that it polymerises ( $20 \%$ yield) to a low molecular weight polyester at $160^{\circ} \mathrm{C}$ under pressure of $2000 \mathrm{MPa}$. Lactones with a greater number of atoms in the ring can polymerise readily ( $\delta$-valorolactone and $\varepsilon$ caprolactone) or with nore difficulty (3- $n$-propyl- $\delta$-valerolactone 2 and 6,6 dimethyl- $\delta$-valerolactone 3 ) or do not polymerise at all (pentadecanolide). A similar belnaviour is found for cyclic diesters (polymerisability of diglycolide $4>$ dilactide $5 \gg$ tetraphenyldiglycolide 6 and tetramethyldiglycolide 7) $[37]$ 
<smiles>CCCC1CCCOC1=O</smiles><smiles>[14CH3][C]1CCCC(=O)O1</smiles>

2<smiles>O=C1COC(=O)CO1</smiles>

4<smiles>[Y19]C1OC(=O)COC1=O</smiles>

5<smiles>O=C1OC(c2ccccc2)(c2ccccc2)C(=O)OC(c2ccccc2)(c2ccccc2)C1=O</smiles>

6<smiles>[Y16]C1(C)OC(=O)C([Y4])(C)OC1=O</smiles>

7

The ring size also has a very important effect on the extent to which the cyclic monomers can be converted into polyesters. For instance, a substantial amount of $\delta$-valerolactone was reported to exist in equilibrium with the polymer at temperatures exceeding $150^{\circ} \mathrm{C}$ [38].

Along with the above-mentioned method for polymer preparation including alcoholysis, the latter reaction can occur in polymers, too, as represented in Sclieme 4.

$$
\begin{aligned}
& \underset{\mathrm{O}}{\mathrm{C}}-\mathrm{B}-\underset{\mathrm{O}}{\mathrm{CO}}-\mathrm{A}-\mathrm{O} \cdots+\mathrm{R}-\mathrm{OH} \stackrel{t^{\circ}}{\longrightarrow} \\
& \stackrel{t^{\circ}}{\longrightarrow} \underset{0}{\mathrm{C}}-\mathrm{B}-\underset{0}{\mathrm{CO}}-\mathrm{R}-\mathrm{O} \cdots+\mathrm{HO}-\mathrm{A}-\mathrm{O} \cdots
\end{aligned}
$$

Scheme 4

This exchange normally leads to a decrease in molecular weight of the polymer. The kinetics of alcoholysis in a poly(decamethylene glycol adipate) polymer was studied by Flory [39]. Korshak et al. have studied the alcoholysis of poly (hexamethylene sebacate) by cetyl alcohol [40]. It has been shown that this type of interchange reaction takes place in the prosence of basic and, especially, of acidic catalysts. The non-catalysed process requiles high temperatures and longer treatment times. Wichterle and Eksner $[41]$ have demonstrated for the first time that the amide bond can also he subject to alcoholysis.

A relatively new method for the "environment-friendly" preparation of polycarbonate also involves an interchange reaction [42]:<smiles>CC(C)(c1ccc(O)cc1)c1ccc(O)cc1</smiles><smiles>CCOc1ccc(C(C)(C)c2ccc(OC3CCC(c4ccc(O)cc4)CC3)cc2)cc1</smiles>

This could be considered as alcoliolysis of diplenyl carbonate by bisphenol A. Non-toxic solvents are employed and the by-product ( $\mathrm{PhOH}$ ) can 
be recycled [42]. The reaction temperature range is $150-320^{\circ} \mathrm{C}$, while the pressure applied can be from atmospheric to less than I mm Hg. Typical catalysts are bases, such as alkali metals ( $\mathrm{Li}, \mathrm{Na}$ ) or their hydroxides.

A number of carbonate esters successfully produced via interchange reactions of diphenyl carbonate and aromatic diols are reported in the literatnre. In general, aliphatic diols do not possess the thermal stability required to survive the polymerisation reaction. Attenpts have been made to produce diaryl carbonates by the direct oxidative coupling of phenols to carbon monoxide or by direct condensation with carbon dioxide [43]. The expensive and relatively inefficient catalysts (Group VIII metals, Pd being favoured) and low yields have precluded a commercial process. It is generally acknowledged that the discovery of a convenient and cheap direct production of diaryl carbonates, without the agency of phosgene, would be a revolutionary development.

\subsubsection{Acidolysis}

The exchange reaction between carboxyl and ester groups, commonly called acidolysis, is schematically represented below for $(-A-B-)$ type monomers, and is also valid for (-D-) type monomers, where $A, B$ and $R$ can be aliphatic or aromatic (Scheme 5) [44].

$$
\begin{gathered}
n \mathrm{R}-\mathrm{CO}_{2}-\mathrm{A}-\mathrm{O}_{2} \mathrm{C}-\mathrm{R}+n \mathrm{HO}_{2} \mathrm{C}-\mathrm{B}-\mathrm{CO}_{2} \mathrm{H} \leftrightharpoons \\
-(\mathrm{O}-\mathrm{A}-\mathrm{O}-\mathrm{CO}-\mathrm{B}-\mathrm{CO}-)_{n}+2 n \mathrm{RCO}_{2} \mathrm{H}
\end{gathered}
$$

Scheme 5

As for other cster-exchange reactions, it is generally accepted that the above interaction is an "equilibriım" one. The value of the respective eqnilibrium constant can be calculated from the equilibrinm constants of hydrolysis of the esters, i.e., $K=K_{h} / K_{h^{\prime}}$ where $K_{h}$ and $I_{h^{\prime}}$ are the equilibrium constants of the hydrolysis of $\mathrm{RCO}_{2} \mathrm{~A}$ - and $-\mathrm{BCO}_{2} \mathrm{~A}-$, respectively. If the chemical structures of the esters are not too different, it can be assumed that $K_{h}$ and $K_{h}$, have similar values and consequently $K$ could be approximated to unity. In accordance with the expected low $K$-value, acidolysis can be successfully applied for the synthesis of polyesters, provided that $\mathrm{RCO}_{2} \mathrm{H}$ can be easily removed from the reacting system. The lower volatility of benzoic acid is probably among the reasons why benzoates are less appropriate than acetates [45]. Due to volatility and monomer cost, acidolysis has been used in practice only when RCO- is an acetyl group. The reaction can be carried out by heating a bisphenol diacetate with a dicarboxylic acid [46] at high temperature in the melt, or in solıtion in a high-boiling solvent or even in the solid state, and acetic acid is removed under reduced pressnre or distilied off with the solvent. It has been found that bulky alkyl groups, such as tert-butyl gronps, adjacent to the phenolic function, can sterically hinder the polyesterification by acidolysis and, 
when diacetates cannot undergo polymerisation, the corresponding bisphonols are insoluble in alkali [46]. Analogously to $(-\mathrm{A}-\mathrm{B}-)$ type monomers, acetoxyarenecarboxylic acids have been converted to ( $-D-$ ) polyesters or included, as comonomers, in the chains of previously prepared polyesters $[47,48]$. When poly (oxy-1,4-phenylenecarbonyl) was obtained by heating $p$ acetoxybenzoic acid in the presence of magnesium turnings at $220-280^{\circ} \mathrm{C}$ under reduced pressure in an argon fiow, it was found that ethorification and decarboxylation side reactions occur also [49]. For the preparation of copolymers, a polyester is melted and heated at high temperaturo with the acetoxyarenecarboxylic acid $[47,48]$ (or with an equinolar mixture of a dicarboxylic acid and a bisphenyl diacetale). After an initial decrease in the molecnlar weight of the starting polyester, as a result of acidolysis and ester-ester exchange reactions, the molecular weight increases again in the subsequent polymerisation step where acetic acid is removed under reduced pressure.

Acidolysis reactions can also be performed ou acetoxy derivatives of aliphalic diols but since they react with more difficulty than diacelates or aromatic compounds, and since the correspouding diols are less expensive and can easily react, with either dicarboxylic acids or their esters, acidolysis is not often employed for aliphatic diols. It has also been found that, for the acetoxy derivalives of aliphatic hydroxyl groups, substituents may hinder polymerisation by acidolysis, while the non-acylated monomer can polyınerise by direct esterification and alcoholysis [50].

Acidolysis can take place in both polyesters aud polyamides. In the case of polyestors, it proceeds according to Scheme 6 and should play an imporlant role in redistribution (of molecular weight and of cononomeric units) duriug melt-blending at high temperature. Evidence of an abrupt decrease in molecular weight when polyester's are heated with low molecular weight compounds bearing carboxyl groups suggests that this reaction takes place to a considerable exteut under the conditions commonly encountered in high-temperature polyesterification and, in certain cases, contributes siguificantly to the overall rate of molecular weight increase $[45,51]$.

$-\mathrm{O}\left(\mathrm{CH}_{2}\right)_{n}-\mathrm{O}-\mathrm{CO}-\left(\mathrm{CH}_{2}\right)_{m}-\mathrm{O}-+\mathrm{RCO}-\mathrm{OH} \stackrel{t^{\circ}}{\longrightarrow}$

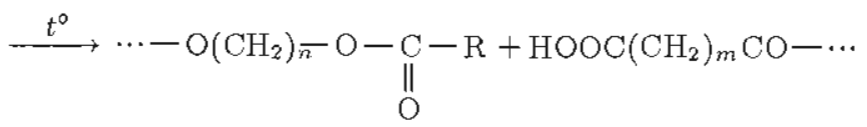

Scheme 6

Many different substances have been reported to be effective catalysts for this reaction: $\mathrm{H}_{2} \mathrm{SO}_{4}, \mathrm{BF}_{3}$, magnesium, and $\mathrm{Bn}_{2} \mathrm{SnO}$ are some examplos; however, this aspect has not been extensively and systematically studied and a comparison of the catalytic activity of various compounds is therefore 
impossible at present.

The mechanism of acidolysis has been studied for low molecular weight compounds in a temperature range well below that commonly used for polymerisation; evidence of both alkyl-oxygen and acyl-oxygen fission has been reported [52]. For polymerisation by acidolysis, two nechanisms have been proposed: according to the first one [46], a reaction occurs by acyl-oxygen fission, involving an intermediate anhydride, analogous to that reported for low molecular weight compounds; the second mechanism [53], rejecting the first one, postulates that the reaction proceeds via a four-memberedring transition state. Both mechanisms are, however, based on uncertain evidence.

As mentioned above for equilibrium constants, very few data have been published about the kinetics; Korshak et al. [5I] suggcsted that the reaction between ethyl stearate and acetic acid in trioxane solution at $164^{\circ} \mathrm{C}$ was first-order overall. The reaction of $p$-butylbenzoic acid with PC was assumed to be second order, and an activation energy of $98 \mathrm{~kJ} / \mathrm{mol}$ was calculated [19]. The scarcity of kinetic data could be one of the reasons why the contribution of acidolysis is usually disregarded in polymerisation when direct esterification and alcoholysis can also occur. However, the presence of dicarboxylic acids has often been observed among the volatile products [54], suggesting that a contribution to the ovcrall molccular weight increase originates from acidolysis. This contribution, which is particularly relevant when the hydroxyl-to-carboxyl end-group ratio becones very low, should be taken into account for the correct interpretation of the experimental results of solid state polymerisation of PBT [55].

\subsubsection{Esterolysis}

Another type of ester exchange reaction, also called ester interchange, double ester exchange or esterolysis, can occur between two ester groups, as shown in Scheme 7 . It is perhaps even less studied than acidolysis $[44,56]$ ard has not found any practical application in the preparation of polyesters since no advantages are expected, compared to the reactions discussed above. Nevertheless, ester-ester exchange reactions may play an important role in determining the chenical structure of copolyesters prepared or processed at high temperature and in infuencing the products prepared by melt-blending of different polyesters. Redistribution of chain lengths and randomisation of chemical units are the consequences of intra- and irtermolecular ester-cster exclange reactions. The control of these reactions may provide a new method for the preparation of copolymers with a wide variation in inicrostructure, directly within processing equipment $[18,19,56-62]$.

$$
\begin{gathered}
\mathrm{RCO}_{2} \mathrm{R}^{\prime \prime}+\mathrm{R}^{\prime} \mathrm{CO}_{2} \mathrm{R}^{\prime \prime \prime} \\
\text { Scheme } 7
\end{gathered}
$$


Difficulties in separating the contribution of ester-ester exchange from those of other ester exchange reactions make its study problematic and ambiguous results can be obtained unless end-capped chains are used and scission reactions avoided $[44,61]$. The failure to use end-capped reaclants may invalidate results attributed to ester-ester exchange, as the same reaction products can also be formed from consecutive alcoholysis or acidolysis reactions.

Few data have been reported for the kimetics and equilibrium of this reaction. A second-order (first-order for both ester gronps) is generally assumed and activation energies of $130-150 \mathrm{~kJ} / \mathrm{mol}$ have bon reported $[61,64]$. A mechanism involving an association complex has been postulated. No data are available for the equilibrium constant; however, it can be expressed as the product of the equilibrinm constants of the alcoholysis reaction of the two esters on the left-hand side of the above equilibrium. For sinilar chemical structures of the esters, the equilibrium constant is expected to be close to unity [52].

\subsubsection{Recent developments in the field of interchange reactions including ester groups}

During the last decade, interchange reactions in polymers have been the subject of extensive research. Iu a series of papers, J. Otton et al. [6568 investigate al! reactions taking place during the formation of $\mathrm{PET}$ via alcoholysis. By means of low molecular weight model compounds, the role of the catalyst was thoroughly examined.

In the alcoholysis reaction, titanium was again pointed out to be the most active catalyst. A detailed investigation by neans of IR and NMR spectroscopy as well as by electroconductivity, revealed two preferential coordinations on the titanium atom: first, the incoming alcolool, through its oxygen, then, the ester through its OR group. With the alkali metal carboxylates (where the order with respect to the ester is 0 ), it is tbe carboxylate anion which acts as a nucleophile on the carbonyl carbon atom of the reacting ester, whereas with Co and $\mathrm{Mn}$ (first order with respect to the ester), it is the metal which acts as an electrophile on the oxygen atom of the carbonyl group of the ester. More recently, Lei ct al. [69] have also studied the kinetics of the interchange reaction in dimethyl terephthalate (DMT) with bis(2-hydroxyethyl terephthalate) in the synthesis of PET and have drawn similar conclusions about the role of the catalysts.

In a series of papers [70-73], the regularities of interchange reactions in lactone-based systems have been studied. The homo- and copolymers of this type have attracted much interest during the last decade because of their usefulness in medicine. Since the copolymeric lactones have shown a wider range of useful properties, attempts have been made to characterise the interchange reactions in both ring-opening lactone polymerisation and in blends of various lactone-based polymers. 
Thus, the copolymerisation of glycolyde (GLY) and $\varepsilon$-caprolactorle (CL) were studied by the NMR technique [70] in order to determine the sequence lengths of GLY and CL units, and to find out the reaction mecharisins of the interchange reactions. Some of the basic results obtained are shown in Table 3.

The sequence analysis of the GLY-CL copolymers shows that, depending on the temperature and nature of the initiator, copolyesters with a broad variety of conpositions and sequences may be obtained. As a rule, acidic catalysts initiate cationic copolymerisation, yielding copolyesters richer in CL units. Complex-forming catalysts initiate an insertion mechanism which favonrs the incorporation of GLX, whereas anionic catalysts exclusively initiate the homopolymerisation of GLY.

When the sequences obtained by copolymerisation of lactones are considered in terms of monomer reactivity, the role of transesterification must be elucidated. In order to determine which of the above catalysts cause intermolecular transesterification, the following experinent was carried out. Poly(c-caprolactone) (pCL) with a degree of polymerisation > 100 was dissolved in nitrobenzene and GLY was polynerised in this solution. Interchange reactions should result in the formation of copolyesters, i.e., of

Table 3. Copolymorisation of glycolyde and $\varepsilon$-caprolactone under various conditions [70]

\begin{tabular}{|c|c|c|c|c|c|}
\hline \multirow[t]{2}{*}{ Initiator ${ }^{2}$} & \multirow[t]{2}{*}{ Conditions $^{\mathrm{b}, \mathrm{C}}$} & \multirow{2}{*}{$\begin{array}{c}\text { Time } \\
\text { (l) }\end{array}$} & \multirow{2}{*}{$\begin{array}{c}\text { Yield } \\
(\%)\end{array}$} & \multicolumn{2}{|c|}{ A verage block length } \\
\hline & & & & $\mathrm{GLY}, \bar{L}_{G}$ & $\mathrm{CL}, \bar{L}_{G}$ \\
\hline $\mathrm{FeCl}_{3}$ & Bulk, $100^{\circ} \mathrm{C}$ & 8 & 75.5 & 2.8 & 2.9 \\
\hline $\mathrm{AlCl}_{3}$ & Bulk, $100^{\circ} \mathrm{C}$ & 44 & 31.5 & 17.0 & 2.2 \\
\hline $\mathrm{BF}_{3} \cdot \mathrm{Et}_{2} \mathrm{O}$ & Bulk, $100^{\circ} \mathrm{C}$ & 44 & 91.0 & 9.0 & 9.2 \\
\hline $\mathrm{FSO}_{3} \mathrm{H}$ & Bulk, $100^{\circ} \mathrm{C}$ & 44 & 58.5 & 2.4 & 7.3 \\
\hline $\mathrm{FeCl}_{3}$ & Nitrobenzene, $70^{\circ} \mathrm{C}$ & 44 & 60.5 & 2.9 & 2.9 \\
\hline $\mathrm{AlCl}_{3}$ & Nitrobenzene, $70^{\circ} \mathrm{C}$ & 44 & 23.5 & $<4.0$ & $>30.0$ \\
\hline $\mathrm{BF}_{3}-\mathrm{Et}_{2} \mathrm{O}$ & Nitrobenzene, $70^{\circ} \mathrm{C}$ & 44 & 77.5 & 7.0 & 3.0 \\
\hline $\mathrm{FSO}_{3} \mathrm{H}$ & Nitrobenzene, $100^{\circ} \mathrm{C}$ & 44 & 27.9 & 2.0 & 0.0 \\
\hline $\mathrm{FSO}_{3} \mathrm{H}$ & Nitrobenzene, $150^{\circ} \mathrm{C}$ & 44 & 71.7 & 2.9 & 5.0 \\
\hline $\mathrm{ZnCl}_{2}$ & Bulk, $100^{\circ} \mathrm{C}$ & 44 & 45.5 & 11.9 & 2.7 \\
\hline$A l\left(O-i-P_{1}\right)_{3}$ & Bulk, $100^{\circ} \mathrm{C}$ & 44 & 80.5 & 5.0 & 4.8 \\
\hline$(n-\mathrm{Bu})_{2} \mathrm{Sn}(\mathrm{OMe})_{2}$ & Bulk, $100^{\circ} \mathrm{C}$ & 44 & 99.0 & 1.5 & 1.8 \\
\hline $\mathrm{Al}(\mathrm{O}-i-\mathrm{Pr})_{3}$ & Nitrobenzene, $150^{\circ} \mathrm{C}$ & 44 & 50.5 & 1.7 & 1.8 \\
\hline$(n-\mathrm{Bu})_{2} \mathrm{Sn}(\mathrm{OMe})_{2}$ & Nitrobenzene, $100^{\circ} \mathrm{C}$ & 44 & 65.0 & 1.8 & 1.9 \\
\hline
\end{tabular}


CL-GLY and GLY-CL bonds. Since the concentration of CL was constant all the time, whereas that of GLY depends on the conversion, the molar ratio of CL-GLY to CL-CL bonds determined from NMR [70] can be a measure of transesterification. The results are listed in Table 4.

Table 4 snggests the following conclusions about the occurrence of interchange reactions: (i) Intermolecular transreaction is only detectable in the presence of $\mathrm{FeCl}_{3}, \mathrm{BF}_{3} . \mathrm{Et}_{2} \mathrm{O}$ and $\mathrm{FSO}_{3} \mathrm{H}$. Its extent increases with reaction time and temperature. (ii) Aluminium isopropylate and dibutyltin dimetbylate do not cause any intermolecnlar transesterification. At first glance, this raight contradict the fact that these alcoholates cause, in the case of copolymerisation of monomers, the formation of short seqnences, i.e., of random copolymers. Therefore, it shonid be pointed out that these initiators calise intramolecular transesterification.

In a snbsequent study, the regularities of the copolymerisation of GLY with $\beta$-propiolactone, $\gamma$-butyrolactone, or $\delta$-valerolactone were disclosed [71]. The results obtained were exactly as in the previous case - cationic initiators $\left(\mathrm{FeCl}_{3}, \mathrm{BF}_{3} . \mathrm{Et}_{2} \mathrm{O}, \mathrm{FSO}_{3} \mathrm{H}\right)$ cause intermolecular transesterification, whereas the complex-forming catalysts $\left(\mathrm{ZnCl}_{2}, \mathrm{AlCl}_{3}\right.$ and $\mathrm{Al}(\mathrm{O}-i-$ Pr) 3 ) do not.

The problem of whether or not an initiator causes transesterification dnring copolymerisation is of significant importance. Initiators with high transesterification activity are useful for the preparation of anorphous copolyesters with random sequences, whereas initiators withont transestcrification ability are useful for the preparation of block copolymers. As far as metal alkoxides are concerned for the polymerisation of lactones, thorough NMR investigations [72] show that transesterification activity is high for tin alkoxicles and low for aluminium alkoxides. Thus, tin alkoxides are useful for initiators when copolylactones with randon sequences are to be synthesized, whereas $\mathrm{A}(\mathrm{O}-i-\mathrm{Pr})_{3}$ is best suited for the synthesis of block copolyesters.

Table 4. Polymexisation of glycolid in nitrobenzene in the presence of poly( $\varepsilon$ caprolactone) $[70]$

\begin{tabular}{llcc}
\hline \multicolumn{1}{c}{ Initiator } & $T\left({ }^{\circ} \mathrm{C}\right)$ & Yicld $(\%)$ & Transesterification $(\%)$ \\
\hline $\mathrm{FeCl}_{3}$ & 100 & 60.0 & 31.0 \\
$\mathrm{BF}_{3} \cdot \mathrm{Et}_{2} \mathrm{O}$ & 100 & 83.5 & 12.0 \\
$\mathrm{BF}_{3} \cdot \mathrm{Et}{ }_{2} \mathrm{O}$ & 150 & 30.0 & 84.0 \\
$\mathrm{FSO}_{3} \mathrm{H}$ & 70 & 79.5 & 0.0 \\
$\mathrm{FSO}_{3} \mathrm{H}$ & 150 & 75.5 & 32.5 \\
$\mathrm{AlCl}_{3}$ & 100 & $21-95$ & 0.0 \\
$\mathrm{Al}_{(\mathrm{O}-i-\mathrm{Pr})_{3}}$ & 100 & 87.5 & 0.0 \\
$(n-\mathrm{Bu})_{2} \mathrm{Sn}(\mathrm{OMe})_{2}$ & 100 & $\infty$ & 0.0 \\
\hline
\end{tabular}

Copolymerisation for $44 \mathrm{~h}$ in nitrobentene 
Along with the copolymerisation of the cyclic mononer lactones, another approach for preparation of copolyners might be the transesterification of the corresponding polyesters [73]. In this investigation, poly(Llactide) ( $\mathrm{pLL}$ ) was solution-blended in equimolar (referred to as monomer units) concentrations with pCL, pGLY of poly(propiolactone). After the common solvent had been evaporated, the physical homopolymer blend was themnostated in a nitrogen atmosphere in a closed flask. The annealing temperatures of the homopolymer blends were maintained in the $100-150^{\circ} \mathrm{C}$ range. Table 5 summarises the results of the cationic transesterification of pLL and pCL at $150^{\circ} \mathrm{C}$ in the presence of various catalysts.

These data indicate that rapid degradation occurs at $150^{\circ} \mathrm{C}$ when triflic acid or methyl triflate are applied as initiators (Nos.1-7), so that copolyester could never be isolated. Better results were obtained with $\mathrm{BF}_{3} . \mathrm{Et}_{2} \mathrm{O}$ (Nos.8-11). At shorter reaction times of 48 and $73 \mathrm{~h}$, copolyesters with relatively long blocks may be obtained. Longer reaction times, however, caused complete degradation of the polyesters, and copolymers with nearly random sequences were not obtained.

An improvement in this direction could be achieved by means of tributyltin methoxide at $150^{\circ} \mathrm{C}$ (Table 6). In this series of experiments, a continuous decrease of the average block length of the homogeneous blocks was detectable at longer times. The smallest block length of $\varepsilon$-oxycaproyl units $\left(\bar{L}_{C}=3.5\right)$, found after $96 \mathrm{~b}$, comes close to the value of a random sequence $\left(\bar{L}_{C}=2.0\right)$. The characterisation of these copolyesters is discussed

Table 5. Cationic transesterification of poly(L-lactide) and poly(E-caprolactone) at $150^{\circ} \mathrm{C}[73]$

\begin{tabular}{|c|c|c|c|c|c|}
\hline No. & Catalyst & Time (h) & Yield $(\%)^{\mathrm{b}}$ & $\eta_{111}(\mathrm{dl} / \mathrm{g})^{\mathrm{c}}$ & $\bar{L}_{G}{ }^{d}$ \\
\hline 1 & $\mathrm{CF}_{3} \mathrm{SO}_{3} \mathrm{H}$ & 8 & 0 & 一 & - \\
\hline 2 & $\mathrm{CF}_{3} \mathrm{SO}_{3} \mathrm{H}$ & 24 & 0 & 一 & - \\
\hline 3 & $\mathrm{CF}_{3} \mathrm{SO}_{3} \mathrm{H}$ & 72 & 0 & - & - \\
\hline 4 & $\mathrm{CF}_{3} \mathrm{SO}_{3} \mathrm{CH}_{3}$ & 8 & 91 & 0.41 & \\
\hline 5 & $\mathrm{CF}_{3} \mathrm{SO}_{3} \mathrm{CH}_{3}$ & 24 & 88 & 0.36 & \\
\hline 6 & $\mathrm{CF}_{3} \mathrm{SO}_{3} \mathrm{CH}_{3}$ & 48 & 0 & - & - \\
\hline 7 & $\mathrm{CF}_{3} \mathrm{SO}_{3} \mathrm{CH}_{3}$ & 72 & 0 & - & - \\
\hline 8 & $\mathrm{BF}_{3} \cdot \mathrm{Et}_{2} \mathrm{O}$ & 8 & 95 & 0.36 & \\
\hline 9 & $\mathrm{BF}_{3} \cdot \mathrm{Et}_{2} \mathrm{O}$ & 48 & 86 & 0.32 & 11 \\
\hline 10 & $\mathrm{BF}_{3} \cdot \mathrm{Et}_{2} \mathrm{O}$ & 72 & 80 & 0.16 & 6 \\
\hline 11 & $\mathrm{BF}_{3} \cdot \mathrm{Et}_{2} \mathrm{O}$ & 120 & 0 & -- & 0 \\
\hline
\end{tabular}

"Molar tatio of monomer units to catalyst $=200: i$

byeld indicates percentage of the homopolyester blend recovered after annealing:

${ }^{c}$ Intrinsic viscosity, measured at $10 \mathrm{~g} / 1$ in chloroform at $30^{\circ} \mathrm{C}$

${ }^{d}$ Calculated from the ${ }^{13} \mathrm{C}$ NMR spectra 
below in more detail.

Finally, it is noteworthy that transesterification experiments conducted with blends of pLL and poly( $\beta$-propiolactone) under the conditions of Tables 5 and 6 yielded either blends of homopolyesters (after short times, $<24 \mathrm{~h}$ ) or resulted in complete degradation.

These results lead to the conclusion that transesterification of poly $(\mathrm{L}$ lactide) does not provide an easy access to entirely random copolylactones. Yet copolyesters with a certain degree of randomness and broad chain heterogeneity can be synthesised in this way, and such copolyesters are difficult to obtain by copolymerisation of L, L-lactide and other lactones. Thus, from a preparative point of view, transesterification of polylactones and copolymerisation of lactones are complementary methods rather than alternatives.

It is worth mentioning the more recent study of Tijarna et al. [74] concerning the interchange reactions in the melt of polypivalactone (pPVL) with several diols, diacetates and diacids.

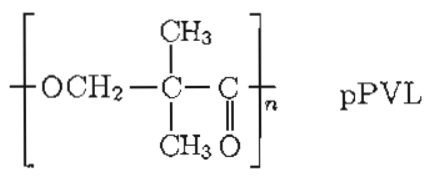

8

These authors have established that interchange of $\mathbf{8}$ with bisphenol diacetates and 1,4-butanediol occurs readily, particularly in the presence of a titanium catalyst; it is suggested that an initial cleavage of ester bonds in the polymer chain of 8 takes place, followed by a reaction between the newly formed ester end-groups and initially present hydroxyl chain ends. The acidolysis of pPVL with the diacids proved to be less effective; in the case of $10 \mathrm{~mol} \%$ isophthalic acid, less than $1 \%$ of the diacid was incorpo-

Table 6. Transesterification of poly(L-lactide) and poly ( $\varepsilon$-caprolactone) with tributyltin methoxide at $150^{\circ} \mathrm{C}[73]$

\begin{tabular}{ccccccc}
\hline No. & M/C & Time $(\mathrm{h})$ & Yield (\%) & $\eta_{\text {int. }}{ }^{\mathrm{b}}(\mathrm{dl} / \mathrm{g})$ & $\mathrm{LL}^{\mathrm{a}} / \mathrm{CL}^{\mathrm{c}}$ & $\bar{L}_{C}{ }^{\mathrm{d}}$ \\
\hline 1 & 200 & 24 & 86 & 0.62 & 1.05 & 13.3 \\
2 & 200 & 48 & 74 & 0.55 & 1.02 & 6.0 \\
3 & 200 & 72 & 67 & 0.49 & 1.05 & 5.1 \\
4 & 200 & 96 & 64 & 0.45 & 0.99 & 3.5 \\
\hline
\end{tabular}

${ }^{\mathrm{a}}$ Molar ratio of monomer units and catalyst

${ }^{b}$ Measured at $2 \mathrm{~g} / \mathrm{L}$ in clloroform at $30^{\circ} \mathrm{C}$

${ }^{\circ}$ Molar ratio of lactidyl and $\varepsilon$-hydroxycaproyl units in the isolated copolyester as determined by ${ }^{1} \mathrm{H}$ NMR spectroscopy

A Average block length of $\varepsilon$-hydroxycaproyl nnits 
rated into the polymer chains and a decrease in the logarithnic viscosity number of only $22 \%$ was found. Both the high stability of the ester hond in pPVL toward acids in general and the heterogeneity of these systems are supposed to be the reasons for this $\mathrm{pPVL}$ behaviour with respect to acidolysis.

The synthesis of copolyesters via interchange reactions of 8 with several componnds has also been studied in the molt. In a first stage, ester honds in the polymer chain are cleaved and new groups are incorporated into the polymer chain, while in a second step condensation of the endgroups formed occurs. Three procednres have been used, with tetrabutyl orthotitanate as a catalyst. pPVL was heated with equimolar mixtures of hisphenol A diacetate (BPAac) and terephthalic acid (TA), bnt no polymers were formed; instead, polycondensation of BPAac with TA occurred, leaving the pPVL nnaffected. From pPVL and mixtmres of BPAac and DMT polymers were obtained which contained a significant amount of copolymeric sequences. However, most of the polymer chains consisted of $p \mathrm{PVL}$ and poly (bisphenol A terephthalate) blocks. Randon copolyners with thermal stability were obtained after heating pPVL with PC and DMT. The latter process was studied in detail by IR, DSC, solubility, and selective degradation tests.

Copolymer composition seems to be closely associated with the mechanism of the interclange reactions, as shown by its Monte-Carlo modelling performed by Montaudo [75] and described in more detail in Chapter 4.

Recent stndies dealing with preparation of polyesters via interchange interactions are mumerous. In this respect, one should mention the vigorous development in the field of non-phosgene preparation of polycarbonates [76-87]. Efforts have been made to design continuous methods for PC preparation $[88,89]$. Modification of $\mathrm{PC}$ polymers at the stage of their preparation via transreactions seems to be very promising, too. In such a way UV stabilised [90] and branched [91] polycaulbonates have been prepared. There are also commnnications disclosing the interchange reactions in blends of $\mathrm{PC}$ and low molecular weight benzophenone derivatives [92] aiming at improvement of the properties of the starting $P C$.

As mentioned above, the large-scale production of diaryl carbonates, being the starting materials for "environment-friendly" PC synthesis throngh alcoholysis, is also a rapidly developing field of research $[42,93,94]$.

Another noteworthy issne is the synthesis of polyestor homo- and copolymers via alcoholysis $[95,96]$. All-aromatic copolymers have been obtained by this technique [97] as well as dyeahle PET-based copolyesters, namely PET-co-poly(ethylene adipate)-co-isophthalate sodium salt [98]. An entirely novel technique for polyester preparation is transesterification in supercritical carbon dioxide [99], which could obviously be used not only for PET bnt also for many other polyesters [100]. As reported recently by Ootoshi et al. [101], poly(ethylene naphthalate) (PEN) can also be produced by alcoholysis of the corresponding diacid ester. 
Interchange reactions of polyesters with low molecular weight reagents (alcohols, acids) is also a possible method of modification of the basic polymer. Al-Haddad et al. [102] and Bakmirzaeva et al. [103] have recently reported on the reaction kinetics of $\mathrm{PET}$ acidolysis with acetoxybenzoic acid. Glycolysis of PET wilh oligomeric polyethers is reportedly [104] a possible way of preparing polyether-esters. Interchange reactions between PET, hydroquinone diacetate and TA have been sudiod by Matthew et al. [105] and proved to be a suitable method of coupling in a copolymer of PET and hydroquinone-terephthalate units.

An interesting trend in the field of transreactions in polyesters is the use of enzymes (mostly lipase and proteinase of various origins) both for transesterification of PET with triglyceride oil $[106,107]$ and for preparation of polyesters by alcoholysis of terephthalic acid diesters with 1,4-butane diol in THF [108]. Similarly, poly(1,4-dibutyl sebacate) was prepared by Linko et al. [I09] using substituted diacids and diols, reaching molecular weights of $>130,000$. Partial transesterification of sucrose [110] and the preparation of its soybean [atty polyester [111] are also worth inentioning. Other examples of lipase-catalysed interchange reactions are the alcoholysis of triglycerides to yield di- and monoglycerides, reported by Kumar et al. [112], and the lipase-catalysed transesterification of rape seed oil [113].

Interchange reactions in polyesters blends are also subject of extensive research due to the broad range of materials that can be produced in this way. Even in immiscible blends, where oxchange interactions are possible, drastic changes in miscibility occur. The mechanical blends transtorn first into block copolymers, the block lengths gradually decreasing to attain, at equilibrium, random copolymers (see [114] and references therein). A more detailed approach to this issue may be found elsewhere in this book (see Chapter 8).

Recently, Guo has studied the relationship of interchange reactions and miscibility [115]. The author examined the formation of a single phase as a consequence of transesterification, or vice versa, in some polyester blends. On the basis of NMR data, the conclusion was drawn that the intercluange reaction (transesterification) is not the necessary condition for miscibility.

PET, PG, and PEN containing polyester blends are anong the most studied systems as far as interchange reactions in polymer blends are concerned. Interesting for a possible industrial application are the copolymers obtained via interchange reactions in $\mathrm{PET} / \mathrm{PC}$ [1 16-118], PEN/PC [119], $\mathrm{PEN} / \mathrm{PCL}[120]$, and PET/PEN blends [121-126]. The PET/PBT blend reportedly offers some uselul advantages in studying the sequence ordering and length of the copolymers produced, by means of NMR [127] and by $\mathrm{DSC}[128]$.

Kollodge et al. $[129,130]$ studied a binary homopolymer blend composed of poly(2-ethyl-2-methylpropylene terephthalate) and PC in which interchange reactions were induced. Special attention was paid to the socalled midchain-midchain (esterolysis) and midchain-end-group reactions 
(alcoholysis or acidolysis) and their impact on the phase behaviour. It was found that the extent of interchange reactious required to shift the phase behaviour from two phases to one was $4 \%$ (2.8\% alcoholysis and $1.2 \%$ esterolysis). It is worth mentioning here the studies of $\mathrm{Ha}$ et al. [131; on a PET/PEI blend, indicating a transformation from block into random ordering with the advance of interchange reactions. Kokkalas et al. have studied the catalyst influence in the so-called postpolycondensation of PET, involving interchange reactions between different PET macromolecules causing an increase of the molecular weight [132].

Polyester blends containing polyarylate 9 and interchange reactions therein have also attracted scientific interest [133-135]. Similar trends toward formation of copolymers and blend compatibilisation have been found and proved by thermal and NMR techniques.

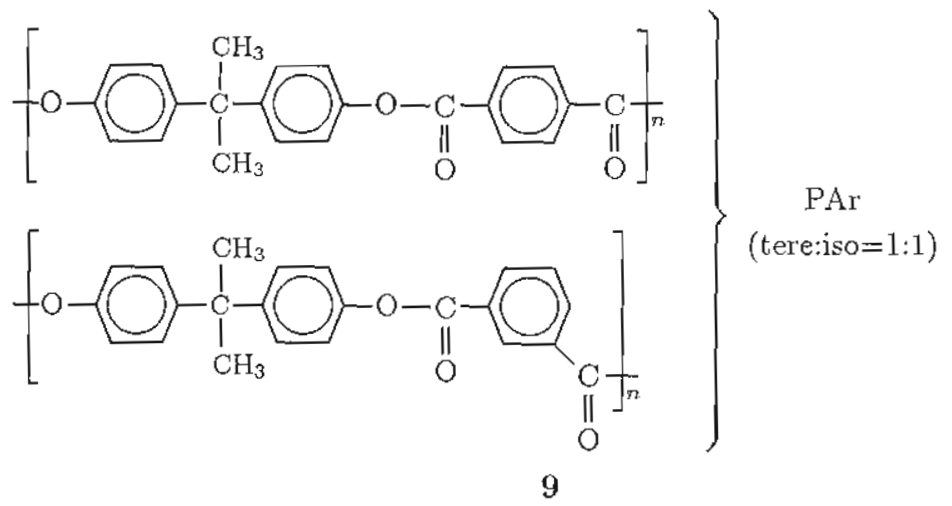

Interchange reactions are often induced between polyesters (or polycarbonates) and some liquid-crystalline polyners. Again, the most studied aspects are the phase behaviour in such systems and their rheological properties as a fuuction of the interchange reaction completion [136-147]. In this respect it is worth mentioning that the acidolysis of phenol acetates is the most widely used polycondensation method for the preparation of fully aromatic polyesters, in particular for all commercial liquid-crystalline polyesters - Vectra(B), Rodrun(B), Xydar(B), Granla(B, etc. Nurnerous papers and patents exist on this subject $[105,148,149]$ and a recent review paper of Gallot [150] summarised the principles and strategies for the synthesis of block and comb-like liquid-crystalline polymers for biological applications.

Interchange interactions in the process of ring-opening polymerisation and in copolymer systems produced in this way liave also been given some attention. Isoda et al. lhave studied the impact of the Lewis acid catalyst on the occurrence of interchange reactions in the process of $\delta$-valerolactone polymerisation [151]. It was found that some of the aluminium porplyrins used as catalysts cause transesterification, resulting in a broadening of the 
polymer molecular weight distribution.

Ma et al. [152] studied the miscibility, interchange reactions and the formation of ringed spherulites in a PBT/pCL blend at $250^{\circ} \mathrm{C}$. By means of DSC and polarised light microscopy, the authors proved that an interchange reaction in this system depends on the miscibility of the starting blend.

Type (-D-) copolymers of CL and L-lactide could reportedly be prepared in the melt at $110^{\circ} \mathrm{C}[153]$. CL is polymerised first to yield a polymer with pendant $\mathrm{OH}$ groups. The latter initiates the polymerisation of subsequently added L-lactide. When L-lactide was first polymerised, lollowed by copolymerisation with CL, random copolymers were produced, their formation being attributed to interchange reaction (transesterification).

Thermal decomposition of poly(lactic acid) was studied by Kopinke et al. by several techniques, including DSC, TG, and pyrolysis [154]. The reaction pathway was found to involve intramolecular transesterification, giving rise to the formation of cyclic oligomers.

A very recent study by Montaudo et al. [155] discloses the mechanism of interchange reactions in PBT/PC blends. Employing appropriate polymer samples (end-capped or containing reactive middle-chain and end-groups), the authors showed that the exchange process may prococd via two different mechanisms: (i) a direct interchange between inner functional groups, i.c., located inside the polymer chains or (ii) an attack of reactive chain-onds on the inner groups. When the concentration of the reactive end-groups is lower (e.g., in high molecular weight PBT/PC and PET/PC blends and in the presence of a transesterification catalyst), the first type of exchange interaction takes place which, in lact, represonts an ester-carbonate exchange. With lower molecular weight reagents, the second type of interaction prevails. The latter includes either alcoholysis or acidolysis, depending on the type of reactive end-groups involved. The authors showed that by monitoring the composition of the copolymers formed, it is possible to distinguish between the contributions of the above two reaction patterns. This approach makes it possible to control the composition and yield of the copolymer and may be used in other systems where interchange reactions occur.

As a concluding remark concerning the exchange interactions in polyesters, it can be inferred that acidolysis is the most useful method for the polycondensation of phenols, but not successful for alcohols (diols). Alcoholysis is, in contrast, useless for diphenols. Therefore, acidolysis and alcoholysis are complementary methods for the synthesis of polyesters, and the so-called direct ester--ester exchange is appropriate for the synthesis of copolyesters. 


\subsection{Reactions taking place in polyamides involving amine and amide groups}

Many excellent reviews have been written on polyamides, their synthesis and possible reactions [156-160]. In this section, only interchange reactions involving amine or amide groups are discussed.

The polymerisation reaction in polyamide synthesis is polyamidation. Its elementary step, amidation, corresponds to the reversible reaction of amide hydrolysis (or alcoholysis) and therefore proceeds via the same tetrahedral iutermediate as that of the iatter reaction [161]. Scheme 8 sums up the mechanisms of acid-catalysed and non-catalysed amidation of a carboxylic or ester group by an amino group $\{156\}$.

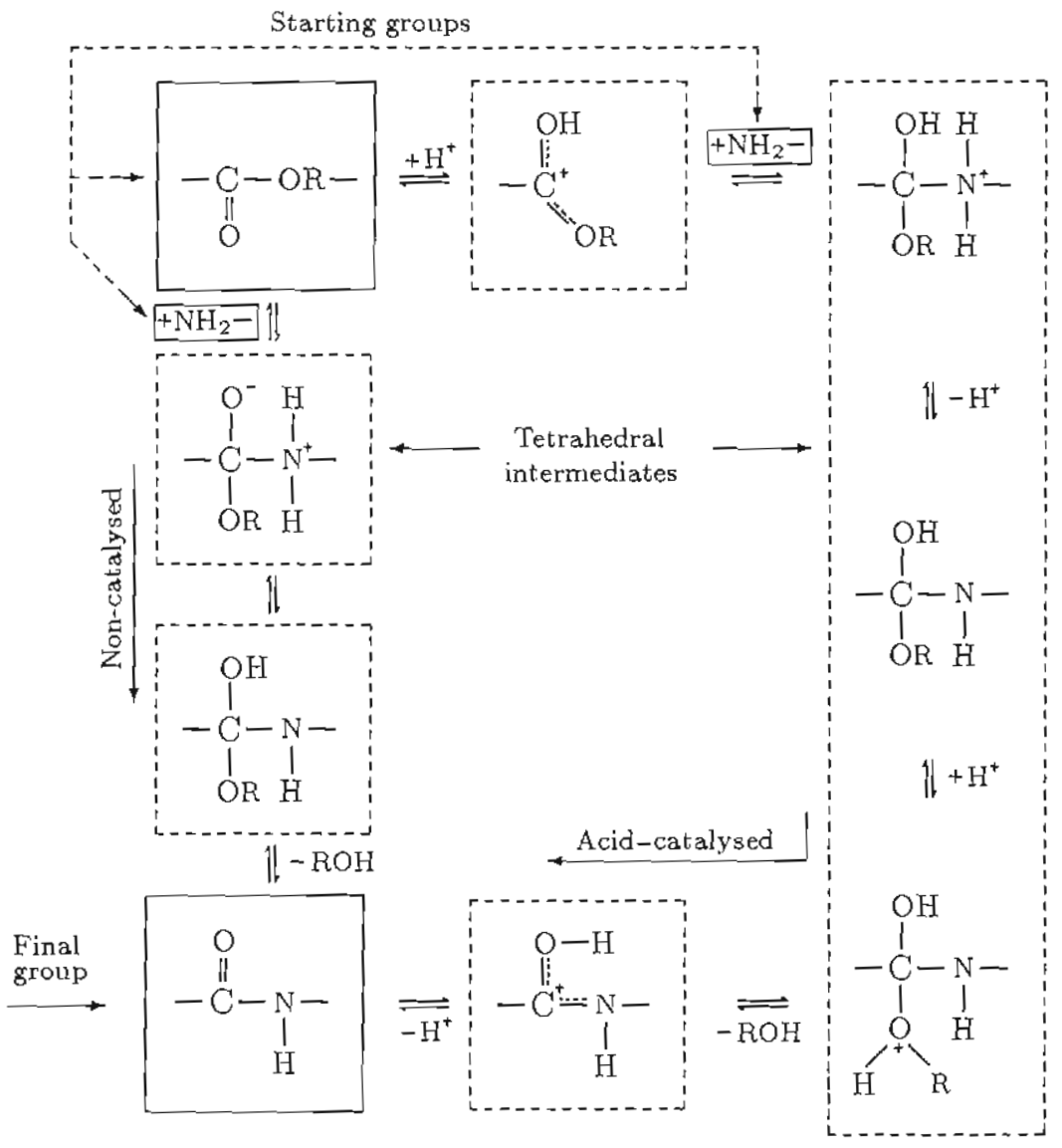

Scheme 8 
Polyamides of the $(-A-B-)_{n}$ type can be prepared from diamines and diacids (Reaction (a)) and are also called Nylons, whereas polyanides of the $(-\mathrm{D}-)_{\mathrm{r}}$ type can be prepared from either aminoacids througl their self-condensation (Reaction (b)) or cyclic aunides (lactans) by an addition process (c).

$$
\begin{aligned}
& n \mathrm{H}_{2} \mathrm{~N}-\mathrm{A}-\mathrm{NH}_{2}+n \mathrm{HOOC}-\mathrm{B}-\mathrm{COOH}= \\
& {\left[\begin{array}{lrr}
\mathrm{H} & \mathrm{O} & \\
1 & \mathrm{~N} \\
\mathrm{~N}-\mathrm{A}-\underset{\mathrm{N}}{\mathrm{N}}-\mathrm{C} & -\mathrm{B} & -\mathrm{C} \\
\mathrm{H} & \mathrm{C}
\end{array}\right] n+2 n \mathrm{H}_{2} \mathrm{O}} \\
& n \mathrm{H}_{2} \mathrm{~N}-\mathrm{D}-\mathrm{COOH} \rightleftharpoons\left[\begin{array}{l}
\mathrm{H} \\
1 \\
-\mathrm{N}-\mathrm{D}-\underset{\mathrm{C}}{0}
\end{array}\right] n+n \mathrm{H}_{2} \mathrm{O} \\
& -\mathrm{NH}_{2}+\underset{\substack{\mathrm{N}-\mathrm{C} \\
\mathrm{H} O}}{\mathrm{D}}=\underset{\substack{\mathrm{O} \\
\mathrm{H}}}{\mathrm{C}-\mathrm{D}-\mathrm{NH}_{2}}
\end{aligned}
$$

To initiate the hydrolytic polymerisation of lactams, a fraction of the rings has first to be opened (Reaction (d)). These polymers are called polyamides or Nylons $(x+1)$, and important representatives are polyamides $4,6,11$, and 12 .

$$
\left(\begin{array}{c}
\left(\mathrm{CH}_{2}\right)_{x} \\
\mathrm{~N}-\mathrm{C} \\
b \\
\mathrm{H} O
\end{array}\right.
$$

Another synthetic route uses interchange reactions (e) and (f) involving at least one amide group. The total number of end-groups remains unchanged by these reactions, but the chain lengths are redistributed continuously. In Reaction (f), a diamine is formed which, under appropriate conditions, can be removed from the system. The lactam ring addition step (c) can also be regarded as an interchange reaction.

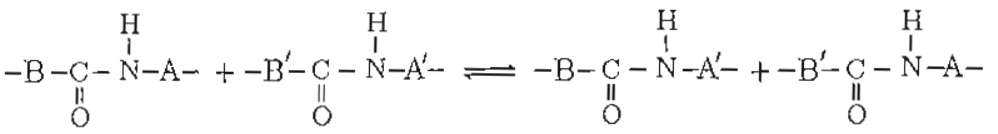

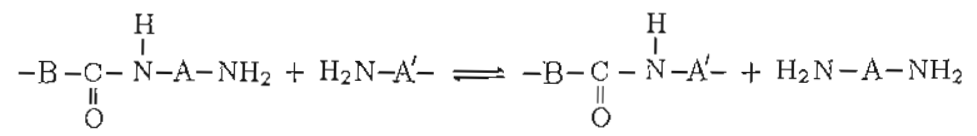


Melt polycondensation of $\omega$-aminoacids or equimolar mixtures (salts) of diamines ( $\mathrm{R}=$ alkyl or aryl group) and diacids was the very first method of polyamide synthesis; nevertheless it is still largely used. Paradoxically, the weak point of melt polycondensation is the use of ligh temperatures to carry out the reaction, causing thermal decomposition of certain reactants. This can be avoided by the use of monomers having modified functional groups instead of the zwitterionic aminium and carboxylate groups [162]. Modification of the carboxylates into esters or amides eliminates the ionic crystallinity of the monomer and avoids the need for excessive heating. However, this is not a real advantage when one has to operate above the melting temperature of the resulting polymer in order to achieve high molecular weight. Polyamides are readily formed iu the same way from $\omega$-aminocarboxylic esters [163] and diamines [164].

The mecharism of condensation of amines and carboxylic esters is essentially the same as that of non-catalysed condensation (see Scheme 8) and could be considered as an interchange reaction hetween ester and amine groups. It should be mentioned that the ease of the aninolytic (nucleophilic) reaction by the attack of a given amine is influenced by the electronic and steric environments of the ester group and by the nature of the leaving group. In the absence of $\mathrm{H}^{+}$jons, the reaction rate becomes slow in the later phase of polycondensation; for this reasou partial hydrolysis of the starting naterial is profitable in some cases $[165,166]$. On the other hand, the use of alkyl esters sometimes gives rise to partial $\mathrm{N}$-alkylation, which could limit the molecular weight of the resulting polyner and worsen its properties [167].

Similarly to the polyester synthesis, the interchange reactions in polyanides should be considered taking into account the polycondensation equilibriun. At different stages of this equilibrium, different types of exchange interactions are predominant. In the very first stages (a) and (b) of polyamide formation, exchange reactions between $\mathrm{COOH}$ (or $\mathrm{COOR}$ ) and $\mathrm{NH}_{2}$ groups lrom the monomers are responsible for the chain growth. This is also valid for the lactam polymerisation (c). At a later moment, when the concentration of the NHCO groups becomes high enough, they are involved in amide iuterchange (f). Reactions (g)-(in) give a general idea of the equilibria that should be considered in the hydrolytic amidation process.

Reaction (g) shows the polyamide salt formation. These ions cannot yield the amide group directly; what is more, they hinder the amidation. Hence, polyamidation proceeds either from the neutral carboxylic group (li) or via acid-catalysed reaction (in). It is obvious tbat the amount of water and the $\mathrm{pH}$ of the system should also have some effect.

$$
\begin{aligned}
& -\mathrm{NH}_{2}+\mathrm{HOOC}=-\mathrm{NH}_{3}^{+-} \mathrm{OOC}- \\
& -\mathrm{NH}_{2}+\mathrm{HOOC}-\leftrightharpoons-\mathrm{NH}-\mathrm{CO}-+\mathrm{H}_{2} \mathrm{O}
\end{aligned}
$$




$$
\begin{aligned}
-\mathrm{NH}_{2}+\mathrm{H}_{2} \mathrm{O} & \leftrightharpoons-\mathrm{NH}_{3}^{+}+\mathrm{OH}^{-} \\
-\mathrm{COOH}+\mathrm{H}_{2} \mathrm{O} & \leftrightharpoons-\mathrm{COO}^{-}+\mathrm{H}_{3}^{+} \mathrm{O} \\
2 \mathrm{H}_{2} \mathrm{O} & \leftrightharpoons \mathrm{H}_{3} \mathrm{O}^{+}+\mathrm{OH}^{-} \\
-\mathrm{COOH}+\mathrm{H}^{+} \leftrightharpoons-\mathrm{C}(\mathrm{OH})_{2}^{+} & \leftrightharpoons-\mathrm{CO}-\mathrm{NH}-+\mathrm{H}^{+}+\mathrm{H}_{2} \mathrm{O}
\end{aligned}
$$

The reactivity of the functional groups has little dependence on either the length of the aliphatic group or the length of the polymer chain $[168,169]$. Therefore, the polyamidation kinetics of the various polyanides are comparable. In contrast, for lactam ring structures, the reaction equilibria depend on the ring size $[170]$.

The main anide equilibria are: (i) condensation and ring opening and (ii) amide interchange and ring addition. As far as exchange reactions are concerned, the second equilibrium seems to be more important. For the ring addition (c), the equilibrium value under polymerisation conditions determines the minimal final content of lactam, which is $7.8 \%$ for Nylor 6 at $250^{\circ} \mathrm{C}$ and even higher for some other polymers [170]. Unfavourable values for some lactam polymers (Nylons 4 and 5) make them thermally nnstable at higher temperatures.

When two different polyamides are mixed for $3 \mathrm{~min}$ at $260^{\circ} \mathrm{C}, 5 \%$ of the amide gromps (as measured by NMR) have already undergone amide interchange and a block copolymer is formed. For longer reaction times ( 120 min at $260^{\circ} \mathrm{C}$ ), a completely random copolyamide can be formed $[171-173]$. The amide interchange reaction is acid-catalysed [172].

In some cases, the residual monomers can be removed by an amide interchange raction (f). More particularly, volatile diamines are removed in this way and are therefore often added in excess at the beginning of the reaction.

Copolymerisation of caprolactam with other lactams, e.g., 12 dodecanelactam, by hydrolytic schemes has the same advantages and disadvanlages as homopolymerisation. Copolymerisation with Nylon salts can be perforned without the addition of water, eliminating the hydrolysis step and retaining only the ring opening and polycondensation steps. Compared to the homopolymer, the random copolymers, showing depressed crystalliuity, are produced on a much smaller scale [157]. Small amounts of comonomer are incorporated in order to influence the dyeing behaviour of textile or carpet fibres. Higher levels of comonomer systems (e.g., hexamethylenediamine-isophthalic acid salt) are used to prepare largely amorphous products which are valued for their transparency [157].

At this point, there have been quite a lot of stndies on the phenomenon of interchange reactions in polyamides, enough to clarify the mechanism of transamidation. Korshak and Frunze [174] referred to the processes as aminolysis and/or acidolysis, bul did not report any rate-determining anal- 
ysis. They indicate that polyamides having capped amine and carboxyl groups do undergo exchange reactions, but at a lower rate. Flory [173] also suggested that aminolysis occurs with the possibility of true anide exchange in polyamide melts. These reactions are:

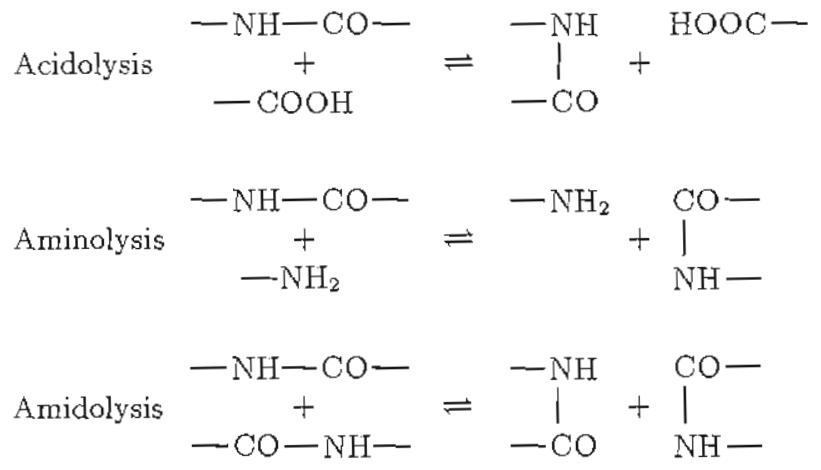

Beste and Houtz [172] have shown that when sebacamide and $\mathrm{N}_{1} \mathrm{~N}^{\prime}-$ diacetylhexamethylenediamine are heated together, amide interchange occurs to form acetamide and poly(hexamethylene sebacamide). These authors have found that the presence of water and carboxyl groules significantly affects the reaction and suggested a square-root dependence on the

Table 7. Amide interchange; 50 min a.t $245^{\circ} \mathrm{C}^{\mathrm{a}}$ [172]

\begin{tabular}{cccccc}
{$[\mathrm{S}]_{0}$} & {$[\mathrm{H}]_{0}$} & $\left.\left[\mathrm{CO}_{2} \mathrm{H}\right]_{0}\right\}^{1 / 2}$ & {$[\mathrm{~A}]$} & $k_{2}$ & $K_{25}$ \\
\hline 5.09 & 4.89 & 10.25 & 0.363 & 0.31 & 30 \\
5.00 & 4.98 & 10.16 & 0.374 & 0.32 & 31 \\
4.98 & 5.00 & 10.14 & 0.360 & 0.31 & 31 \\
4.50 & 4.99 & 22.6 & 0.701 & 0.75 & 33 \\
7.48 & 2.50 & 5.2 & 0.140 & 0.15 & 29 \\
2.50 & 7.48 & 3.0 & 0.072 & 0.077 & 26 \\
\hline
\end{tabular}

"Concentrations are given in mequiv/g: $[S]_{0}=$ inilial concentration of sebacamide; $[\mathrm{H}]_{0}=$ initial concentration of $\mathrm{N}, \mathrm{N}^{\prime}$-diacetylhexamethylenedianine; $[\mathrm{A}]=$ concentra tion of acetarnide after $50 \mathrm{~min} ; k_{2}=$ second-order mule constant. (equiv/g) ${ }^{-1} ; K_{2.5}=$ second-order rate constant (equiv/g)-15 $(\mathrm{min})^{-1}$

Table 8. Effect of water on rate of interchange [172]

\begin{tabular}{cc} 
Added water (wt \%) & $K_{25}$ \\
\hline 0 & 30.2 \\
0.42 & 34.3 \\
1.16 & 47.0 \\
"Anhydrous" & 23.6 \\
\hline
\end{tabular}


carboxyl group concentration. As seen in Tables 7 and 8 , the effect of water is consistent with the catalytic effect of hydrogen ions, i.e., hydrolysis and transamidation are certainly consistent with their results. They also reported a possible mechanism involving the attachment of the proton to the amide nitrogen, followed by reaction with water to give a carboxyl group and an alkylammonium ion. Salt formation and amidation could then occur. Beste and Houtz [172] also estimated that about half of the amide groups will take part in an interchange within $30 \mathrm{~min}$ during the second stage of Nylon 6,6 polymerisation to a molecular weight of about 23000 at $283^{\circ} \mathrm{C}$.

Ogata [175], in his studies on the polymerisation and depolymerisation of poly(e-caprolactam) polymers, found that no intermolecular reaction occurs on heating $\varepsilon$-caprolactam or diketopiperazine with a polyamide in the dry state. The amide groups of chain molecules react with e-caprolactain to a significant extent in the melt - the rates of reactions of monosubstitnted or disubstituted acid anide with nethyl $\varepsilon$-caprolactam or $\varepsilon$ caprolactam being slower than that of the monosubstituted acid amide with $\varepsilon$-caprolactam - and $\mathrm{N}$-nethyl $\varepsilon$-caprolactam did not react at all. He also found that the amino cation $\mathrm{RNH}_{3}^{+}$reacts with the anide group of e-caprolactam, while the dissociated carboxyl group RCOO does not.

Miller [176] found iu studies with mixtures of N-ethylcaproamicle and Nhexylacetamide containing small concentrations of hexylamine and caproic acid that anide exchange improves acidolysis and aminolysis with no detectable contribution of a direct reaction between amide groups. His results show that the exchange rate is not accelerated by hexylamine but is increased by caproic acid and that the formation of an anhydride intermediate yields kinetic equations that provide a good fit for the amide exchange rate data. In the rate equation derived (Eq. (46)), $[\mathrm{A}]_{0},[\mathrm{C}]_{0},[\mathrm{HC}]_{0},[\mathrm{HA}]_{0}$, and $[\mathrm{EC}]_{0}$ are the initial concentrations of acetic acid, caproic acid, hexylcaproamide, hexylacetamide, and ethylcaproamide, respectively.

$$
K=\left([\mathrm{A}]_{0}[\mathrm{EC}]_{0}+2[\mathrm{C}]_{0}[\mathrm{EC}]_{0}+[\mathrm{C}]_{0}[\mathrm{HA}]_{0}\right) / 4
$$

The activation energy in the $231-275^{\circ} \mathrm{C}$ range was $27.7 \mathrm{kcal} / \mathrm{mol}$.

Kotliar [177] showed that the interchange rate for dispersed molecular blends of Nylon 6 is acid-catalysed and is a complex fuction of the water content. However, his results could not definitely show that the interchange rate is a function of the amine ends.

More recently, Fakirov et at. have studied the interchange reactions in PET/Nylon 6 blends [178]. The chemical changes occurring in the esteranuide exchange or condensation reactions in the solid state lead to the formation of copolymer layers between the two components in the blend. The interphase plays the role of a compatibiliser. Prolonged annealing at higher temperatures (below the melting of PET) results in the transformation of the initially isotropic polyamide matrix into a copolymer which affects the morphology and properties of the blend. 
The changes in the thermomechanical behaviour of the same PET/Nylon 6 blend (1:1 by wt) subjected to mechanical and thermal treatments have been examined by means of dynamic mechanical measurements $[179]$. It was established from previous studies that $\mathrm{PET} / \mathrm{Nyl}$ lon blends are incompatible in the isotropic state, but form the so-called microfibrillarreinforced composites upon extrusion, drawing, and suitable annealing. This study focuses mainly on the amorphous component of the blends and thus complements the above results concerning the crystalline phase. The orientation and crystallisation of the homopolymers induced by drawing improve the dispersion of components and impart some compatibility as far as one glass transition is observed. Yet, by annealing the drawn blend below the melting temperatures of both components (c.g., at $\left.220^{\circ} \mathrm{C}\right)$, the biphasic character of the composite is enhanced, inasmuch as the microstructures of both the crystalline and the amorphous phases are improved and the reorganisation of species within separate phases is favoured. The components of the heterogcneous blend become compatible, provided that annealing is performed at a sufficiently high temperature $\left(240^{\circ} \mathrm{C}\right)$, falling between the melting temperatures of the two components and allowing the isotropisation of the lower-melting component, Nylon 6. The increase of compatibility is attributed to transreactions producing compatibilising layers of PET-Nylon 6 copolymers as phase boundaries between microfibrils and the anorphous natrix. Prolonged annealing $(25 \mathrm{~h})$ leads to the randomisation of the original block copolymers and results in the participation of the entire amount of polyanide in the copolyner, which is evidenced by the disappearance of the glass transition peak of Nylon 6 [179] (see also Chapter 8).

In the stady of transanidation reactions in the melt of polyamide blends; it is important to know whether the resulting product is actually a block copolyner, a random copolymer, or a mixture of two homopolyamides. In blends composed of a semicrystalline aliphatic polyanide and an amorphous aromatic polyamide, knowledge of the length of tha homogeneous blocks of the aliphatic polyamide can provide information about the kinetics and the crystallisability. It is known that at temperatures of about $250^{\circ} \mathrm{C}$, copolymer formation occurs by amide exchange in a melt of two polyamides $[176,180]$. Some attempts have been made to characterise the extent of interchange reactions in mixtures of poly $(m-x y l e n e$ adipamide) and Nylon 6 [181] and also in nixtures of Nylon- $x, y$ polymers [182], where $x$ indicates the number of carbon atoms separating the nitrogen atoms in the diamine and $y$ the number of straight-chain carbon atons in the dibasic acid. However, these analyses by NMR are not sufficiently convincing. According to the literature, proton NMR has been used as a lool to identify polyamides and copolyamides, but as shown in [183], ${ }^{2} \mathrm{H}$ NMR is not a general tool for discriminating between aliphatic copolyamides and blends of homopolyamides. It is now well known $[22,24,184,185]$ that the shift differences for blends of homopolyamides, alternating copolyamides, 
and random copolyamides are best expressed in the ${ }^{13} \mathrm{C}$ carbonyl region. Another method is ${ }^{15} \mathrm{~N}$ NMR, which makes it also possible to determine sequences; however, the advantage of ${ }^{1} \mathrm{H}$ and ${ }^{13} \mathrm{C} N \mathrm{NMR}$ over ${ }^{15} \mathrm{~N} \mathrm{NMR}$ is that the quantitative measurements are more accurate [186].

In a recent paper by Aerdts et al. [187], the ${ }^{13} \mathrm{C}$ NMR spcctra of a blend and a copolymer of the semicrystalline aliphatic Nylon 4,6 and the amorphous aromatic Nylon $6 I$ were studied. Both polyamides are very suitable for such an investigation because of their miscibility over the entire composition range. The absence of multiple phases in the melt simplifies the investigation of transamidation reactions. Another advantage is that this system is of practical interest since both polyamide resins are commcrcially available products. The copolymer is formed after reaction in the melt aud subsequent ${ }^{13} \mathrm{C}$ NMIR measurements suggest that exchange reactions have taken place. Four kinds of dyad sequences could be determiued in the carbouyl resonances in the ${ }^{13} \mathrm{C}$ NMR spectra of the copolyamides and, from their relative pcak areas, it was possible to determinc the number-average block length as well as the degree of randomness using the theory developed for polyesters by Devaux et al. [17]. It was shown that after extruding a Nylon 4,6/Nylon 6I blend (1:1 by wt) for $90 \mathrm{~min}$ at $315^{\circ} \mathrm{C}$, the degree of randomness was $24 \%$ and the average homologous block length of Nylon 4,6 was 8 . The resulting copolymer can still crystallise, as demonstrated in [188].

\subsection{Interchange reactions involving $S i-O$ bonds}

Interchange reactions arc best studied and understood in polyesters and polyamides, but this does not exhaust their variety in polymers. Similar reactions car also take place, involving Si-O bonds. Some aspects related to the exchange reactions in organosilicon chemistry can be found in [189]. In this scction, only the relatively new approach to polymer synthesis employing silylated starting monomers is discussed.

In some cases, classical polycondensation reactions betwccn $\mathrm{COOH}$ for $\mathrm{COOR}$ ) and $\mathrm{OH}$ - or $\mathrm{NH}_{2}$-containing starting monomers prove inappropriate due to various problems arising either during the polycondensation itself (e.g., solidification of the reaction mixture, undesirable side rcactions) or at later stages (e.g., impossibility of purification of the final product). These problens can be avoided by modification (silylation) of all or some of the starting monomers. Such an approach was shown to be highly advantageous in the preparation of some thermotropic poly(ester anhydrides) $[190,191]$ and linear, star-shaped, or hyperhranched poly (ester anides) [192].

Thermotropic poly(ester anhydrides) are of certain practical interest because they combine the useful properties of a fully aromatic polyester with a ligh rate of biodegradation (e.g., by hydrolysis) reached by incorporation of anhydride groups. Scheme 9 depicts the synthetic route via silylated compounds [190]. 


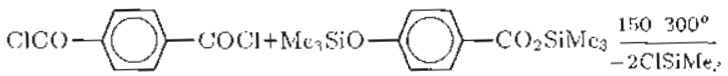

$$
\begin{aligned}
& {[\mathrm{co}-(0)-\mathrm{OO}-\mathrm{O}-\mathrm{Co}-(0)-\mathrm{O}+}
\end{aligned}
$$

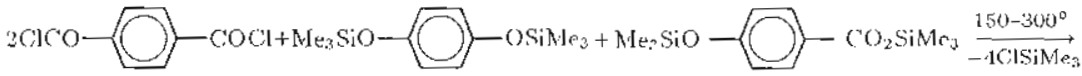

$$
\begin{aligned}
& {[00-(0)-00-0-(0)-0) 00-(0)-00-0-(0)-0-1} \\
& {[(\cos -(0)-60-0-(3)-0) \backslash(00-(0)-00-0-00-(0)-0)]} \\
& 10 \mathrm{a}-\mathrm{f} \\
& \text { a, } m / n=00 / 10 \quad \mathrm{cl}, m / n=60 / 40 \\
& b_{r} n / n=80 / 20 \quad c, m / n=50 / 50 \\
& \text { c. } m / n=r(m / 30 \quad\{, m / 5=30 / 70
\end{aligned}
$$

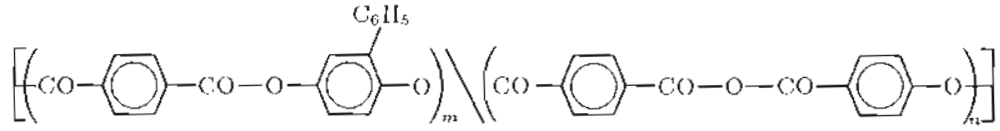

$$
\begin{aligned}
& 11 \mathrm{a}-\mathrm{g} \\
& \text { a, } m / n=90 / 10 \quad \mathrm{~d}, m / n=60 / 40 \\
& \text { b, } m / n=80 / 20 \text { e, } m / n=50 / 50 \\
& \text { c, } m / n=70 / 30 \text { l. } m / n=40 / 60 \\
& \text { g, } m / n=30 / 70 \\
& 12 \mathrm{i}-\mathrm{c} \\
& \text { a. } m / n=2 / 1 \\
& \text { b. } m / n=1 / 1 \\
& \text { c) } m / n=1 / 2
\end{aligned}
$$

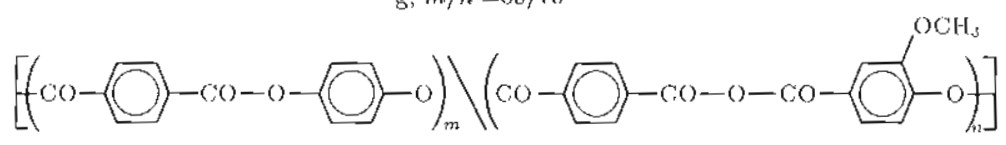

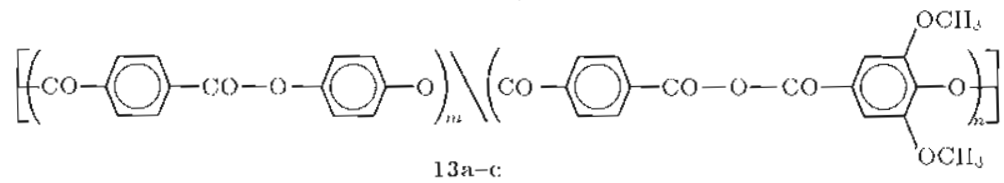

$$
\begin{aligned}
& \text { a) } m / n=2 / 1 \\
& \text { b, } m / n=1 / 1 \\
& c, m / m=1 / 2
\end{aligned}
$$

Scheme 9 
As one may conclnde, the above reactions can be regarded as nonequilibrium interchange (transacylation) between terephthaloyl dichloride and the silylated hydroquinones and silylated 4-hydroxybenzoic: acids to form complex and obviously random sequences of several ester and anhydride groups. Some of the advantages of the "silyt method" arc that the bulk condensation of silylated nonomers does not require solvents and the volatile chlorotrimethylsilane is the only by-product. At the end of polycondensation, by subjecting the reaction mixture to high vacnum at $300^{\circ} \mathrm{C}$, all of the residual low molecnlar weight by-products and starting materials could distill off or sublime.

${ }^{13} \mathrm{C}$ NMR spectra were obtained from freshly prepared solutions of poly(ester anhydrides) in a mixture of $\mathrm{CDCl}_{3}$ and $\mathrm{CF}_{3} \mathrm{COOH}(4: 1 \mathrm{v} / \mathrm{v})$; they are particularly easy to interpret when the molar ratio of hydroqnimone and hydroxybenzoic acid is close to $1: 1$. The best resolution of carbonyl signals, which are most sensitive to sequence effects, was obtained for samples 11 and $11 \mathrm{f}$ (containing phenylhydroquinonc). As shown in Figure 17 , six relatively strong $\mathrm{CO}$ signals are observable. Taking into account that poly (phenylhydroquinone terephthalate), when moasured separately, exhibits only one $\mathrm{CO}$ signal (signal a in Figure 17 ), four $\mathrm{CO}$ signals are expected according to the above formula of $1.1 \mathrm{e}$. However, it was demonstrated in a previous paper that the synthesis of polyanhydrides by the "silyl method" involves rapid transacylation [191]. Therefore, two of the six Co signals may originate from the colresponding homoanhydrides formed according to Scheme 10. Furthermore, three weak CO signals $(x, y$ and $z$ in Figure 17) are detectable and they result either from transestcrification or from end-groups. Low molecular weight model compounds of the endgroups, such as 4 -acetoxybenzoic acid or monomethyl terephthalate, did not prove to be useful for reliable assignments. Therefore, the synthesis of sample the was repeated at a lower maximum reaction tempatature of

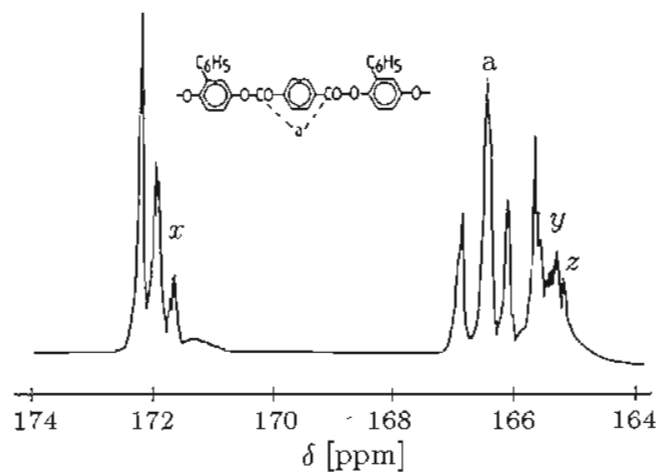

Figure $17.75 .4-\mathrm{MHz}{ }^{13} \mathrm{C}$ NMR spectrum of the carbonyl signals of poly(ester anhydride) 11 measured in $\mathrm{CDCl}_{3} / \mathrm{CF}_{3} \mathrm{COOH}(4: 1 \mathrm{v} / \mathrm{v})[190]$ 
$250^{\circ} \mathrm{C}$ and a polymer of lower molecular weight was obtained. Under these conditions, the signals of end-groups should be more intense, and signals resnlting from transesterification should be weaker or absent. In fact, the intensities of signals $x, y$ and $z$ were higher by a factor of 2 . This finding indicates the absence of transesterification, in agreement with previons results [191].

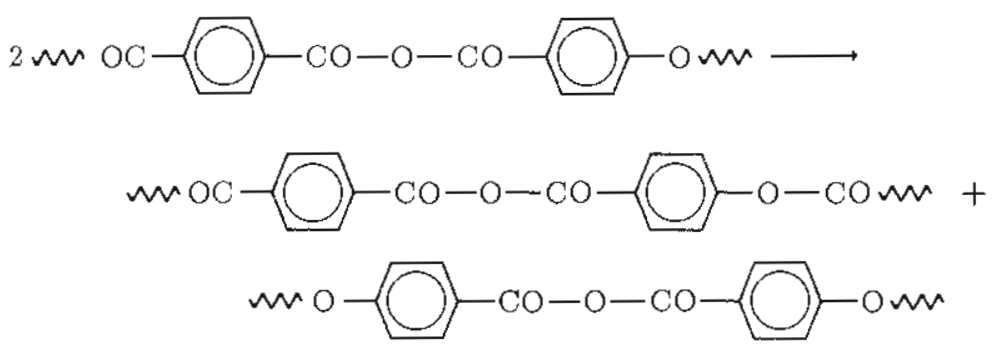

Scheme 10

It is worth mentioning here that silylated hydroquinone and 4hydroxybenzoic acid derivatives can easily be prepared by refluxing with hexamethyldisilazane in toluene for $2-4 \mathrm{~h}$, followed by distillation under reduced pressure [190].

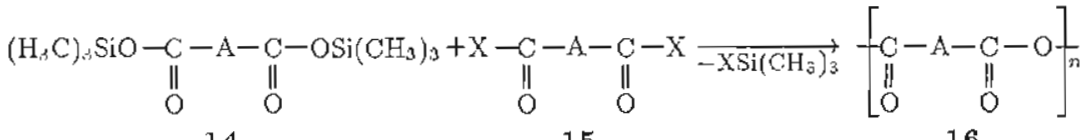

$$
\begin{aligned}
& 14 \quad 15 \\
& 16 \\
& \mathrm{X}=\mathrm{F}, \mathrm{Cl} \\
& 14 \mathrm{a}, 15 \mathrm{a}, 16 \mathrm{a}:-\mathrm{A}-=\left(\mathrm{CH}_{2}\right)_{6} \\
& \text { b: }-\mathrm{A}-=\left(\mathrm{CH}_{2}\right)_{8} \\
& \text { c: }-\mathrm{A}-=\left(\mathrm{CH}_{2}\right)_{10}
\end{aligned}
$$

Scheme 11

The low or even absent solubility of the fully aromatic homo- and copolyanhydrides can be overcome by implementation of aliphatic reagents according to Scheme 11 [191]. Obviously, when the A-radicals of the silylated acid and acid halide differ from each other, copolyanhydrides could be prepared. In Figure 18, the ${ }^{13} \mathrm{C}$ MMR spectrum of an amorphous copolyanhydride, prepared from silylated sebacic acid and isophthaloyl chloride, is shown; it is clear that, as a resnlt of interchange reactions (transacylation, acidolysis) the copolymer contains the following sequences in a nearly random order: 

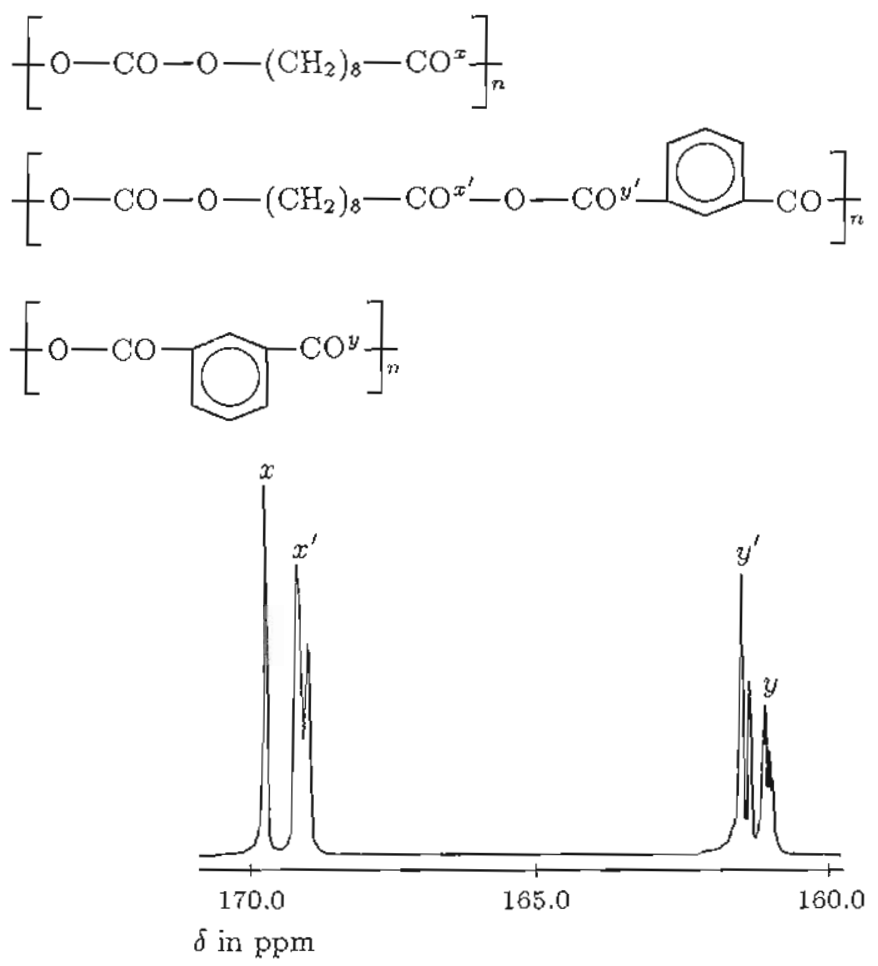

Figure 18. 75.4-MHz ${ }^{13} \mathrm{C}$ NMR spectrum of a copolyanhydride 16, prepared from silylated sebacic acid 14 and isophthaloyl cliloride 15 , measured in $\mathrm{CDCl}_{3}$ with internal standard TMS

Another example of interchange reactions involving $\mathrm{Si}-\mathrm{O}$ groups is the synthesis of the so-called "hyperbranched polymers". They are thought to have a structure that is intermediate between those of linear polymers and dendrimers. As their name implies, these polymers are also highly branched, but their structure is neither regular nor symmetrical, i.c., it contains randomly located branched as well as linear units. The synthesis of such polymers represents one-pot and "self governed" polycondensation process of trifunctional ( $A_{2} B$ type) monomers and has the advantage of being much simpler and inexpensive, as compared to that of dendrimers. The hyperbranched polymers possess most of the useful properties of dendrimers: numerous reactive functional end-groups, high solubility, and possibly compatibility witb other polymers, low viscosity in solntion, eliminated crystallinity, etc. [192].

A major problem in the polycondensation of $\mathrm{A}_{2} \mathrm{~B}$ monomers is the occurrence of undesirable side reactions that lead to the formation of crosslinks, thins preventing the preparation of completely soluble hyperbranched 
structures. The first approach to the synthesis of completely soluble randomly branched (hyperbranched) polyesters was reported in [193] and used later by other research groups $[194,195]$. It is based on the polycondensation of 3,5-bis(trimethylsiloxy) benzoyl chloride, 17. A more versatile synthetic route was developed later, employing polycondensation of the trimethylsilyl esters 18 of acetylated trifunctional hydroxybenzoic acids. All studies on these systems demonstrated that polycondensation of silylated carboxylic acids represents a cleaner process, because these acids do not contain acidic protons. Thus the occurrence of acid-catalysed decarboxylation or Fries rearrangement leading to the formation of crosslinks is eliminatcd to a. greater extert.

It is worth mentioning here that the polycondensation of $\mathrm{R}-\mathrm{CO}_{2} \mathrm{SiMe}_{3}$ with acetylated phenol groups is the only ester-interchange reaction (or esterolysis) that does not need a transesterification catalyst at temperalures higher that $250^{\circ} \mathrm{C}$.

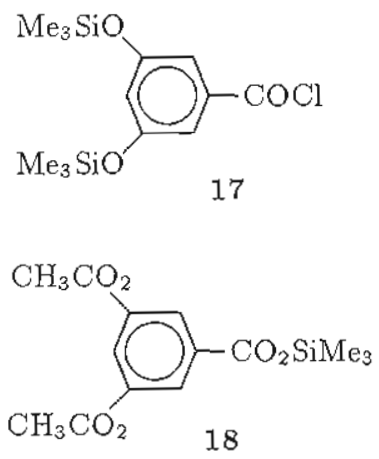

1.8
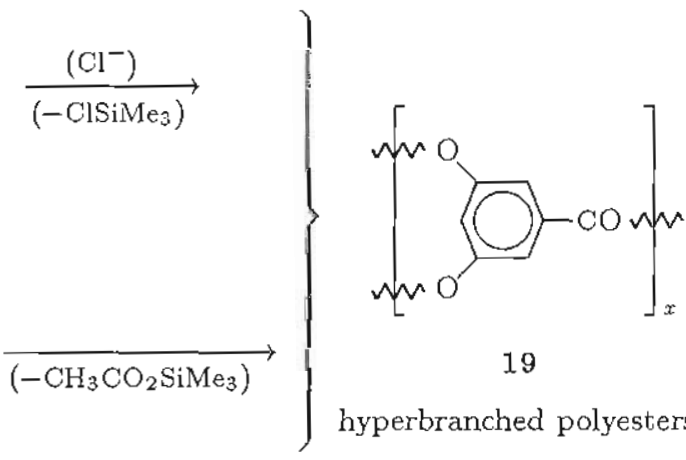

19

Scheme 12

Using this approach (Scheme 12), randomly lyperbranched polyesters 19 [196] and polyanides $[192,197]$ were successfully prejared. Irr both cases, the application of silylated monomers gave better results, in terms of molecular weight and solubility of the hyperbranched polymers, than the nonsilylated ones.

The synthetic approach described in [192] is based on the regioselective acylation of silylated 3,5-diaminobenzoic acid 21 with 3-acetoxybenzoyl chloride 20 (Scheme 13). The silylation of 21 and the distillation of the $\mathrm{N}, \mathrm{N}^{\prime}, \mathrm{O}$-tris(trimethylsilyl) derivative is an effective purification procedure for this monomer. Furthermore, the silylation slightly activates the nucleophilicity of the annino groups and canses a quantitative acylation, whereas the carboxyl group is prolected against acylation at moderate temperatures $\left(<100^{\circ} \mathrm{C}\right)$ in the absence of chloride ions. The clean and almost quantitative acylation of 21 by 20 enables the direct polycondensation of monomer 22 without its isolation ("one-pot" procedure, Scheme 13). Hydrolysis of 

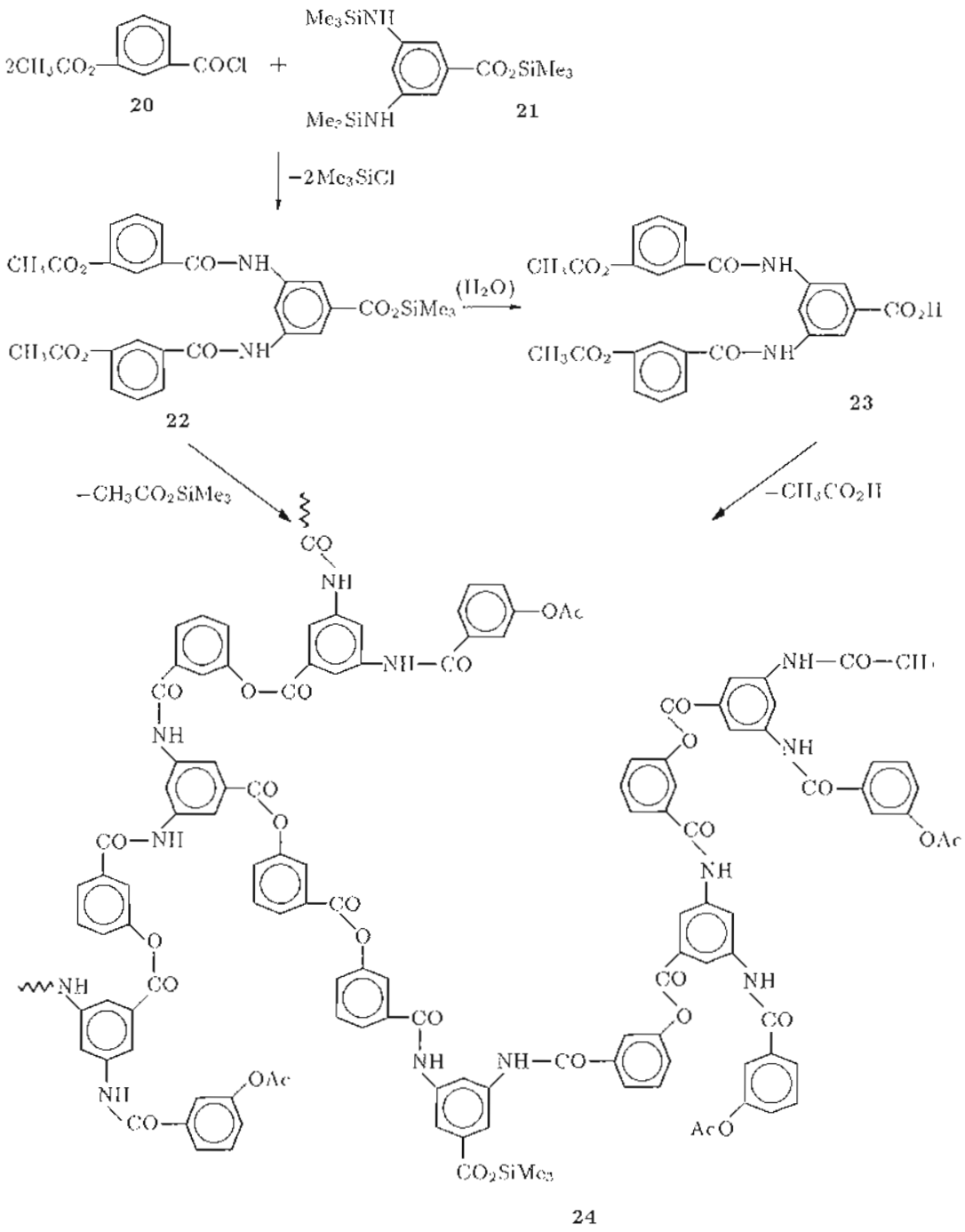

Scheme 13

22 yields the crystalline monomer 23 which can be polycondensed as well (two-step procedure, Scheme 13).

In order to synthesize star-shaped polymers with dondritic star arms, three tetrafnnctional comotioners, 27, 28, and 29, were prepared. As illustrated in Scheme 14, the silylated diamine (piperazine 26 in this particular case) was acylated with 3,5-diacetoxybenzoyl chloride, 25.

Three polycondensations were conducted with the isolated monomer 
<smiles>COc1cc(OC)cc(C(=O)NCCN2CCN([As]C(C)=O)CC2)c1</smiles><smiles>COc1cc(OC(C)=O)cc(OC(=O)N2CCCN(CCCCOc3cc(OC(C)=O)cc(OC(C)=O)c3)CC2)c1</smiles><smiles>COc1cc(OC(C)=O)cc(OC(=O)Nc2ccc(-c3ccc(NC(=O)c4cc(OC)cc(OC(C)=O)c4)c(OC)c3)cc2OC)c1</smiles><smiles>COC(OC)c1cc(OC(C)=O)cc(C(=O)NNc2ccc(-c3ccc(-c4ccc(NC(=O)c5cc(OC(C)=O)cc(OC(C)=O)c5)cc4)cc3)cc2)c1</smiles>
29

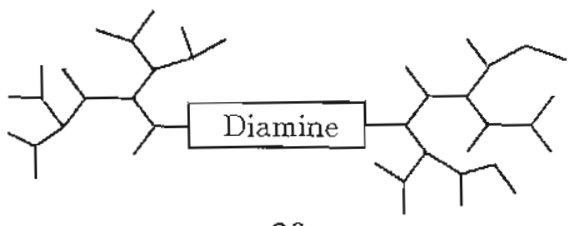

30

Scheme 14

23 and the maximum reaction temperature was varied between 250 and $280^{\circ} \mathrm{C}$. The resulting poly(ester amides) 24 were completely soluble, and thus non-crosslinked, when the reaction temperature did not exceed $270^{\circ} \mathrm{C}$. At a final reaction temperature of $280^{\circ} \mathrm{C}$, a polymer forming gel particles was obtained. A similar series of polycondensations was conducted with 
the silylated monomer 22. Although this monomer was not isolated and purified, completely soluble poly(ester amides) 24 were obtained up to temperatures of $270^{\circ} \mathrm{C}$, by analogy with the results found for monomer 23. However, the viscosity values of the polymers prepared from 22 were higher. Thus, the polycondensation of 22 is clearly the more attractive approach, the more so as it may be conducted as a "one-pot" procedure.

In this connection, it is worth noting that the products resulting from the "acetate method" on the one liand, and from the "silyl acetate method" on the other haud, differ not only in their viscosities but also in their chemical structures. While their IR and ${ }^{1} \mathrm{H}$ NMR spectra are almost identical, the ${ }^{13} \mathrm{C}$ NMR spectra exhibit significant differences, mainly in the region of the CO signals, indicating that the products of the acetate method arc inHuenced by more intensive ester-amide interchange reactions and by more side reactions.

Several polycondensations were conducted by in situ preparation of the silylated monomer and subsequent heating with one of the comonomers 27,28 , or 29 up to a maximum temperature of $270^{\circ} \mathrm{C}$. The monomer/comononer ratio was varied from 30:1 to 60:1 and 90:1. The results suggest that all three comonomers $27-29$ were actually incorporated into the poly(ester amides) 24 because the inherent viscosities increase with the monomer/comonomer ratios. The ${ }^{1} \mathrm{HI}$ NMR spectra confirm this conclusion. This means, in turn, that the copoly(ester amides) considercd here possess the structure of a star with hyperbranched arms (30). Structure 31 obtained from 22 and 27 conld be an example. Similar results are also reported in $[197]$.

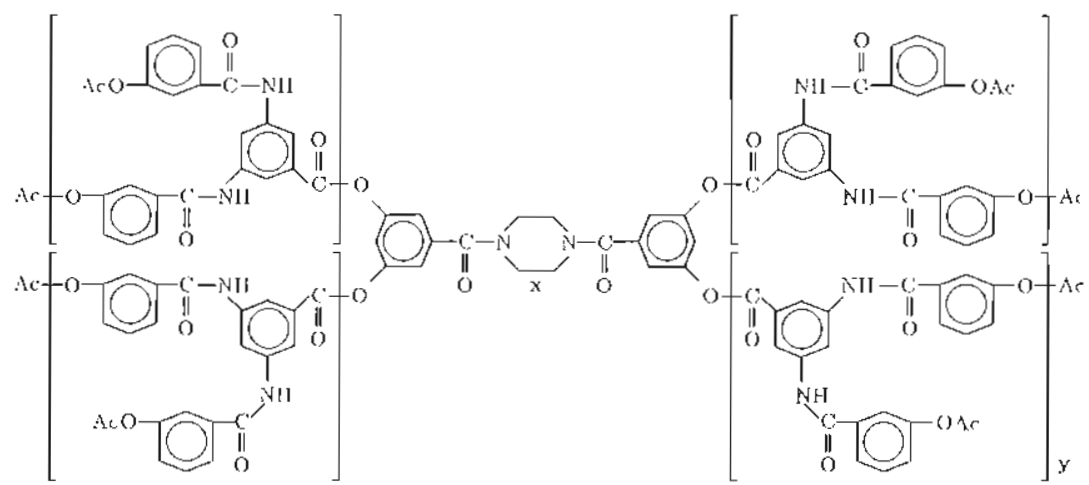

31

In conclusion, it shonld be mentioned that interchange reactions involving $\mathrm{Si}-\mathrm{O}$ bonds, i.e., employing silylated starting monomers, might be very useful in step-growth polycondensation reactions to produce rather complex polymors that are otherwise more difficult or even impossible to prepare. 


\subsection{Interchange reactions involving urethane and urea groups}

A great variety of polymers are described by the general term polyurethanes. These materials are typically syntliesised by the addition reaction of an alcohol and an isocyanate group (Scheme 15) [198].

$$
\mathrm{R}-\mathrm{NCO}+\mathrm{H}-\mathrm{OR}^{\prime} \rightleftharpoons \mathrm{R}-\mathrm{NH}-\mathrm{CO}-\mathrm{OR}^{\prime}
$$

Sclleme 15

Polyurethanes based on 4,4-diphenylmethanediisocyanate (MDI), I,4butanediol (BDO) and polyoxytetramethylene have been investigated intensively because of their practical importance. The structure and morphology of the so-called hard segments, formed by the polyaddition of MDI and BDO, has been a topic of major interest. To obtain reliable experimental data from which to derive firm conclusions, it was nocessary to synthesise strictly nonodisperse oligourethanes as model compounds for the hard segments of segmented polyurethanes and as hard-segment precursors for the synthesis of model elastomers.

The following series of oligomers has been syrthesised independently in several laboratories [199-210]. The strategy of oligomer synthesis included the use of protecting groups for both stoichionctric and non-stoichiometric ratios of the reactants, as showr below.<smiles>[R2]C(C)(C)Nc1ccc(Cc2ccc(NC(=O)OCCCCCCCC)cc2)cc1</smiles>

with $5 \geq n \geq 0$

and $\mathrm{R}=-\mathrm{O}-\left(\mathrm{CH}_{2}\right)_{4}-\mathrm{OH}_{4} \quad \mathrm{R}^{\prime}=\mathrm{H}$ (diol), or<smiles>[R]OCCCOC(=O)Nc1ccc(Cc2ccccc2)cc1</smiles><smiles>[R]=CC(=O)Nc1ccc(Cc2ccccc2)cc1</smiles>

In the synthesis of the above model oligourethancs, the condensation reaction $(n)$ between a primary amine and a chloroformate is employed [198\}:

$$
\mathrm{R}-\mathrm{NH}_{2}+\mathrm{R}^{\prime}-\mathrm{OCOCl} \underset{-\mathrm{HCl}}{\longrightarrow} \mathrm{RNH}-\mathrm{CO}-\mathrm{O}-\mathrm{R}^{\prime}
$$


In fact, the reaction pathway is rather complex due to the necessity to isolate and characterise the intermediate products. Thus, the $4,4^{\prime}$ diaminomethylenebis(benzene) (MDA) is protected by connecting one of its $\mathrm{NH}_{2}$ groups to a carbobenzoyloxy group (Reaction (o)) to give 32 and BDO is converted to 33 (Reaction (p)) [211].<smiles>Nc1ccc(Cc2ccc(Nc3ccc(COC(=O)Cl)cc3)cc2)cc1</smiles>

$$
\begin{aligned}
& \underset{-\mathrm{HCl}}{\square}-\mathrm{CH}_{2} \mathrm{OC}-\mathrm{O}_{32}^{\mathrm{H}}-\left(\square-\mathrm{CH}_{2}-\left(\square-\mathrm{NH}_{2}\right.\right. \\
& \mathrm{HO}-\left(\mathrm{CH}_{2}\right)_{4}-\mathrm{OH}+\left(\mathrm{CH}_{3}\right)_{3}-\mathrm{CCl} \underset{-\mathrm{HCl}}{\longrightarrow}\left(\mathrm{CH}_{3}\right)_{3} \mathrm{C}-\mathrm{O}\left(\mathrm{CH}_{2}\right)_{4}-\mathrm{OH} \\
& \underset{-\mathrm{HCl}}{\mathrm{COCl}_{2}}\left(\mathrm{CH}_{3}\right)_{3} \mathrm{C}-\mathrm{O}\left(\mathrm{CH}_{2}\right)_{4}-\underset{\|}{\mathrm{OC}}-\mathrm{Cl}
\end{aligned}
$$

By reacting 32 and 33 and subjocting the reaction products to a lather complex chemical treatment [211] that falls beyond the scope of this chapter, the model oligomers 34 are obtained.

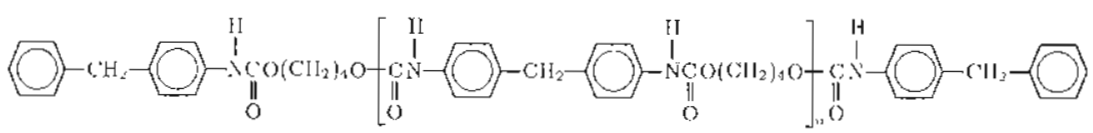

34

$$
n=0 \text { เ. } 7
$$

In the monodisperse oligourethane synthesis with $4,4^{\prime}$-diphenylmethane iminocarbonyloxy units, a special type of urethanc interchange reaction observed only for these materials should be mentioned. Peculiar DSC thermograms and size exclusion chromatography (SEC) of the oligourethanes after melting and recrystallisation rovealed that the monodispersity had been destroyed and a polydisperse oligourethane mixture had been formed $[199,200,202]$. This was demonstrated unambiguously by the diphenylmethane iminocarbonyl-terminated oligonrethanes, which do not have a reactive end-group; thus the reactivity is given by the urethane group only. Starting with the first nember of this oligomer series $(34, n=1$, i.e., a monodisperse material) leads to an oligomer mixture containing all the homologues from $n=0$ to 7 (the highest homologue resolved by SEC) 
in the most probable distribution $[199,210,212]$. This transurethanisation (Reaction (q)) proceeds in the solid state at temperatures well below the melting point and up to about $195^{\circ} \mathrm{C}$ without any evidence of re-formation of isocyanate and hydroxyl groups, which is the usual decomposition reaction of urethanes at elevated temperatures and is also observed for these oligourethanes above $200^{\circ} \mathrm{C}$ (Reaction (q)).<smiles>[R]O[R]O[W]</smiles>

From a number of model experiments with differently structured monoand bisurethanes, it can be inferred that this reaction is self-catalysed by

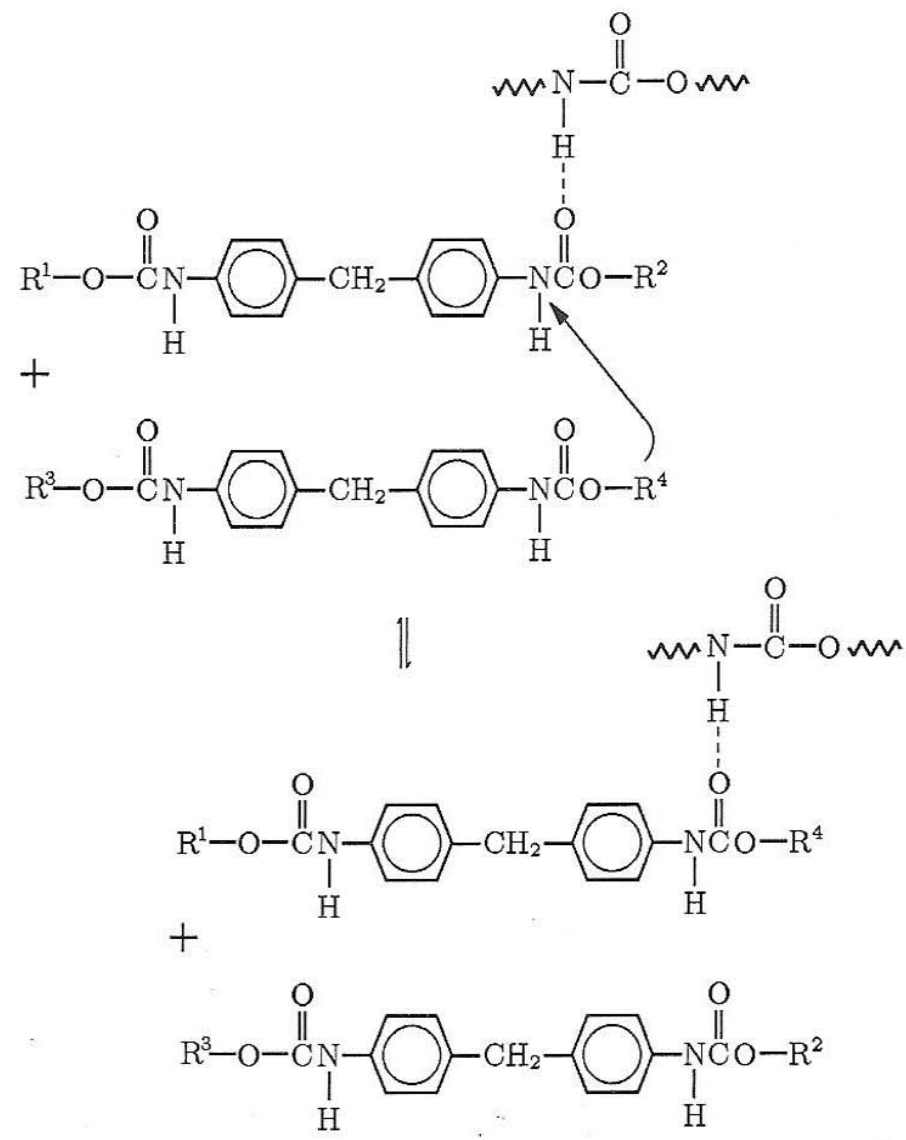

Scheme 16 
hydrogen bond formation between urethane groups of adjacent chains. The transurethanisation possibly proceeds by a urethane interchange reaction of parallel chains (Scheme 16) or by a four-centre type of reaction of antiparallel chains or oppositely arranged groups (Scheme 17). The implications of this particular reaction are that the monodispersity of such oligourethanes is easily lost, and therefore any treatment of the sample at elevated temperatures destroys its uniformity. This reaction is non-catalysed. In the presence of a typical catalyst used in urethane formation (such as organic tin compounds), the urethane interchange reaction is shifted to much lower temperatures; this allows the synthesis of a mixture of the lower molecular weight oligomers. Therefore, any catalyst should be carefully excluded when synthesising model urethanes with diphenylmethane units. From the finding discussed above, the question arises of whether the oligourethanes and polyurethane elastomers synthesised in the presence of a catalyst have the tailored structure, that is taken for granted to establish structure-property relationships [213].<smiles>[R]OC(=O)Nc1ccc(Cc2ccc(N(C(=O)O[R])[Y]([H])([H])C(=O)O[R])cc2)cc1</smiles><smiles>[R]OC(=O)Nc1ccc(Cc2ccc(N[Y]([H])([H])C(=O)O[R])cc2)cc1</smiles>

Scheme 17

One of the possible ways to obtain polyureas is via silylated intermediates [198]. Since this interchange reaction does not include formation and breaking of $\mathrm{Si}-\mathrm{O}$ bonds, it is discussed here.

Polyureas generally exhibit higher melting points, lower solubility, and higher thermal stability than the corresponding polyurethanes. This is mainly a consequence of the bifurcated hydrogen bonds and therefore stronger interactions between neighbouring urea groups [214,215]. These polymer materials have numerous applications of high commercial importance, due to their special properties as well as because of the relatively

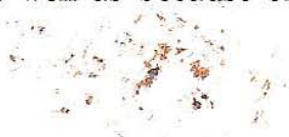


easy and fast formation of the urea linkage [216].

The synthesis of poly(1,6-hexamethyleneurea) 38 by using 1,6hexamethylenediamine 35 and trimethylisocyanatosilane 36 or hexamethyldisilazane $\mathbf{3 7}$ as starting materials (Scheme 18) has been reported [217]:

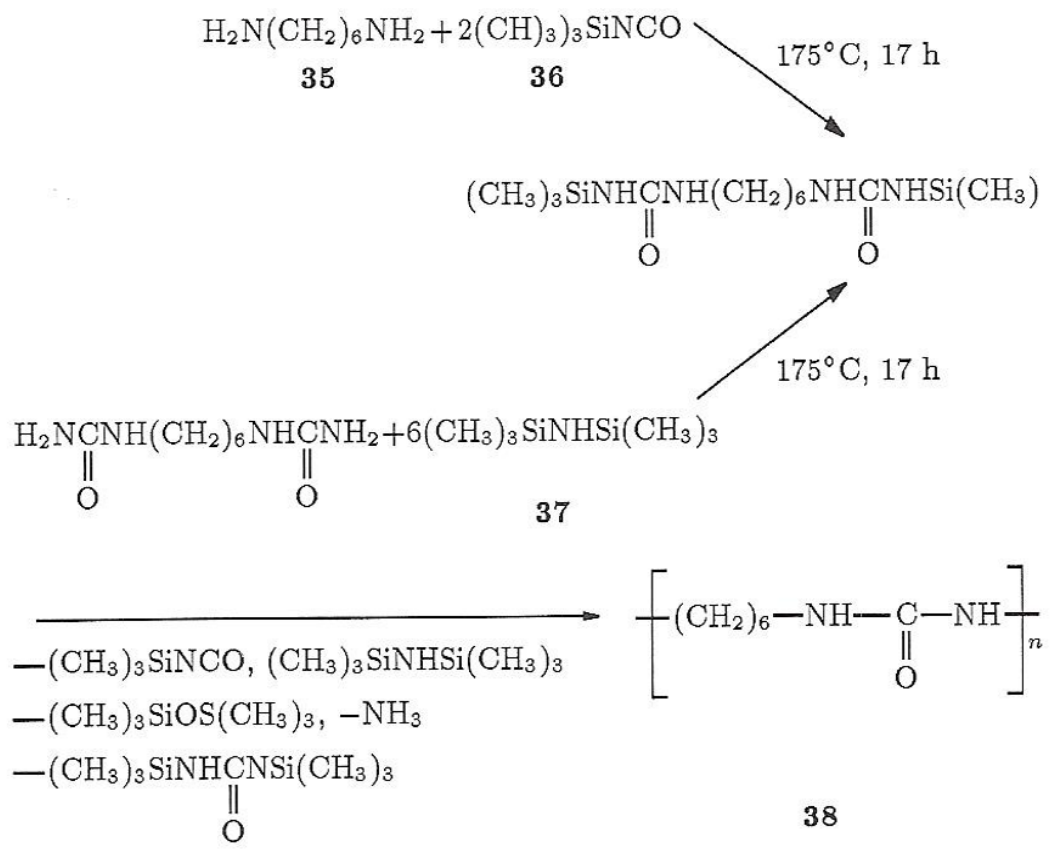

Scheme 18

The silylated intermediate in Scheme 18 is thought to be the first reaction product formed. Its further reaction gives polyurea together with various silicon compounds (hexamethyldisiloxane, bis(trimethylsilyl) carbodiimide, hexamethyldisilazane, trimethylisocyanatosilane) and ammonia as side products of the polycondensation reaction. The molar masses $\left(\mathrm{M}_{n}\right)$ are reported to be in the range from 1650 to 2460 .

\section{Concluding remarks}

An attempt is made here to present an overview on the wide variety of functional groups involving interchange reactions that take place in condensation polymers. Due to the limited length of this chapter, many particular aspects of this issue fall beyond its scope. However, they are discussed elsewhere in this book. Here we would like to only mention some reactions 
occurring in the thermal degradation of condensation polymers that are somehow related to interchange reactions and are not discussed further.

For instance, as far as hydrogen atoms in condensation polymers could be regarded as a special case of functionality, it is worth mentioning the hydrogen transfer in its various forms $(\mathrm{N}-\mathrm{H}, \mathrm{C}-\mathrm{H}$ and $\mathrm{O}-\mathrm{H})$ taking place via an ionic mechanism at temperatures above $350^{\circ} \mathrm{C}$. On the other hand, upon thermal treatment, intramolecular exchange becomes quite efficient, giving rise to cyclic oligomers, this process being thermodynamically favoured at high temperatures, or to alternating copolymers. These issues are discussed in detail by Montaudo et al. [218] (see Chapter 4).

Interchange reactions occurring mostly in polyesters and polyamides in the solid state and the related phenomenon of chemical healing is disclosed by Fakirov in [219]. In most cases, these processes are accompanied by an abrupt increase of the molecular weight and may have a practical application for recycling purposes (see Chapter 11).

In conclusion, it is worth mentioning again that interchange reactions in polyesters and polyamides are best studied and understood because of their prime industrial importance. The trend toward the implementation of transesterification and transamidation in the preparation of new homoand copolymers will most probably have a major importance in the future. However, the rapid development of novel polymer systems will require a deeper insight in interchange reactions involving polyurethanes as well as in the mechanisms of some alternative polycondensation pathways, employing silylated monomers, as in the cases of polyureas, polyanhydrides and hyperbranched structures.

\section{References}

1. V. V. Korshak, Pure Appl. Chem. 12, 101 (1966)

2. V. V. Korshak, Usp. Khimii 35, 1030 (1966) (in Russian)

3. S. Spasov, M. Arnaudov, "Application of Spectroscopy in Organic Chemistry", Nauka i Izkustvo Publ. House, Sofia 1978, p. 205 (in Bulgarian)

4. A. E. Tonelly, "NMR Spectroscopy and Polymer Microstructure: the Conformational Connection", VCH Publishers, New York 1989

5. F. A. Bovey, "Nuclear Magnetic Resonance", Academic Press, New York 1988

6. F. A. Bovey, L. W. Jelinski, "Nuclear Magnetic Resonance", in: Encyclopedia of Polymer Science, Wiley, New York 1987, vol. 10, p. 254

7. J. B. Stothers, "Carbon-13 NMR Spectroscopy", Academic Press, New York 1972

8. D. Canet, "Nuclear Magnetic Resonance - Concepts and Methods", John Wiley \& Sons, Chichester, New York, Brisbane, Toronto, Singapore 1996

9. N. L. Alpert, Phys. Rev. 72, 637 (1947)

10. E. M. Purcell, H. C. Torrey, R. V. Pound, Phys. Rev. 69, 37 (1946)

11. F. Bloch, W. W. Hansen, M. E. Packard, Phys. Rev. 69, 127 (1946)

12. A. Odajima, J. Phys. Soc. Japan 14, 777 (1959)

13. F. A. Bovey, G. V. D. Tiers, G. Filipovich, J. Polym. Sci. 38, 73 (1959) 
14. F. A. Bovey, G. V. D. Tiers, Fortschr. Hochpolymer. Forsch. 3, 193 (1963)

15. T. Harada, N. Ueda, Chem. High Polymers (Japan) 22, 685 (1965)

16. R. Yamadera, M. Murano, J. Polym. Sci. 5A-1, 2259 (1967)

17. J. Devaux, P. Godard, J. P. Mercier, J. Polym. Sci., Polym. Phys. Ed. 20, $1875(1982)$

18. J. Devaux, P. Godard, J. P. Mercier, R. Touillaux, J. M. Dereppe, J. Polym. Sci., Polym. Phys. Ed. 20, 1881 (1982)

19. J. Devaux, P. Godard, J. P. Mercier, J. Polym. Sci., Polym. Phys. Ed. 20, $1901(1982)$

20. M. Valero, J. J. Iruin, E. Espinosa, M. J. Fernandez-Berridi, Polym. Commun. 31, 127 (1990)

21. K. F. Kuhlmann, D. M. Grant, J. Am. Chem. Soc. 90, 7355 (1968)

22. H. R. Kricheldorf, R. Mühlhaupt, Angew. Makromol. Chem. 65, 169 (1977)

23. S. C. E. Backson, A. M. Kenwright, R. W. Richards, Polymer 36, 1991 (1995)

24. H. R. Kricheldorf, W. Hull, J. Macromol. Sci.-Chem. A11, 2281 (1977)

25. H. Marsmann, "Silicon-29 NMR", in: Encyclopedia of Nuclear Magnetic Resonance, edited by D. M. Grant, R. K. Harris, John Wiley \& Sons, Chichester, New York, Brisbane, Toronto, Singapore 1996, vol. 7, p. 4386

26. J. Mason, "Nitrogen NMR", in: Encyclopedia of Nuclear Magnetic Resonance, edited by D. M. Grant, R. K. Harris, John Wiley \& Sons, Chichester, New York Brisbane, Toronto, Singapore 1996, vol. 5, p. 3221

27. F. Pilati, "Polyesters", in: Comprehensive Polymer Science, edited by G. Allen, Pergamon, Oxford, New York, Beijing, Frankfurt, Sao Paulo, Sydney, Tokyo, Toronto 1989, vol. 5, p. 297

28. K. Ravindranath, R. A. Mashelkar, in: Developments in Plastics Technology, edited by A. Whelan, J. L. Craft, Elsevier, London 1985, vol. 2, p. 1

29. G. C. Overberger, J. Shebenda, J. Polym. Sci. 7A-1, 2875 (1969)

30. N. Ogata, S. Okamoto, J. Polym. Sci., Polym. Chem. Ed. 11, 2537 (1973)

31. G. Challa, Makromol. Chem. 38, 105 (1960)

32. P. J. Flory, J. Am. Chem. Soc. 62, 2261 (1940)

33. F. Pilati, P. Manaresi, B. Fortunato, A. Munari, V. Passalacqua, Polymer 22, 799 (1981)

34. K. Tomita, H. Ida, Polymer 16, 185 (1975)

35. G. Torraka, R. Turriziani, Chim. Ind. (Milan) 44, 483 (1962)

36. K. Saotome, Y. Kodaira, Makromol. Chem. 82, 41 (1965)

37. H. K. Hall, Jr., A. K. Schneider, J. Am. Chem. Soc. 80, 6409 (1958)

38. B. J. Tighe, in: Developments in Polymer Degradation, edited by N. Grassie, Applied Science, London 1984, vol. 5, p. 31

39. P. J. Flory, J. Am. Chem. Soc. 62, 2255 (1940)

40. V. V. Korshak, V. V. Golubev, Izv. Akad. Nauk SSSR, Ser. Khim. 1949, 379 (in Russian)

41. O. Wichterle, O. Eksner, Coll. Czechosl. Comm. 25, 1371 (1960)

42. Y. Ono, Pure Appl. Chem. 68, 367 (1996)

43. A. J. Chalk, US 4096169, General Electric Co., 1988

44. A. M. Kotliar, Macromol. Rev. 16, 367 (1981)

45. F. I. Hamb, J. Polym. Sci., Polym. Chem. Ed. 10, 3219 (1972)

46. M. Levine, S. C. Temin, J. Polym. Sci. 28, 179 (1958)

47. W. J. Jackson, H. F. Kuhfuss, J. Polym. Sci., Polym. Chem. Ed. 14, 2049 (1976) 
48. US 3778410 (1973), Eastman Kodak Co., Inv.: H.F. Kuhfuss, W. J. Jackson; Chem. Abstr. 80, 146894t (1974)

49. J. Economy, R. S. Storm, V. I. Matkowitch, S. G. Cottis, B. E. Nowak, J. Polym. Sci., Polym. Chem. Ed. 14, 2207 (1976)

50. H. K. Reimschuessel, T. DeBona, Macromolecules 13, 1582 (1981)

51. V. V. Korshak, S. V. Vinogradova, in: Polyesters, edited by J. Burdon, Pergamon, Oxford 1965, p. 261

52. J. Koskikallio, in: The Chemistry of the Carboxylic Acids and Esters, edited by S. Patai, Interscience, New York 1969, ch. 3, p. 103

53. D. F. Loncrini, J. Polym. Sci. 4A-1, 1531 (1966)

54. B. Fortunato, F. Pilati, P. Manaresi, Polymer 22, 655 (1981)

55. F. Pilati, G. S. Gostoli, G. C. Sarti, Polym. Process. Eng. 4, 303 (1986)

56. V. V. Korshak, S. V. Vinogradova, in: Polyesters, edited by J. Burdon, Pergamon, Oxford 1965, p. 266

57. J. Devaux, P. Godard, J. P. Mercier, Polym. Eng. Sci. 22, 229 (1982)

58. M. Kimura, R. S. Porter, G. Salee, J. Polym. Sci., Polym. Phys. Ed. 21, 367 (1983)

59. M. Kimura, G. Salee, R. S. Porter, J. Appl. Polym. Sci. 29, 1629 (1984)

60. F. Pilati, E. Marianucci, C. Berti, J. Appl. Polym. Sci. 30, 1267 (1985)

61. P. Goddard, J. M. Dekoninck, V. Devlesaver, J. Devaux, J. Polym. Sci., Polym. Chem. Ed. 24, 3301 (1986)

62. P. Goddard, J. M. Dekoninck, V. Devlesaver, J. Devaux, J. Polym. Sci., Polym. Chem. Ed. 24, 3315 (1986)

63. P. J. Flory, Chem. Rev. 39, 137 (1946)

64. H. G. Ramjit, J. Macromol. Sci.-Chem. A19, 41 (1983)

65. J. Otton, S. Ratton, J. Polym. Sci., Polym. Chem. Ed. 26, 2183 (1988)

66. J. Otton, S. Ratton, V. A. Vasnev, G. D. Markova, K. M. Nametov, V. I. Bakhmutov, L. I. Komarova, S. V. Vinogradova, V. V. Korshak, J. Polym. Sci., Polym. Chem. Ed. 26, 2199 (1988)

67. J. Otton, S. Ratton, V. A. Vasnev, G. D. Markova, K. M. Nametov, V. I. Bakhmutov, S. V. Vinogradova, V. V. Korshak, J. Polym. Sci., Polym. Chem. Ed. 27, 3535 (1989)

68. J. Otton, S. Ratton, J. Polym. Sci., Polym. Chem. Ed. 29, 377 (1991)

69. G. D. Lei, K. I. Choi, Ind. Eng. Chem. Res. 57, 123 (1992)

70. H. R. Kricheldorf, T. Mang, J. M. Jonté, Macromolecules 17, 2173 (1984)

71. H. R. Kricheldorf, T. Mang, J. M. Jonté, Makromol. Chem. 186, 955 (1985)

72. H. R. Kricheldorf, M. Berl, N. Scharnagl, Macromolecules 21, 286 (1988)

73. H. R. Kricheldorf, I. Kreiser, J. Macromol. Sci.-Chem. A24, 1345 (1987)

74. E. J. Tijama, L. v. der Does, A. Bantjes, Makromol. Chem. 194, 2807 (1993)

75. G. Montaudo, Macromolecules 26, 2541 (1993)

76. A. G. Shaikh, S. Sivaram, Ind. Eng. Chem. Res. 31, 1167 (1992)

77. A. G. Shaikh, S. Sivaram, C. Puglisi, F. Samperi, G. Montaudo, Polym. Bull. 32, 427 (1994)

78. M. M. Despande, A. S. Jadhav, A. A. Gunari, J. C. Sehra, S. Sivaram, J. Polym. Sci., Polym. Chem. Ed. 33, 701 (1995)

79. Jpn. Kokai Tokkyo Koho JP 0959501 [97 59501] (1997), Asahi Chem. Ind., Japan, Inv.: H. Yatani, K. Komya, Chem. Abstr. 126, 278349x (1997)

80. Jpn. Kokai Tokkyo Koho JP 0912843 [97 12483] (1997), Daicel Chem. Japan, Inv.: T. Sugano, Y. Okano, Chem. Abstr. 126, 172466t (1997) 
81. Jpn. Kokai Tokkyo Koho JP 08333446 [96 333446] (1996), Teijin Ltd. Japan, Inv.: T. Sawaki, S. Hirata, M. Shimonari, K. Sasaki, Chem. Abstr. 126, 157958m (1997)

82. Jpn. Kokai Tokkyo Koho JP 08302005 [96 302005] (1996), Idemitzu Kosan Co. Japan, Inv.: K. Tanaka, Chem. Abstr. 126, 104584e (1997)

83. Jpn. Kokai Tokkyo Koho JP 08302004 [96 302004] (1996), Idemitzu Kosan Co. Japan, Inv.: M. Nakae, Y. Ishikawa, Chem. Abstr. 126, 104583d (1997)

84. Jpn. Kokai Tokkyo Koho JP 08245782 [96 245782] (1996), Idemitzu Kosan Co. Japan, Inv.: J. Takeda, K. Hayashi, K. Iura, T. Kawakami, Chem. Abstr. 126, 104584e (1997)

85. K. Tanaka, Idemitzu Giho 39, 555 (1996)

86. D.-J. Liaw, P. Chang, Polymer 37, 2857 (1996)

87. US 5519106 (1996), Mitzubishi Chem. Co. Japan, Inv.: M. Nukui, T. Tayama, T. Kashiwagi, M. Kimura, H. Shoji, Chem. Abstr. 125, 87534y (1996)

88. Jpn. Kokai Tokkyo Koho JP 08337648 [96 337648] (1996), Teijin Ltd. Japan, Inv.: T. Sawaki, M. Shimonari, K. Sasaki, T. Muraoka, Chem. Abstr. 126, 172068q (1997)

89. Jpn. Kokai Tokkyo Koho JP 08333447 [96 333447] (1996), Teijin Ltd. Japan, Inv.: T. Sawaki, K. Sasaki, T. Muraoka, M. Shimonari, Chem. Abstr. 126, 157959n (1997)

90. US 5556936 (1996), General Electric Co. USA, Inv.: J. A. King, P. J. McCloskey, A. M. Colley, D. M. Dardaris, L. P. Fontana, J. G. Berndsen, Chem. Abstr. 125, 277535x (1997)

91. US 5597887 (1997), General Electric Co. USA, Inv.: J. A. King, P. J. McCloskey, M. Allice, D. M. Dardaris, Chem. Abstr. 126, 186847e (1997)

92. Y. Makimura, E. Yoshida, T. Kitao, Polym. J. (Tokyo) 29, 128 (1997)

93. Jpn. Kokai Tokkyo Koho JP 0959225 [97 59225] (1997), Mitsubishi Chem. Co. Japan, Inv.: M. Inaba, K. Sawa, T. Tanaka, Chem. Abstr. 126, 277275h (1997)

94. Y. Ono, Catal. Today 35, 15 (1997)

95. Jpn. Kokai Tokkyo Koho JP 0944838 [97 44838] (1997), Cheil Synthetic Textiles Co., Ltd. S. Korea, Chem. Abstr. 126, 252109u (1997)

96. Russ. Pat. 2048484 (1995), Inv.: V. N. Eliseenkov, B. E. Ivanov, N. G. Galakova, A. P. Gorbatenko, I. N. Zhmyklov, Izobretenia 32, 190 (1995), Chem. Abstr. 124, 344483y (1996)

97. D. Frich, K. Goranov, L. Schneggenburger, J. Economy, Macromolecules 29, 7734 (1996)

98. Jpn. Kokai Tokkyo Koho JP 08269820 [96 269820] (1996), Asahi Chemical Ind. Japan, Inv.: K. Tsuruoka, A. Yamashita, J. Kato, Y. Yagi, Chem. Abstr. 126, $32959 f(1997)$

99. A. L. Burke, G. Maier, J. M. Desimone, Polym. Mater. Sci. Eng. 74, 248 (1996)

100. PCT Int. Appl. WO 9639456 (1996), Inv.: J. M. Desimone, G. Maier, Chem. Abstr. 126, 104577e (1997)

101. Jpn. Kokai Tokkyo Koho JP 08283395 [96 283395] (1996), Mitsubishi Gas Chem. Co. Japan, Inv.: M. Ootoshi, F. Suzuki, K. Ishiguro, Chem. Abstr. 126, 60530c (1996)

102. A. A. Al-Haddad, J. Matthew, React. Funct. Polym. 32, 83 (1997) 
103. G. Z. Bakmirzaeva, S. V. Zaljalieva, B. J. Kabulov, V. E. Kim, B. A. Yulchbaev, Dokl. Akad. Nauk Resp. Uzg. 1995, 36 (in Russian), Chem. Abstr. 125, 276822b (1996)

104. C. C. F. S. Souza, D. M. M. Lima, E. B. Schoor, K. Tabak, Latin Am. Appl. Res. 26, 61 (1996)

105. J. Matthew, R. S. Ghagade, A. Lodha, S. Ponratham, S. D. Prasad, Macromolecules 30, 57 (1997)

106. L. W. Barret, L. H. Sperling, Abstr. Papers Am. Chem. Soc. 203, 563 (1992)

107. L. W. Barret, G. S. Ferguson, L. H. Sperling, J. Polym. Sci., Polym. Chem. Ed. 31, 1287 (1993)

108. H. G. Park, H. N. Chang, J. S. Dordick, Biocatalysis 11, 263 (1994)

109. Y. Linko, Zh.-L. Wang, M. Lamza, J. Seppala, Ann. NY Acad. Sci. 1996, 799

110. US 5596085 (1997), Krafts Food USA Inv.: R. S. Silver, G. L. Hasenhüttl, Chem. Abstr. 126, 186305b (1997)

111. PCT Int. Appl. WO 9640701 (1996), Procter and Gamble Co. USA, Inv.: E. P. Grandberg, R. G. Schafermeyer, J. A. Letton, Chem. Abstr. 126, 119342y (1997)

112. G. S. Kumar, A. Ghogare, D. Mukesh, J. Appl. Polym. Sci. 63, 35 (1997)

113. Y. Linko, Zh.-L. Wang, E. Uosukainen, J. Seppala, M. Lamsa, VTT Symp. 1996, 163, 237

114. R. S. Porter, L. H. Wang, Polymer 33, 2019 (1992)

115. M. Guo, Polym. Mater. Sci. Eng. 75, 12 (1996)

116. W. G. Zheng, Z. H. Wan, Z. N. Qi, F. S. Wang, Polymer 34, 4982 (1993)

117. M. Fiorini, C. Berti, V. Ignatov, M. Toselli, F. Pilati, J. Appl. Polym. Sci. 55, $1157(1995)$

118. V. N. Ignatov, C. Carraro, V. Tartari, R. Pippa, M. Scarpin, F. Pilati, C. Berti, M. Toselli, M. Fiorini, Polymer 38, 201 (1997)

119. M. J. Fernandez-Berridi, J. J. Iruin, I. Maiza, Macromol. Chem. Rapid Commun. 16, 483 (1995)

120. K. Han, H.-J. Kang, Pollimo 20, 224 (1996) (in Korean), Chem. Abstr. 124, 318676u (1996)

121. M. Guo, J. Am. Chem. Soc., Polym. Prepr. 38, 88 (1997)

122. M. Okamoto, T. Kotaka, Polymer 38, 1357 (1997)

123. F. J. Baltá Calleja, L. Giri, H. G. Zachmann, J. Mater. Sci. 32, 1117 (1997)

124. Jpn. Kokai Tokkyo Koho JP 08269179 (1996), Mitzubishi Rayon Co. Japan, Inv.: S. Tanaka, S. Ishiwatari, M. Tokumitzu, J. Yoshida, Chem. Abstr. 126, 32673h (1997)

125. PCT Int. Appl. WO 9635571 (1996), Hoechst Celanese USA, Inv.: P. N. Chen, K. P. Music, G. W. McNeely, Chem. Abstr. 126, 32463q (1997)

126. D. W. Ihm, S. Y. Park, Ch. G. Chang, Y. S. Kim, H. K. Lee, J. Polym. Sci., Polym. Chem. Ed. 34, 2841 (1996)

127. S. C. E. Backson, A. M. Kenwright, R. W. Richards, Polymer 36, 1991 (1995)

128. Y. Yu, K.-J. Choi, Polym. Eng. Sci. 37, 91 (1997) 129.

129. J. S. Kollodge, R. S. Porter, Macromolecules 28, 4097 (1995)

130. J. S. Kollodge, R. S. Porter, Macromolecules 28, 4106 (1995)

131. W. S. Ha, Y. K. Chun, S. S. Jang, D. M. Rhee, Ch. R. Park, J. Polym. Sci., Polym. Phys. Ed. 35, 309 (1997)

132. D. E. Kokkalas, D. N. Bikiaris, G. P. Karayannidis, J. Appl. Polym. Sci. 55, 787 (1995) 
133. E. Espinosa, M. J. Fernandez-Berridi, I. Maiza, M. Valero, Polymer 34, 382 (1993)

134. J. M. Martinez, J. Nazabàl, J. I. Eguiazabàl, J. Appl. Polym. Sci. 51, 223 (1994)

135. M. J. Fernandez-Berridi, J. J. Iruin, I. Maiza, Polymer 36, 1357 (1995)

136. C. I. Hwang, O. O. Park, Polym. J. 27, 232 (1995)

137. D. Frich, J. Economy, K. Goranov, Polym. Eng. Sci. 37, 541 (1997)

138. S. M. Hong, S. S. Hwang, Y. Seo, I. J. Chung, K. U. Kim, Polym. Eng. Sci. 37, 646 (1997)

139. D. S. Han, D. H. Kim, S. D. Cho, B. W. Jo, J. Korean Chem. Soc. 41, 157 (1997)

140. K. U. Kim, S. M. Hong, S. S. Hwang, Y. Seo, J. Y. Lee, J. Jang, Korea Polym. J. 4, 198 (1996)

141. A. Nakai, T. Shiwaku, W. Wang, H. Hasegawa, T. Hashimoto, Macromolecules 29, 5990 (1996)

142. R. Benavente, Z. Zhu, J. M. Perena, A. Bello, E. Perez, Polymer 37, 2379 (1996)

143. G. D. Choi, S. H. Kim, W. H. Jo, M. S. Rhim, J. Appl. Polym. Sci. 55, 561 (1995)

144. K.-H. Wei, J.-Ch. Ho, Macromolecules 30, 1587 (1997)

145. M. J. Stachovski, A. T. Dibenedetto, Polym. Eng. Sci. 37, 252 (1997)

146. K.-H. Wei, H.-Ch. Ho, J. Appl. Polym. Sci. 631527 (1997)

147. E. M. Woo, S. N. Yau, J. Polym. Sci., Polym. Chem. Ed. 35, 97 (1997)

148. E. T.-G. Choi, Y.-K. Yun, J. Jin, Polym.-Plast. Technol. Eng. 36, 135 (1997)

149. S. Jacob, J. M. Adduci, Polym. Prepr. (Am. Chem. Soc., Div. Polym. Chem.) 38, 201 (1997)

150. B. Gallot, Progr. Polym. Sci. 21, 1035 (1996) and references therein

151. M. Isoda, H. Sugimoto, T. Aida, S. Inoue, Macromolecules 30, 57 (1997)

152. D. Ma, X. Xiang, X. Luo, T. Nishi, Polymer 38, 1131 (1997)

153. P. J. A. In't Veld, E. M. Velner, P. Van De Witte, J. Hamhuis, P. J. Dijkstra, J. Feijen, J. Polym. Sci., Polym. Chem. Ed. 35, 219 (1997)

154. F:-D. Kopinke, M. Remmler, K. Mackenzie, M. Moeder, O. Wachsen, Polym. Degrad. Stab. 53, 329 (1996)

155. G. Montaudo, C. Puglisis, F. Samperi, Macromolecules 31, 650 (1998)

156. H. Sakiguchi, B. Coufin, "Polyamides" in: Handbook of Polymer Synthesis, Part A, edited by H. R. Kricheldorf, Marcel Dekker Inc., New York 1992, p. 807

157. R. Gaymans, D. Sikkema, "Aliphatic Polyamides" in: Comprehensive Polymer Science, edited by G. Allen, Pergamon, Oxford, New York, Beijing, Frankfurt, Sao Paulo, Sydney, Tokyo, Toronto 1989, vol. 5, p. 357

158. J. Zimerman, in: Encyclopedia of Polymer Science and Engineering, 2nd Ed., edited by H. F. Mark, N. M. Bikales, C. G. Overberger, G. Menges, Wiley, New York 1988, vol. 11, p. 315

159. R. E. Putscher, in: Kirk-Othmer Encyclopedia of Chemical Technology, edited by H. F. Mark, D. F. Othmer, C. G. Overberger, C. G. Seaborg, Wiley, New York 1987, vol. 18, p. 328

160. I. K. Miler, J. Zimmerman, Am. Chem. Soc. Symp. Ser. 285, 159 (1985) 
161. B. C. Challis, J. A. Challis, "Amides and Related Compounds", in: Comprehensive Organic Chemistry; Synthesis and Reactions of Organic Compounds, edited by I. O. Sutherland, Pergamon, Oxford 1979, vol. 2, p. 957

162. S. B. Speck, J. Am. Chem. Soc. 74, 2876 (1952)

163. T. Curtis, F. Goebel, J. Prakt. Chem. 37, 150 (1988)

164. R. Meyer, Justus Liebigs Ann. Chem. 347, 41 (1906)

165. C. F. Horn, B. T. Freure, H. Vineyard, H. J. Decker, J. Appl. Polym. Sci. 7, 887 (1963)

166. Ger. 1203466 (1965), BASF, Inv.: M. Heinzeler, H. Linge; Chem. Abstr. 62, 7964d (1965)

167. G. Bier, "Addition and Condensation Polymerisation Processes", in: Advances in Chemistry Series, edited by R. F. Gould, Am. Chem. Soc., Washington DC 1969, vol. 91, p. 612

168. E. Schwarz, in: Kunststoff Handbook, edited by E. H. R. Vieweg, A. Muller, Hanser, München 1966, vol. 6, ch. 2

169. P. J. Flory, "Principles of Polymer Chemistry", Cornell Univ. Press, Ithaca, NY 1953, p. 102

170. H. Sakiguchi, in: Ring-Opening Polymerisation, edited by K. J. Ivin, T. Saegusa, Elsevier, London 1984, vol. 2, ch. 12

171. C. Ayers, J. Appl. Chem. 4, 444 (1954)

172. L. F. Beste and R. C. Houtz, J. Polym. Sci. 8, 395 (1952)

173. P. J. Flory, J. Am. Chem. Soc. 64, 2205 (1942)

174. V. V. Korshak, T. M. Frunze, "Synthetic Heterochain Polyamides", Monson, Jerusalem 1964, p. 258

175. N. Ogata, Makromol. Chem. 30, 212 (1959)

176. I. K. Miller, J. Polym. Sci., Polym. Chem. Ed. 14, 1403 (1976)

177. A. M. Kotliar, J. Am. Chem. Soc., Polym. Prepr. 19, 111 (1978)

178. S. Fakirov, M. Evstatiev, J. M. Schultz, Polymer 34, 4669 (1993)

179. T. Serhatkulu, B. Erman, I. Bahar, S. Fakirov, M. Evstatiev, D. Sapundjieva, Polymer 36, 2371 (1995)

180. I. Lüderwald, H. R. Kricheldorf, Angew. Makromol. Chem. 56, 173 (1976)

181. I. Takeda, D. R. Paul, Polymer 32, 2771 (1991)

182. I. Takeda, D. R. Paul, Polymer 33, 3899 (1992)

183. H. R. Kricheldorf, E. Leppert, G. Schilling, Makromol. Chem. 175, 1705 (1974)

184. H. R. Kricheldorf, E. Leppert, G. Schilling, Makromol. Chem. 176, 81 (1975)

185. G. Shilling, H. R. Kricheldorf, Makromol. Chem. 176, 3341 (1975)

186. H. R. Kricheldorf, Pure Appl. Chem. 54, 467 (1982)

187. A. M. Aerdts, K. L. L. Eersels, G. Groeninckx, Macromolecules 29, 1041 (1996)

188. K. L. L. Eersels, A. M. Aerdts, G. Groeninckx, Macromolecules 29, 1046 (1996)

189. E. E. Bostic, in: Chemical Reactions of Polymers; High Polymers, edited by

E. E. Fettes, Interscience, New York 1964, vol. 19, p. 515

190. H. R. Kricheldorf, D. Lübbers, Macromolecules 25, 1377 (1992)

191. H. R. Kricheldorf, D. Lübbers, Makromol. Chem., Rapid Commun. 11, 83 (1990)

192. H. R. Kricheldorf G. Löhden, Macromol. Chem. Phys. 196, 1839 (1995) 
193. H. R. Kricheldorf, Q.-Z. Zang, G. Schwarz, Polymer 23, 1821 (1982)

194. C. J. Hawker, J. M. J. Fréchet, J. Am. Chem. Soc. 112, 7638 (1990)

195. S. R. Turner, B. I. Voigt, T. H. Moureg, Macromolecules 26, 4617 (1993)

196. H. R. Kricheldorf, O. Stöber, D. Lübbers, Macromol. Chem. Phys. 196, 3549 (1995)

197. H. R. Kricheldorf, G. Löhden, J. Macromol. Sci. - Pure Appl. Chem. A32, 1915 (1995)

198. C. D. Eisenbach, H. Nefzger, "Poly(urethanes) and Related Polymers", in: Handbook of Polymer Synthesis, Part A, edited by H. R. Kricheldorf, Marcel Dekker Inc., New York 1992, p. 685

199. Cl. Günter, Diploma Thesis, University of Freiburg, 1982

200. Y. Camberlin, J. O. Pascault, J. Polym. Sci., Polym. Chem. Ed. 20, 383 (1982)

201. C. D. Eisenbach, Cl. Günter, Proc. Div. Polym. Mater. Sci. Eng. 49, 239 (1983)

202. Z. Y. Qin, C. W. Macosko, S. T. Wellinghoff, Proc. Div. Polym. Mater. Sci. Eng. 49, 475 (1983)

203. K. K. S. Hwang, K. S. Wu, S. B. Lin, S. L. Cooper, J. Polym. Sci., Polym. Chem. Ed. 22, 1677 (1984)

204. J. A. Miller, S. B. Lin, K. K. S. Hwang, K. S. Wu, P. E. Gibson, S. L. Cooper, Macromolecules 18, 32 (1985)

205. C. D. Eisenbach, 35 Jahre Fonds der Chem. Industrie, Verband der Chem. Polym. Prepr. (Am Chem. Soc., Industrie), Frankfurt 1985, p. 77

206. C. D. Eisenbach, M. Baumgartner, Cl. Günter, J. Am. Chem. Soc., Polym. Prepr. 26, 7 (1985)

207. C. D. Eisenbach, Cl. Günter, U. Struth, Spez. Ber. KFA Jülich, 316, 107 (1985)

208. Z. Y. Qin, C. W. Macosko, S. T. Wellinghoff, Macromolecules 18, 553 (1985)

209. Cl. Günter, Dissertation, University of Freiburg, 1986

210. C. D. Eisenbach, Cl. Günter, M. Baumgartner, "Advances in Elastomer and Rubber Elasticity", edited by J. Lal, Pergamon, New York 1987, p. 51

211. H. Thaufelder, Diploma Thesis, University of Beyreuth, 1988

212. C. D. Eisenbach, H. Nefzger, M. Baumgartner, Cl. Günter, Ber. Bunsenges. Phys. Chem. 89, 1190 (1985)

213. J. A. Miller, S. B. Lin, K. K. S. Hwang, K. S. Wu, P. E. Gibson, S. L. Cooper, Macromolecules 18, 553 (1985)

214. L. Bom, H. Hespe, Colloid. Polym. Sci. 263, 335 (1985)

215. R. Hill, E. E. Walker, J. Polym. Sci. 3, 609 (1948)

216. D. Dietrich, Houben-Weyl Methoden der Organischen Chemie, 4th Ed., edited by H. Barth, J. Falbe, Georg Thieme, Stuttgart 1987, vol. 20/2, p. 1721

217. A. L. DiSalvo, J. Polym. Sci., Polym. Lett. Ed. 12, 641 (1974)

218. G. Montaudo, C. Puglisi, "Thermal Degradation in Condensation Polymers", in: Comprehensive Polymer Science, edited by G. Allen, Pergamon, vol. 11, 1989, pp. 227-251 and references therein

219. S. Fakirov, "Solid State Reactions in Linear Polycondensates", in: Solid State Behavior of Linear Polyesters and Polyamides, edited by J. M. Schultz, S. Fakirov, Prentice Hall, Englewood Cliffs, NJ 1990, pp. 1-67 and references therein 